\title{
Identification of Novel Translation Related Genes in Saccharomyces cerevisiae
}

Le Hoa Tan

A Thesis submitted to

the Faculty of Graduate Studies and Research

in partial fulfilment of

the requirements for the degree of

Master of Science

in

\author{
Biology \\ Carleton University \\ Ottawa, Ontario, Canada
}

May 2014

Copyright (c)

2014 - Le Hoa Tan 


\section{Abstract}

Translation in eukaryotic organisms is a vital process in the gene expression pathway. This process requires control and precision to generate functional proteins that mediate cell activities. Previously, a large scale screening approach identified 80 novel Saccharomyces cerevisiae's genes that appeared to affect translation fidelity. In this current research, four candidate genes were selected for further investigation: YGR117C, YNL122C, YJR014W and YNL040W. The deletions of these genes were investigated for their effects on translation fidelity using plasmids, pUKC817, pUKC818 and pUKC819, containing premature stop codons, UAA, UGA and UAG, respectively, in $L a c Z$ cassette. A GAL1 inducible plasmid was used to test translation efficiency of these deletion strains. YNL040W and YJR014W were screened for genetic interactions with other translation genes. Altogether, our findings provide evidence for the involvement of the target genes in translation. It also supports the idea that there exist other novel translation genes that need to be investigated. 


\section{Acknowledgments}

I would like to give my utmost gratitude to my supervisor Dr. Ashkan Golshani, whose support, guidance and contributions have helped me considerably throughout the research. I would also like to extend my thanks to my thesis committee member Dr. Myron Smith who have given insightful ideas for improvements of the research. Thanks to Bahram Samanfar for training and continuous technical support and encouragements in the lab. Thanks to Dr. Firoozeh Chalabian for her collaboration. I would also like to thank all the lab members who have provided constant encouragements and kindness. Thank you to my family for their support throughout

my studies and to my wonderful partner, Kevin Kung, for his love, encouragements and patience. A part of this work is published in Samanfar et al, 2014, Molecular BioSystems, 10(4):916-24. 


\section{Table of Contents}

Abstract

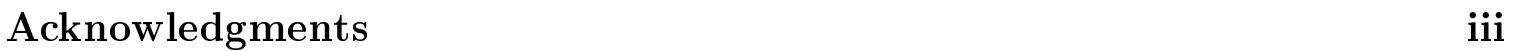

List of Tables $\quad$ vii

List of Figures viii

List of Acronyms $\quad \mathrm{x}$

List of Appendices xiv

1 Introduction 1

1.1 Systems Biology . . . . . . . . . . . . . . . 1

1.1.1 Functional Genomics ................. 2

1.1.2 Genetic Interactions . . . . . . . . . . . . 3

1.2 Yeast as a Model Organism . . . . . . . . . . . . 6

1.3 Eukaryotic Ribosome . . . . . . . . . . . . . . 7

1.3.1 Ribosome Structure . . . . . . . . . . . 7

1.3.2 Ribosome Biosynthesis . . . . . . . . . . . . 8

1.3.3 Regulations of Ribosome Biogenesis . . . . . . . . . . . 11

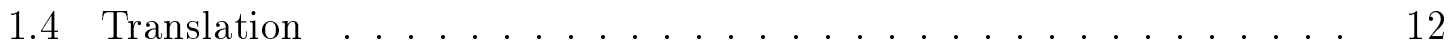

1.4.1 Translation Regulation and Diseases . . . . . . . . . . 12 
1.4.2 Mechanism of Eukaryotic Translation . . . . . . . . . . . 14

1.4.3 Translation Initiation . . . . . . . . . . . . . 15

1.4.4 Translation Elongation . . . . . . . . . . . 18

1.4.5 Translation Termination .............. 20

1.5 Purpose and Objectives . . . . . . . . . . . . 22

2 Materials and Methods $\quad 24$

2.1 Buffer, Solutions and Reagents . . . . . . . . . . . . . . 24

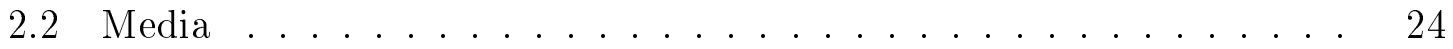

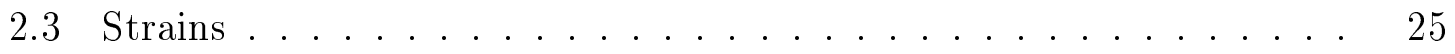

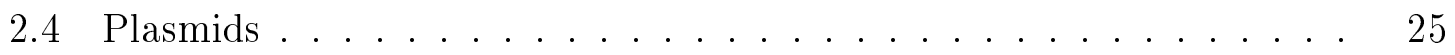

2.5 Transformations ....................... 26

$2.6 \quad \beta$-galactosidase Assay . . . . . . . . . . . . . . . 27

2.7 Drug Sensitivity Spot Test . . . . . . . . . . . . 29

2.8 Quantitative Reverse Transcriptase Polymerase Chain Reaction (qRT-

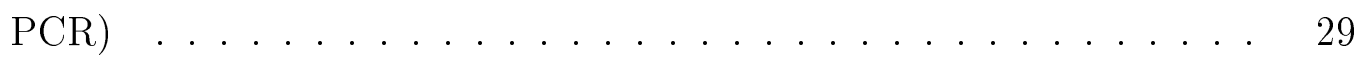

2.9 Primer Design . . . . . . . . . . . . . . . 30

2.10 PCR-Mediated Gene Deletion and Query Strain Construction . . . . 33

2.11 Synthetic Genetic Array Analysis . . . . . . . . . . . . . . 37

2.12 Random Spore Analysis . . . . . . . . . . . . . . . 39

2.13 Conditional Interaction Analysis . . . . . . . . . . . . . . 39

2.14 Synthetic Dosage Lethality Assay . . . . . . . . . . . . . . . 39

2.15 Phenotypic Suppression Analysis . . . . . . . . . . . . . 40

3 Results $\quad 41$

3.1 Selections of Target Genes for Follow-up Analysis . . . . . . . . . . 41

3.2 Translation Fidelity of Target Genes . . . . . . . . . . . . . 42

3.3 Translation Efficiency of Selected Genes . . . . . . . . . . . 46 
3.4 Drug Sensitivity Analysis Using Translation Inhibitory Drugs . . . . . 50

3.5 Synthetic Genetic Interactions of $Y N L 040 \mathrm{~W}$ with Translation Related

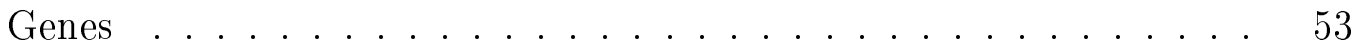

3.6 Synthetic Dosage Lethality (SDL) Analysis for YNL040W and

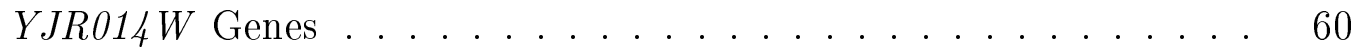

3.7 Phentypic Suppression Analysis (PSA) of YNL040W and YJR014W

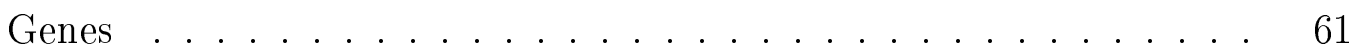

4 Discussions $\quad 68$

5 Conclusions $\quad 83$

References $\quad 85$

$\begin{array}{lr}\text { Appendix } & 99\end{array}$ 


\section{List of Tables}

Table 1 - List of Acronyms ................ $\mathrm{x}$

Table 2 - List of Primer Designs for YNL040W Gene Deletion . . . . . . 36 


\section{List of Figures}

Figure 1 - Genetic Interactions of Genes . . . . . . . . . . . 4

Figure 2 - Yeast Ribosomal DNA . . . . . . . . . . . . 10

Figure 3 - Translation Initiation in Eukaryotes $\ldots \ldots \ldots \ldots \ldots$

Figure 4 - Translation Elongation in Eukaryotes . . . . . . . . . . . 19

Figure 5 - Translation Termination in Eukaryotes . . . . . . . . . . 21

Figure 6 - Primer design . . . . . . . . . . . . . . . 32

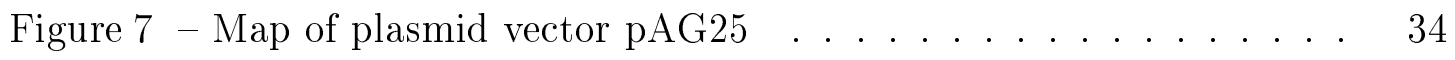

Figure 8 - Gene Knockout Through PCR Mediated Gene Deletion . . . 35

Figure 9 - Schematic Synthetic Genetic Array Methodology . . . . . . 38

Figure 10-Relative $\beta$-galactosidase activity for 3 premature stop codons . 44

Figure 11- Quantification of $\beta$-galactosidase mRNA Contents of Strains

Containing pUKC plasmids Using qRT-PCR . . . . . . . . . 45

Figure 12- $\beta$-galactosidase Assay Testing Translation Efficiency Using an

Inducible p416 Plasmid . . . . . . . . . . . . . . . . 48

Figure 13- Quantification of $\beta$-galactosidase mRNA Contents of Strains

Containing p416 Using qRT-PCR . . . . . . . . . . . . . . 49

Figure 14- Increased Sensitivity of YNL040WD and YJR014WD to Translation Inhibitory Drugs . . . . . . . . . . . . . . 51

Figure 15- Increased Sensitivity of YLR192CA to translation inhibitory drugs 52

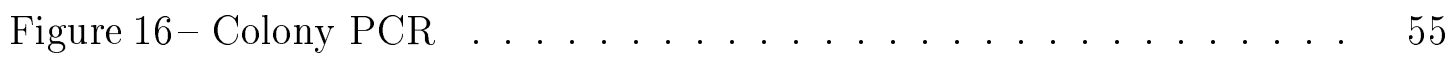


Figure 17- A Map of Genetic Interactions of YNL040W With Translation Related Genes ................... 58

Figure 18- SGA Conditional Interactions of YNL040W With Translation Related Genes .................. 59

Figure 19- PSA Interactions for YJR014W Overexpression . . . . . . 63

Figure 20- PSA Interactions for YNL040W Overexpression . . . . . . 64

Figure 21 - Spot Test Confirmation of PSA Interactions for YJR014W Over-

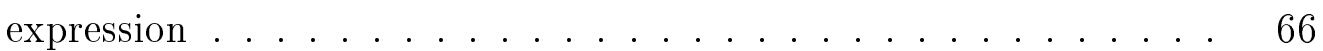

Figure 22- Spot Test Confirmation of PSA Interactions for YNL040W Over-

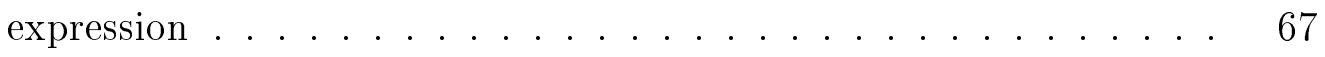

Figure 23- Gene Cluster for SDL and PSA Interactions for YJR014W . . 80

Figure 24- Gene Cluster for SGA, SDL and PSA Interactions for YNL040W 82 


\section{List of Acronyms}

Table 1: List of Acronyms

\begin{tabular}{ll}
\hline Acronyms & Definition \\
\hline \hline -galactosidase & Beta-galactosidase \\
$\mu \mathrm{m}$ & Micro-meters \\
$\mu \mathrm{L}$ & Micro-liters \\
${ }^{\circ} \mathrm{C}$ & Degrees Celsius \\
$\Delta$ & Deletion \\
$\mathrm{AD}$ & Alzheimer's Disease \\
$\mathrm{APP}$ & Amyloid- $\beta$ Precursor Protein \\
$\mathrm{bp}$ & Base Pair \\
$\mathrm{cDNA}$ & Dalton \\
$\mathrm{D}$ & Complementary DNA \\
& \\
&
\end{tabular}




\begin{tabular}{ll} 
DMD & Duchenne Muscular Dystrophy \\
DMSO & Dimethyl Sulfoxide \\
DNA & Deoxyribonucleic Acid \\
DO & Dropout \\
eEF & Eukaryotic Elongation Factor \\
eIF & Eukaryotic Initiation Factor \\
ESM & Enriched Sporulation Medium \\
EtBr & Ethidium Bromide \\
ETS & External Transcribed Spacer \\
GFP & Green Fluorescent Protein \\
GST & Glutathione S-Transferase \\
GTP & Milligrams \\
mo & Guanosine-5-Triphosphate \\
LiOA & Hour \\
\hline M & Internal Transcribed Spacer \\
\hline Lithium Acetate
\end{tabular}




\begin{tabular}{|c|c|}
\hline $\mathrm{mL}$ & Milli-liters \\
\hline $\mathrm{mM}$ & Milli-Molar \\
\hline mRNA & Messenger Ribonucleic Acid \\
\hline $\mathrm{NaOH}$ & Sodium Hydroxide \\
\hline NAT & nourseothricin \\
\hline ng & Nanograms \\
\hline NGD & No-Go Decay \\
\hline nt & Nucleotides \\
\hline NTS & Non-Transcribed Spacer \\
\hline OD & Optical Density \\
\hline ONPG & O-Nitro-Phenyl- $\beta$-D-Galactosidase \\
\hline $\mathrm{ORF}$ & Open Reading Frame \\
\hline PABP & Poly (A)-Binding Protein \\
\hline PCR & Polymerase Chain Reaction \\
\hline PEG & Polyethylene Glycol \\
\hline PKA & Protein Kinase A \\
\hline PSA & Phenotypic Suppression Analysis \\
\hline qRT-PCR & Quantitative Reverse Transcriptase-PCR \\
\hline rDNA & Ribosomal DNA \\
\hline
\end{tabular}




$\begin{array}{ll}\text { RF } & \text { Release Factor } \\ \text { RNA } & \text { Ribonucleic Acid } \\ \text { RNP } & \text { Ribonucleoprotein } \\ \text { RPM } & \text { Revolutions Per Minute } \\ \text { rRNA } & \text { Ribosomal RNA } \\ \text { RT } & \text { Room Temperature } \\ \text { S } & \text { Svedberg units } \\ \text { SC } & \text { Synthetic Complete } \\ \text { SDL } & \text { Synthetic Dosage Lethality } \\ \text { SGA } & \text { Synthetic Genetic Array } \\ \text { SGD } & \text { Saccharomyces Genome Database } \\ \text { SnoRNPs } & \text { Small Nucleolar Ribonucleoprotein Particles } \\ \text { TOR } & \text { Target Of Rapamycin } \\ \text { UTR } & \text { Untranslated Region } \\ \text { WT } & \text { Wild Type } \\ \text { YGPD } & \text { Yeast non-essential Gene Deletion Array } \\ & \end{array}$




\section{List of Tables}

\section{List of Appendices}

Appendix 1 YEPD and -URA Media Preparation . . . . . . . . . . 99

Appendix 2 Amino Acids Supplement Powder Mixture for Synthetic Complete Media . . . . . . . . . . . . . . . 100

Appendix $3 \quad$ Map of p416 Plasmid . . . . . . . . . . . . . . . . . 101

Appendix 4 Z-Buffer Solution Preparation . . . . . . . . . . . . . . 102

Appendix 5 List of Potential Translation Related Genes . . . . . . . . . . . 103

Appendix 6 Drug Sensitivity Analysis of Deletion Strains on Streptomycin . 104

Appendix 7 Drug Sensitivity Analysis for All Deletion Strains Under Cycloheximide Drug Condition . . . . . . . . . . . . . . . 105

Appendix 8 Drug Sensitivity Analysis of Deletion Strains on Paromomycin . 106

Appendix 9 Confirmation of Results From SGA Analysis Using Random Spore Analysis . . . . . . . . . . . . . . . 107

Appendix 10 Description of Translation Related Genes Interacting With $Y N L 040 W \ldots \ldots \ldots \ldots \ldots \ldots \ldots \ldots \ldots$ 
Appendix 11 Description of Translation Related Genes Interacting With YNL040W Under Cycloheximide Drug Condition . . . . . . 109

Appendix 12 Description of Translation Related Genes Interacting With YJR014W Overexpression . . . . . . . . . . . 110

Appendix 13 Description of Translation Related Genes Interacting With YNL040W Overexpression . . . . . . . . . . . . 111

Appendix 14 Description of Translation Related Genes Interacting With YJR014W Overexpression on Cycloheximide . . . . . . . . 112

Appendix 15 Description of Translation Related Genes Interacting With YNL040W Overexpression on Cycloheximide . . . . . . . 113 


\section{Chapter 1}

\section{Introduction}

\subsection{Systems Biology}

Rather than the studies of individual parts of cells or organisms, systems biology looks at the function of an entire biological system as an independent entity. It views the structure and the network of interacting macromolecules, along with the dynamics of the system and how it changes and functions under different conditions (Kitano, 2002). Previous works on elucidating the functions of genes generally involved studying a single gene and performing extensive experiments to obtain isolated data. The isolated data is then combined with other isolated data from literature for the same gene in order to substantiate its functions. This method can not convey an accurate representation of the structure or dynamics of the biological network as a whole. Furthermore, this method is time consuming and requires extensive resources for the amount of data obtained. Fortunately, technologies in research are constantly improving to produce vast amount of data in shorter periods of time and utilizing a smaller quantity of materials. High-throughput tools and rapid screening techniques such as collections of yeast deletion strains, synthetic genetic arrays (SGAs) (Tong et al., 2001), diploid synthetic lethality analysis by microarray (Ooi et al., 2003) and 
mass spectrometry have significantly enhanced research productivity in systems biology. These means have allowed quantification of genetic interaction profiles of many genes in yeast and have identified and quantified large numbers of proteins at a time (Chuang et al., 2010; Ideker et al., 2001). Another powerful tool is reverse transcriptase polymerase chain reaction (RT-PCR) that can provide information on mRNA abundance and depict gene expression profiles in yeast (Stahlberg et al., 2008). Adversely, with more data, it has become more challenging for data analysis and the myriad of data being piled onto databases require continuous improvements in computer programs to maintain and update. Computer programs have advanced in parallel to meet these challenges and can parse textual passages, extract key concepts from literature and catalog them systematically in databases (Andrade and Valencia, 1998). This vast wealth of up to date genomic data is indispensable for functional genomics studies.

\subsubsection{Functional Genomics}

Functional genomics studies contribute to the development of the genetic network and assist in the elucidation of the complete functional map of the cell. Functions of unknown genes can be inferred from its interactions to genes of known function, and as such, it involves functional genomics which is to understand genes and how they function at the molecular level. It is a tremendous task to fulfill, nevertheless, promising high-throughput tools and techniques such as RNAi based approaches (Horn et al., 2011), and the yeast deletion mutant collections for synthetic genetic array (SGA) analysis can provide an abundance of genetic information. In addition to these resources, the plethora of data on protein-protein interactions and metabolic networks can be used to predict new gene functions using computational methods (Kelly and Ideker, 2005). Bioinformatic methods are progressing rapidly to assist in interpreting the different types of biological information and predicting gene 
functions. These tools and techniques, in addition to many others, are necessary for studying all the elements of the biological system. Many are used in combinations for integrating the information to provide a comprehensive scheme of the biological network.

\subsubsection{Genetic Interactions}

One way to identify the functionality of a gene is to ascribe the function based on the genes it interacts with. Genes can conceal the presence of other genes or combine to produce an entirely new phenotype. This makes it difficult to characterize the features of the biological pathways and to identify all the key components (Miko, 2008). With current genome sequencing and large-scale genetic analyses, this task has become less daunting and a myriad of genetic interactions in biological systems have been identified (Costanzo et al., 2010; Tong et al., 2006). A genetic interaction is defined as mutations in two or more genes in overlapping pathways or within the same pathway that produce an unexpected phenotype not found in any of the mutations alone (Mani et al., 2007). It is considered a negative genetic interaction when a gene deletion in two separate pathways or two gene deletions in the same pathway produce a more severe phenotype than expected (Figure 1). Positive genetic interactions can occur when the deletion of a gene rescues the deletion of a second gene and generate a less severe phenotype than any of the two single mutants. Genetic interactions can provide significant functional information regarding the interacting genes, and so do protein-protein interactions. Protein-protein interactions are physical interactions between proteins performing similar functions and can reveal the roles of the proteins within the cell (Chepelev et al., 2008).

Many genetic interactions have been discovered from large-scale genetic screens 
A.
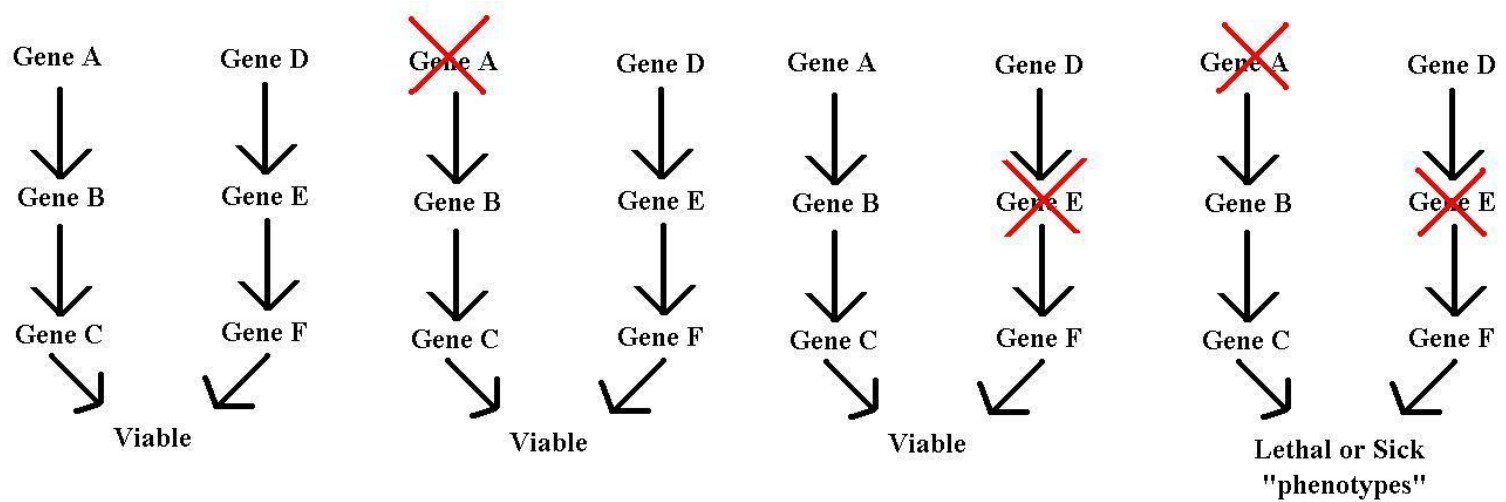

B.
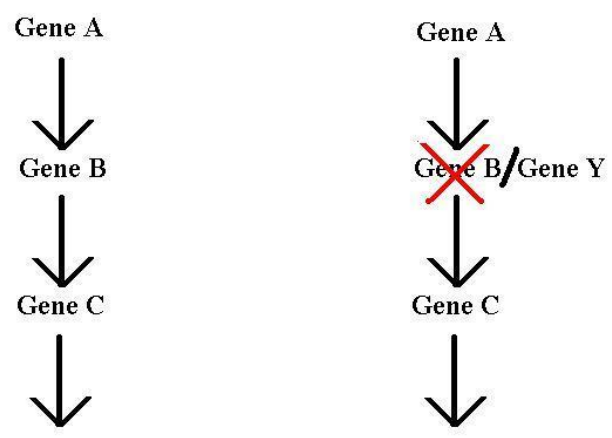

Viable

Viable

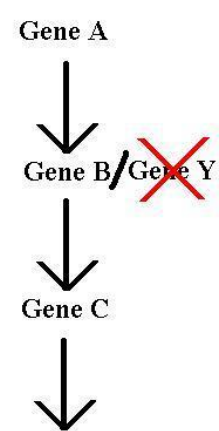

Viable
Gene A

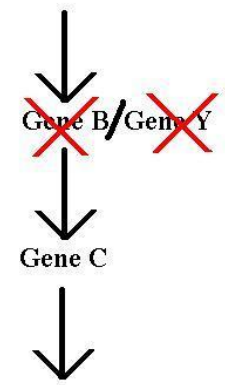

Lethal or Sick "phenotypes"

Figure 1: A. Mutation of a gene in one pathway can be compensated by a parallel pathway with no phenotypic effect. Mutations in two genes, one in each of the parallel pathways will produce a synthetic lethal or sick interaction. B. Mutation in one pathway can be compensated by a redundant gene in the same pathway, but mutations in both the genes will result in a phenotypic effect. 
in yeast and other model organisms using SGA analysis (Tong and Boone, 2006). SGA utilizes a yeast gene-deletion set with $\approx 5000$ haploid strains, each having a deletion of a specific gene. Crossing of these mutants with the mutant query strain of interest will produce $\approx 5000$ double mutants that can be scored for fitness defects (synthetic sick or synthetic lethal) (Boone et al., 2007; Tong and Boone, 2006). Each yeast deletion strain in the collections has the target gene replaced with a kanamycin-resistance marker. Some collections, additionally, have each deletion strain carrying two unique 20 bp flanking barcodes so each mutant can be selected for and quantified (Wach et al., 1994). SGA is a very powerful technique and can be applied to investigate many things including chromosome segregation, (Measday et al., 2005) and genetic interactions in other organisms such as E. coli (Butland et al., 2008).

Other genetic interactions can be obtained from synthetic dosage lethality assay (SDL) (Measday and Hieter, 2002). The increased levels of a gene expression typically does not affect the fitness in a wild type cell but may be detrimental in a mutant strain with reduced activity of an interacting gene (Dixon et al., 2009). SDL uses an overexpression query strain that is mated to the deletion mutant array to observe if the overexpression of the query gene will accentuate the defect in any of the deletion mutation strains (Kroll et al., 1996). Additionally, phenotypic suppression analysis (PSA) (Alamgir et al., 2008) can be applied by testing the resulting SDL colonies on drugs to examine for the reverse inhibitory effect. This will determine whether the overexpression of one gene can compensate for the deletion of another under drug condition. 


\section{$1.2 \quad$ Yeast as a Model Organism}

Yeast, (Saccharomyces cerevisiae), also known as baker's yeast, is a fungus with a typical size ranging from 3-4 $\mu \mathrm{m}$. Yeast has its genome completely sequenced making it easy to manipulate. The genome of a yeast cell is approximately 15 megabases and has 16 linear chromosomes containing from 200-2200 kb with approximately 6000 open reading frames (ORF), 4800 of which are coding ORF (Bjornsti, 2002; Kowalczuk et al., 1999). It is estimated that out of all yeast genes, only $20 \%$ are essential, about $30 \%$ have been characterized, and over $30 \%$ have no known functions (Bjornsti, 2002). In 2007, some 21\% of yeast genes, numbering well over 1000 individual genes, remained uncharacterized (Pena-Castillo and Hughes, 2007). Many methods can be used in combinations to identify new genes. One way is gene knockout which can be created by PCR mediated gene deletion for the gene of interest. This will allow for the observation between the knockout strain and the normal individual. An inference can be made from the differences in the phenotype.

Yeast is easy and fast growing depicted by their $\approx 90$ minute doubling time on rich medium. It has many features found in more complex eukaryotes and since many cellular pathways are conserved among eukaryotes, it makes yeast a model organism for studying a variety of topics. Yeast can also grow in aerobic and anaerobic conditions making them very useful for studying gene expressions during cellular responses in various conditions (Fu, 2009). Yeast grows by dividing mitotically forming a bud that pinches off into a daughter cell and a mother cell, making them simple to monitor cell cycle progression for the study of mutants that affect cell cycle (Hartwell, 1992, 2004). Yeast can survive as haploid of either two mating types, "a" and " $\alpha$ " or as diploid. The opposite mating type haploids can fuse to grow indefinitely in the mitotic state, but can be induced to undergo meiosis and produce spores contained in 
ascus that can be used for genetic studies (Lundblad, 1997). For these reasons, it has been extensively used to study the genetics of cell division, genome fidelity, telomerase activity and therapeutics in cancer (Bjornsti, 2002; Gao et al., 2010; Hartwell, 2004).

\subsection{Eukaryotic Ribosome}

The ribosome is a large macromoleculer complex responsible for decoding the ge-

netic codes from mRNAs into proteins. Approximately two-thirds of the mass of a ribosome is composed of RNA and one-third is protein (Ramakrishnan, 2002). Not only do the RNA components contribute significantly to the mass, but also to the main function of the ribosome. With such an essential task, it is crucial ribosomes are accurately synthesized and assembled. Ribosome biogenesis involves the processing and modification of ribosomal RNAs (rRNA) and ribosomal proteins (RP) along with the correct assembly of all the components (Kressler et al., 2010). Ribosomes are highly conserved both in structure and in functions, due to its integral role in gene expression.

\subsubsection{Ribosome Structure}

The ribosome is a large ribonucleoprotein (RNP) particle, comprised of ribosomal RNAs (rRNAs) and proteins organized into two subunits (Venema and Tollervey, 1999). The ribosome subunits are characterized by sedimentation coefficients (Svedberg units). In eukaryotes, they are the $40 \mathrm{~S}$ and $60 \mathrm{~S}$, whereas prokaryotic ribosomes consist of the 30S and 50S subunits (Frank and Spahn, 2006). Eukaryotic ribosomes are notably larger than prokaryotic ribosomes due to the quantity of additional proteins present. In particular, yeast ribosome has a molecular mass of approximately $3.0 \times 10^{6} \mathrm{D}$ compared to Escherichia coli with a molecular mass of 
$2.3 \times 10^{6}$ D (Frank and Spahn, 2006; Hanson et al., 2003).

In the yeast, $S$. cerevisiae, the $40 \mathrm{~S}$ subunit consists of the $18 \mathrm{~S}$ rRNA, which is 1798 nucleotides (nt) long, and 33 ribosomal proteins (Frank and Spahn, 2006; Kressler et al., 2010). The 60S subunit consists of the 5.8S, 25S and 5S rRNAs, totalling 3671 nt, and 46 ribosomal proteins (Kressler et al., 2010). The small ribosome subunit (40S) mediates the decoding of mRNA while the large subunit (60S) catalyzes peptide bonds between amino acids (Frank and Spahn, 2006; Kothe, 2010).

\subsubsection{Ribosome Biosynthesis}

As cells grow and proliferate, ribosomes are constantly being produced to keep up with the cells functional requirements. In G1 phase of cell proliferation, rRNA synthesis and ribosome assembly are increased to allow for increased protein synthesis in the S phase when many resources and extensive energy are required to replicate the DNA (Ruggero and Pandolfi, 2003). Ribosome biogenesis requires active targets of rapamycin (TOR) pathway that is involved in regulating growth as well as the Protein Kinase A (PKA) pathway and many other endo- and exonucleolytic digestion pathways (Rudra and Warner, 2004). In addition to these active pathways, sufficient amino acids and many accessory proteins are required for ribosome synthesis to occur.

In yeast, the rDNA unit is $9.1 \mathrm{~kb}$ long and consists of the $5 \mathrm{~S}$ rRNA gene at the 5' end followed by the non-transcribed spacer 2 (NTS2). Proceeding that is the $35 \mathrm{~S}$ pre-rRNA operon which contains three rRNA genes, $18 \mathrm{~S}, 5.8 \mathrm{~S}$ and $25 \mathrm{~S}$, interrupted by two internal transcribed spacers, ITS1 and ITS2. The operon has two external transcribed spacers, 5'ETS and 3'ETS, at the ends and the non-transcribed spacer 1 (NTS1) completes the rDNA at the 3' end (Venema and Tollervey, 1999, Figure 2). Ribosome biogenesis usually takes place in a specialized compartment 
within the nucleus called the nucleolus. The process starts with the synthesis of $5 \mathrm{~S}$ rRNA by RNA polymerase III, and 35S pre-rRNA by RNA polymerase I (Dinman, 2009; Fromont-Racine et al., 2003). The pre-rRNAs go through a complex pathway involving endo- and exonucleolytic digestions and are modified by 75 different small nucleolar ribonucleoprotein particles (snoRNPs) into 5.8S, 25S, 5S and 18S rRNAs (Fromont-Racine et al., 2003). The 18S rRNA becomes the rRNA component of the small $40 \mathrm{~S}$ subunit while the $5.8 \mathrm{~S}$ and the $25 \mathrm{~S}$ rRNAs along with the independently transcribed $5 \mathrm{~S}$ become the parts of the 60S subunit (Fromont-Racine et al., 2003). These ribosomal rRNAs then require over 170 accessory proteins and snoRNPs before they can be assembled into pre-40S and pre-60S subunits and exported separately to the cytoplasm for further assembly and usage (Fromont-Racine et al., 2003; Kressler et al., 2010). 
rDNA repeat $(9.1 \mathrm{~kb})$

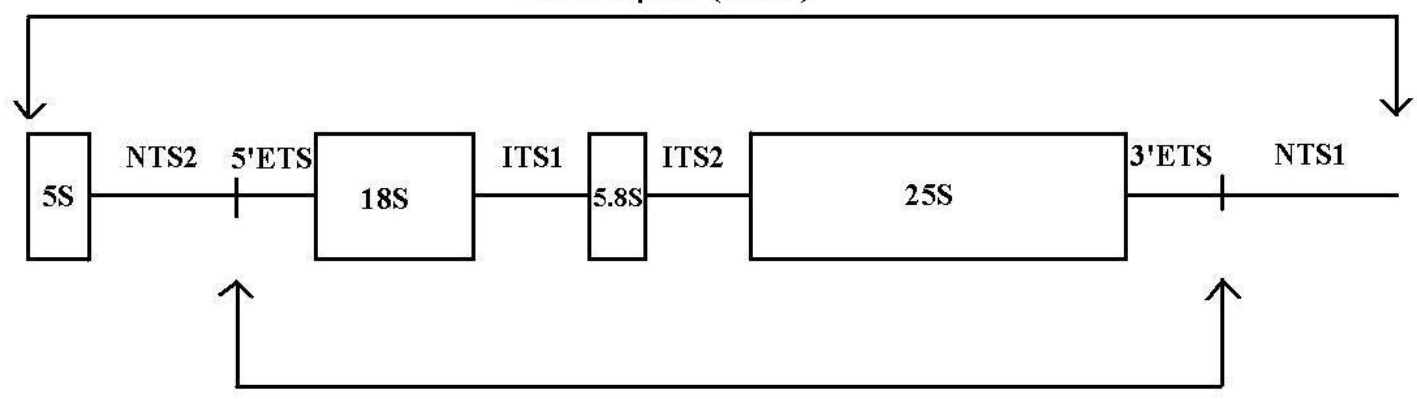

35S Operon

Figure 2: A map of the yeast ribosomal DNA. The 5S rRNA is separated by the non transcribed spacer 2 (NTS2) from the $35 \mathrm{~S}$ pre-rRNA operon. The $35 \mathrm{~S}$ prerRNA operon contains the 5' external transcribed spacer (5'ETS) followed by $18 \mathrm{~S}, 5 \mathrm{~S}$ and $25 \mathrm{~S}$ that are disrupted by internal transcribed spacers, ITS1 and ITS2. The operon ends with the 3' external transcribed spacer (3'ETS) and the non transcribed spacer 1 (NTS1) marks the end of the yeast ribosomal DNA (Venema and Tollervey, 1999). There are 150 copies of yeast rDNA in tandem repeats (Kobayashi et al., 1998). Figure adapted from Venema and Tollervey, 1999. 


\subsubsection{Regulations of Ribosome Biogenesis}

The transcription of ribosomal RNA accounts for roughly $60 \%$ of total transcription in a cell. Consequently, changes in the regulation of ribosome synthesis will have a substantial effect on the expression of other genes (Rudra and Warner, 2004). The regulation of ribosome biogenesis is crucial to maintain cellular activity and prevent damaged ribosomes from wasting valuable energy translating non-functional and potentially harmful proteins (Kressler et al., 2010). Ribosomes can become damaged from incorrect assembly, external damage from UV radiation and oxidative stress or from other environmental agents. These damaged ribosomes require mechanisms in the biological system for detection and removal.

In $S$. cerevisiae, ribosome biogenesis can be repressed by inactivating the TOR pathway and reducing PKA activity, as well as, by nutritional starvation and external stimuli (Rudra and Warner, 2004). In the event of a damaged ribosomal RNA, specifically a non-functional $25 \mathrm{~S}$ rRNA of the $60 \mathrm{~S}$ subunit was identified that the proteins of this subunit are targeted and degraded by components of an E3 ubiquitin ligase complex (Fujii et al., 2009). However, the degradation of a faulty 40S subunit involves a different pathway similar to no-go decay (NGD) of mRNA since it utilizes the same proteins as those in NGD (Cole et al., 2009). In NGD, mutated 18S rRNA of the 40S subunit is degraded but is dependent on an active translation process, therefore damaged 40S is detected during stalled translation elongation (Cole et al., 2009). Generally, mutants produced during ribosome biogenesis prevent the accumulation of rRNA precursors, arresting ribosome assembly. The intermediates are then targeted for degradation (Venema and Tollervey, 1999). It is still ambiguous how intermediates are selected to be degraded when they have failed to be further processed and the specific mechanisms of the selection process are still unknown. Alternatively, 
exosome can also degrade defective rRNAs in addition to degradation of the external transcribed spacers (Venema and Tollervey, 1999). Much is known about ribosome biogenesis and assembly, however, there are no known specific mechanisms for the degradation of rRNAs during ribosome biogenesis and its regulation remains elusive.

\subsection{Translation}

Translation is an important component in the gene expression pathway, whereby a gene's DNA sequence is decoded into functional proteins in the cell. It is very complex and consumes a significant amount of energy and demands a large portion of resources such as ribosomes, tRNAs, translation factors and many other proteins to operate. An estimated $35-45 \%$ of the minimal genes required to support life are dedicated to translation (Mathews et al., 2000). Thus the magnitude of resources and energy required for translation makes it very important that it is adequately controlled for cell survival.

\subsubsection{Translation Regulation and Diseases}

Deficient control of translation can cause the biological system to experience abnormal cellular activities, which can lead to numerous human health problems including cancer and ageing. Translation related diseases can arise from altered translation levels of specific mRNAs due to mutated ribosomes, or from alterations in any of the components involved in the translation process. Any number of mutations can produce premature termination or continued translation of an mRNA strand during translation yielding dysfunctional proteins that can have severe physiological repercussions. For example, Wolcott-Rallison syndrome (WRS), characterized by infantile onset of diabetes mellitus stems from mutations in a translation initiation factor gene. This gene encodes the eukaryotic translation initiation factor $2 \alpha$ kinase 3 
(EIF2AK3) also known as protein kinase R (PKR)-like endoplasmic reticulum kinase (PERK) that phosphorylates eIF2 when there are misfolded protein accumulations in the endoplasmic reticulum (ER) (Scheper et al., 2007). PERK plays a key role in translation control during the unfolded protein response and mutations in the gene would ultimately impair or destroy PERK's activity allowing the overproduction of insulin. The increased production of insulin eventually wears out the cells of the pancreas causing patients to suffer many health issues including diabetes.

There has to be a balance of all required proteins for a cell to function normally, and for example, if PERK was elevated, it can be fatal for the cell. In the case of Alzheimer's disease (AD), energy deprivation or excess PERK heightens the phosphorylation of eIF2 and increases beta-site APP cleaving enzyme 1 (BACE1) levels (O'Conner et al., 2008). The abundant product from BACE1 results in increased cleavage of the amyloid- $\beta$ precursor protein (APP) giving rise to the accumulation of neurotoxic peptides, $\beta$-amyloid $(\mathrm{A} \beta)$, typically found in Alzheimer's patients (Lammich et al., 2004; Zhao et al., 2007). Increased or reduced expression of a gene typically yields undesirable phenotypes, but the inhibition of certain genes can produce positive outcomes. For instance, inhibition of various translation complex genes in the nematode, Caenorhabditis elegans, including eIF4G, results in the extension of worm's lifespan (Chen et al., 2007; Pan et al., 2007).

Tumorigenesis and many diseases have been associated with components of the ribosome that have been deregulated or misexpressed. For example, mutations in the $D K C 1$ gene which encodes dyskerin, a synthase that mediates posttranscriptional modification of ribosomal RNA, can cause increased susceptibility to cancer (Ruggero et al., 2003). Another example is the mutated gene encoding the S19 ribosomal protein which has been linked to Diamond-Blackfan anaemia, a disease of the bone 
marrow (Draptchinskaia et al., 1999).

Despite extensive research in translation, it is still not fully elucidated in terms of control. Translational control was defined by (Diaz-Guerra et al., 2008) as the change in translation efficiency or the change in the number of functional proteins produced per molecule of mRNA per unit time, which should be constant under steady-state conditions. The regulation of gene expression at the translation level is significant, in particular, data indicates that approximately $13 \%$ of mRNAs are regulated at translation during an immune response against viral infections, parasites and tumor control when T cells are activated in humans (Mikulits et al., 2000). Additionally, many infectious diseases achieve successful infection by targeting the translation process, and various antibacterial drugs are designed to target the same process in viruses and bacteria (Belova et al., 2001; Brodersen et al., 2000). Control at the translation stage has the advantage of allowing a much faster response and control of the expression of proteins in response to stress and environmental changes (Scheper et al., 2007). For these reasons, it is important that we continue to search and understand the components and their interactions with each other for a better comprehension of translation in the biological system. This will benefit the pursuit of new treatments and approaches to prevent the onset of translation related diseases.

\subsubsection{Mechanism of Eukaryotic Translation}

Most cellular instructions are stored in DNA as genes, which are transcribed and translated into proteins. In eukaryotes, a gene is transcribed inside the nucleus and a complementary RNA strand, the pre-mRNA is produced (Linder, 1992). This pre-mRNA is then modified by the removal of non-coding regions (introns) and the addition of a cap structure at the 5' end. In addition, the 3' end of the transcript is also modified with a poly-A tail, which contributes to the protection of the mRNA from 
degradation and regulates the efficiency of translation (Gallie, 1991). The modified mRNA is then transported from the nucleus to the cytoplasm and is ready to be translated. Translation is a multistep process and can be divided into three distinct phases: initiation, elongation and termination. Initiation requires ribosomes and many initiation factors to bind onto the mRNA. This step is proceeded with elongation where amino acids are linked into a polypeptide chain as the mRNA is being read by ribosomes. The last step of translation is termination where the polypeptide chain is released and the ribosomes are discharged from the mRNA.

\subsubsection{Translation Initiation}

Translation initiation is considered the rate limiting step and begins with the assembly of the ribosomes requiring at least nine eukaryotic initiation factors (eIFs) (Jackson et al., 2010; Zaher and Green, 2009). It is the most complex step in translation and can be divided further into two stages; the formation of the 48S initiation complex and the joining of this complex to the $60 \mathrm{~S}$ ribosomal subunit to produce the $80 \mathrm{~S}$ ribosome (Jackson et al., 2010). Initiation begins when a ternary complex consisting of eIF2, GTP and an initiator Met-tRNAi ${ }^{\text {Met }}$ binds to a $40 \mathrm{~S}$ ribosomal subunit to form the 43S preinitiation complex (HernÃąndez et al., 2009; Linder, 1992; Preiss and Hentze, 2003). The 40S subunit is stabilized by eIF3, eIF1 and eIF1A which all serve to stimulate binding of the eIF2 ternary complex with 40S subunit (HernÃąndez et al., 2009; Jackson et al., 2010; Preiss and Hentze, 2003). At the same time, eIF4E, the cap binding protein, recognizes the $\mathrm{m}^{7} \mathrm{G}$-Cap at the 5 ' end and forms a complex with eIF4G, the scaffold protein (HernÃąndez et al., 2009; Linder, 1992; Preiss and Hentze, 2003). eIF4G interacts with eIF4E, eIF4A (an RNA helicase) and the poly(A)-binding protein (PABP) to form a cap binding complex called eIF4F (HernÃąndez et al., 2009; Jackson et al., 2010; Preiss and Hentze, 2003). Binding of PABP and eIF4G promotes the circularizing of mRNA and eIF4B serves to unwind 
the secondary structures of the 5' untranslated region (UTR), enabling the eIF4F complex to recruit the $43 \mathrm{~S}$ preinitiation complex to the 5' UTR and initiate scanning for the first start codon (Hern Âąndez et al., 2009; Jackson et al., 2010). Once the start codon is recognized by the anticodon of Met-tRNAi ${ }^{\text {Met }}$, eIF5 hydrolyzes eIF2bound GTP, and the 48S preinitiation complex is formed. At this time, the eIF2-GTP is hydrolyzed and releases eIF2-GDP. eIF5B enters with the 60S subunit and joins the $40 \mathrm{~S}$ subunit and displaces the initiation factors and launches into the elongation phase (HernÃąndez et al., 2009; Jackson et al., 2010; Sonenberg and Hinnebusch, 2009, Figure 3). 


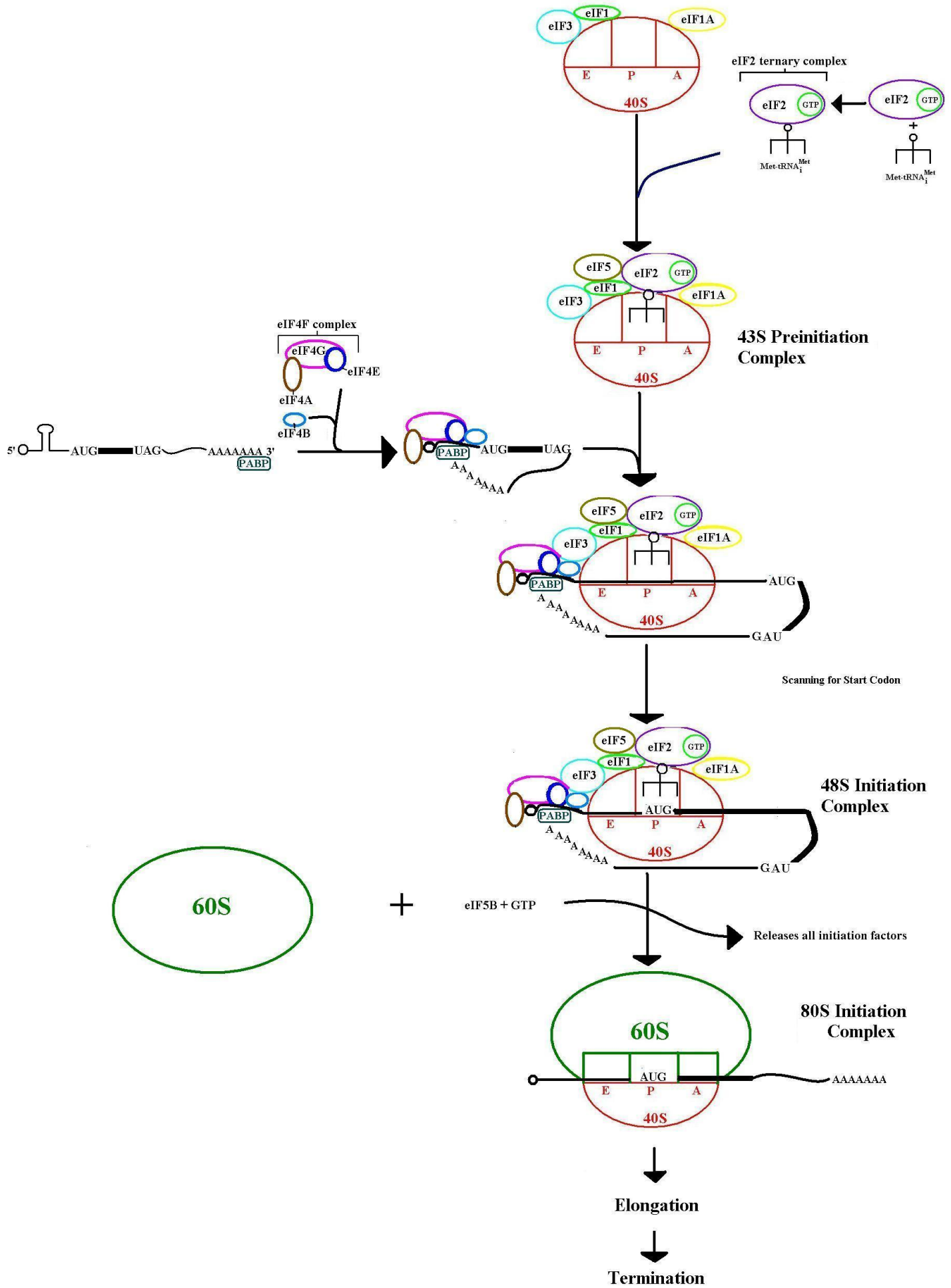

Figure 3: The mechanism of translation initiation in mammalian system. The 43S preinitiation complex is formed in parallel with the formation of the cap binding protein complex (eIF4F). They are then joined at the mRNA 5'UTR to start the scanning for the first start codon where it forms the 48S preinitiation complex and is ready for $60 \mathrm{~S}$ ribosomal subunit binding to prepare for elongation (Jackson et al., 2010). Figure adapted from Jackson et al, 2010. 


\subsubsection{Translation Elongation}

The elongation phase requires two elongation factors, EF-1A and EF-2. Elongation factor $1 \mathrm{~A}, \mathrm{EF}-1 \alpha$ in yeast, binds GTP and the aminoacyl-tRNA, and positions the tRNA in the A-site of the ribosome (Kapp and Lorsch, 2004; Linder, 1992). eEF1A's GTPase activity releases the aminoacyl-tRNA into the acceptor (A) site and the ribosomal peptidyl-transferase catalyzes the formation of a peptide bond between the new amino acid and the peptidyl-tRNA (Kapp and Lorsch, 2004). Thus the tRNA in the puromycin $(\mathrm{P})$ site is deacylated with the acceptor end in the exit (E) site, and the anticodon end in the $\mathrm{P}$ site, which is then completely translocated into the E site by EF-2 (Kapp and Lorsch, 2004). The peptidyl-tRNA then shifts into the P site, leaving the A site vacant shifting down the mRNA by three nucleotides (Kapp and Lorsch, 2004). The vacant A site is then ready to accept the next aminoacyl-tRNA. This process is repeated until a stop codon is reached, whereby the termination of translation commences. Interestingly, there is a third elongation factor, EF-3, found in yeast, which was shown to be essential for viability (Kapp and Lorsch, 2004; Qin et al., 1990). It was discovered to be involved in facilitating the release of the deacylated tRNA in the E site and promotes efficient binding of the EF-1-GTP-tRNA ternary complex to the A site (Kapp and Lorsch, 2004; Triana-Alonso et al., 1995, Figure 4). 


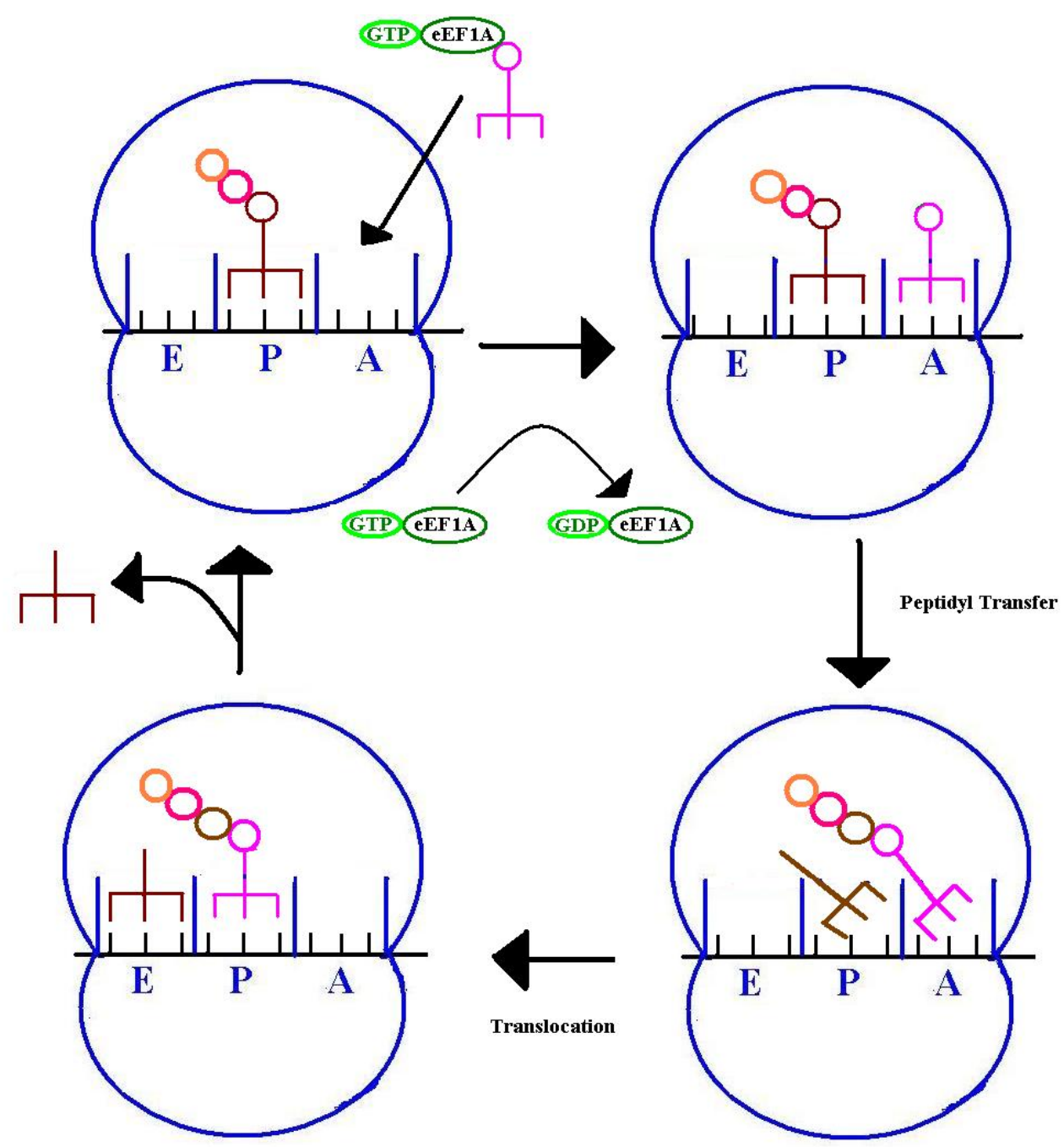

Figure 4: The mechanism of translation elongation in mammalian system. eEF1A -GTP-aminoacyl-tRNA enters the vacant A site where the ribosomal peptidyltransferase forms a peptide bond between the new amino acid and the peptidyltRNA in the P site. The tRNA in the P site is deacylated and translocates into the E site by EF-2. It is then released as the next aminoacyl-tRNA enters the ribosome in the A site. Deacylated tRNAs translocate from A site then to P site and to E site as it shifts down the mRNA by three nucleotides. This leaves $\mathrm{A}$ site vacant to accept the next aminoacyl-tRNA until the stop codon is reached (Triana-Alonso et al., 1995). Figure adapted from Kapp and Lorsch, 2004. 


\subsubsection{Translation Termination}

Translation termination occurs when any one of the three stop codons (UAA, UAG, UGA) is reached in the A site, and is recognized by a eukaryotic release factor 1 (eRF1) (Figure 5). eRF1 triggers the ribosome by activating the large ribosomal subunit peptidyl transferase centre to hydrolyze the peptidyl-tRNA and release the polypeptide chain (Kapp and Lorsch, 2004; Linder, 1992). There are three domains that make up eRF1. The first is the N-terminal domain (domain 1) that is responsible for recognizing any of the three stop codons (Song et al., 2000). The middle domain (domain 2) functions in peptidyl-transferase hydrolysis to release the polypeptide chain (Frolova et al., 1999) and the C-terminal domain (domain 3) is required to interact with eukaryotic release factor 3 (eRF3) (Akhmaloka et al., 2008). Release factor 1 functionally mimics tRNA in that it decodes the stop codon in the A site of the ribosome, however, the mechanism in which it distinguishes stop codons from sense codons is still ambiguous. eRF3 has GTPase activity that functions with eRF1 to recognize stop codons and activate hydrolysis of peptidyl-tRNA to mediate rapid and efficient peptide release by eRF1 (Cheng et al., 2009). These two release factors are essential for optimum efficiency of termination in S.cerevisiae. Once translation has terminated, the ribosomes either get disassembled and are recycled to be used for a different mRNA or they can remain to reinitiate and translate the same mRNA.

The newly synthesized polypeptide requires folding into the appropriate structure before it can be functional. An error in even a single amino acid translation can result in a deformed and nonfunctional protein. However, in yeast, translation is generally a very accurate process and has an approximate $0.15 \%$ frequency of miscoding per codon (Bidou et al., 2010). 


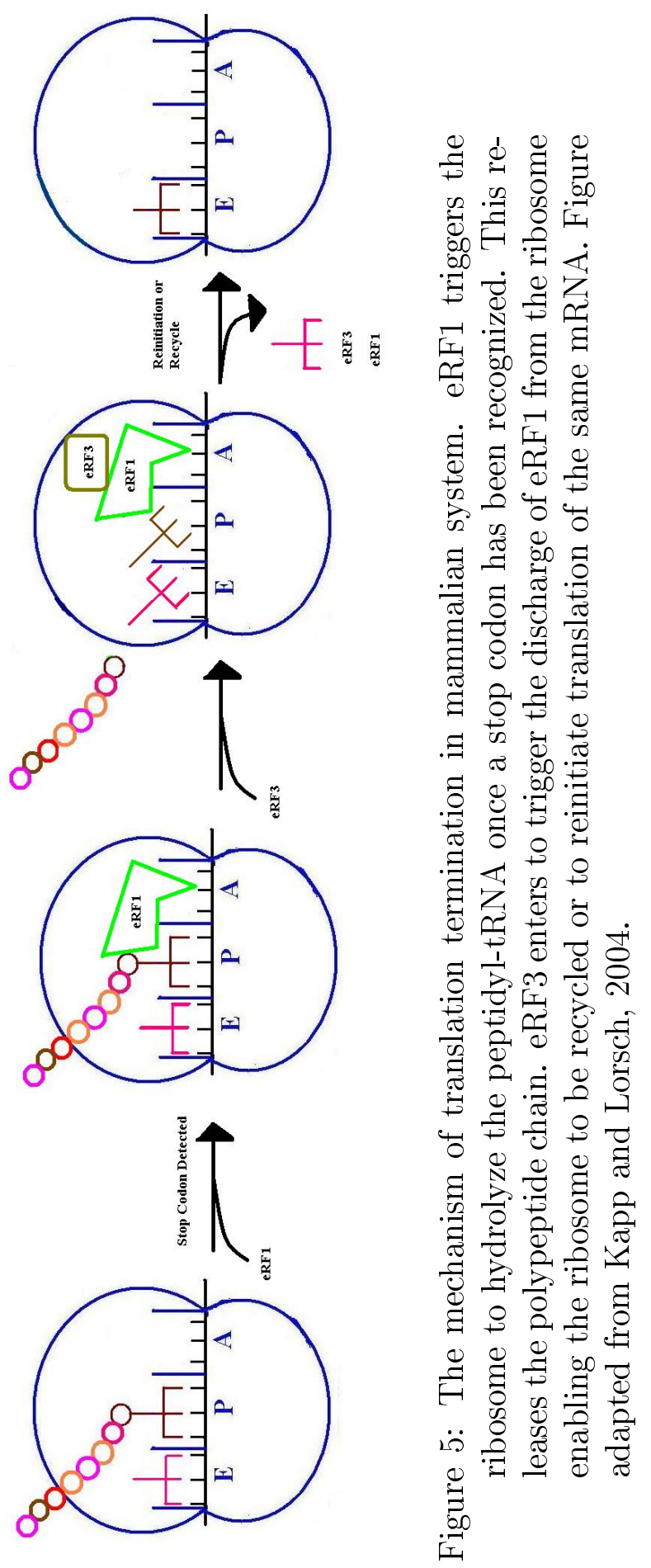




\subsection{Purpose and Objectives}

The objective of this research was to identify novel genes that are involved in the translation pathway. From previous works, the entire yeast non-essential gene deletion collection containing approximately 5000 strains were transformed with pUKC817, pUKC818 and pUKC819 plasmids containing LacZ gene carrying premature stop codons UAA, UAG and UGA, respectively. High throughput transformation was accomplished by transforming the plasmids into the opposite mating type " $\alpha$ " and crossing the transformants with the yeast gene-deletion collection in mating type "a". After a few rounds of selection, single mutant of "a" mating type that carried the target plasmid were selected. A large scale $\beta$-galactosidase colony lift assay was applied to the transformed yeast gene-deletion collection to determine the effect of translation fidelity in the different deletion strains with transformed pUKC817, pUKC818 and pUKC819. In this way, deletion strains that were compromised in translation would have increased bypass of premature stop codons resulting in increased level of $\beta$-galactosidase compared to the control. Of the entire yeast gene deletion collection, 106 deletion mutant strains were found to have increased $\beta$-galactosidase expression. These strains were further investigated by a preliminary small-scale $\beta$-galactosidase liquid assay providing a smaller list of approximately 80 deletion mutant strains. Many of these genes were involved with the process of translation highlighting the ability of the screen to select translation related genes. A number of previously ill-characterized genes were also detected suggesting novel roles for these genes in the process of translation.

From the list of genes with previously unknown function(s), four were selected for follow up investigations to confirm and examine their involvement in the process of translation. The genes we intended to verify and to characterize their roles in protein 
synthesis were $Y G R 117 C, Y N L 122 C, Y J R 014 W$ and $Y N L 040 W$. Firstly, sensitivity of gene deletion mutants for these four target genes against translation drugs, cycloheximide and paromomycin, was investigated. Directed $\beta$-galactosidase liquid assay with premature stop codon constructs was used to confirm the effect of gene deletion for the target genes on translation fidelity. Next, the efficiency of translation was measured in the absence of the target genes using an inducible $\beta$-galactosidase expression cassette. Since elevation of protein expression can also be a result of an increase in mRNA content, qRT-PCR was used to study the content of $\beta$-galactosidase mRNA. Synthetic Genetic Array (SGA) analysis, Synthetic Dosage Lethality (SDL) assay and Phenotypic Suppression Analysis (PSA) were utilized to identify genetic interactions that may link the target genes to specific roles within protein synthesis. Our findings suggest novel roles for $Y N L 040 \mathrm{~W}, Y J R 014 \mathrm{~W}, Y G R 117 \mathrm{C}$ and YNL122C in the process of translation. 


\section{Chapter 2}

\section{Materials and Methods}

\subsection{Buffer, Solutions and Reagents}

All solutions and buffers are made with analytical grade chemicals and prepared with distilled or de-ionized water (Milli-Q Plus Ultra Pure Water system, Millipore, Billerica, MA, USA). Buffers and solutions were sterilized by autoclaving with SG-116 Scientific Gravity Sterilizer for 20 minutes or filter sterilized with $0.2 \mu \mathrm{m}$ Millipore membrane filter. Buffers for RNA experiments were prepared using RNase-free water from Qiagen.

\section{$2.2 \quad$ Media}

Yeast Extract Peptone Dextrose (YEPD), Synthetic Complete (SC) and minus uracil media from Bioshop Canada were used as growth media for yeast (Appendix 1 and 2). Lysogeny broth (LB) was used as growth media for Escherichia coli. Enriched Sporulation Medium (ESM) was used in the synthetic genetic array analysis. The array of deletion strains carrying the geneticin resistant marker was maintained using YEPD medium with geneticin antibiotic (G418, $200 \mu \mathrm{g} / \mathrm{mL}$ ) from Bioshop Canada. 


\section{$2.3 \quad$ Strains}

E. coli strain DH5 $\alpha$ was used to propagate plasmids. The yeast non-essential gene deletion array (yGDA), BY7092 mating type " $\alpha$ " was used for secondary gene

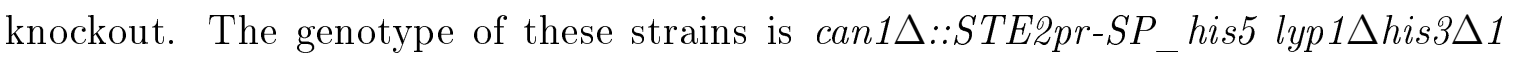
leu2 $\Delta 0$ ura $3 \Delta 0$ met15 $\Delta 0$. Yeast deletion and overexpression sets of BY4741 mating type "a" were used for all genetic experiments in this thesis. The genotype of these strains is MATa, his3 $\Delta 1$ leu2 $\Delta 0$ met15 $\Delta 0$ ura3 $\Delta 0$.

The deletion mutant strains for the genes of interest used were YNL040W YJR014WA, YNL122CA, YGR117CA and YLR192CA (positive control). The control strain used was $D A N 1 \Delta$.

\section{$2.4 \quad$ Plasmids}

To test translation fidelity, expression plasmids pUKC817, pUKC818 and pUKC819 containing premature stop codons UAA, UAG and UGA, respectively, within the LacZ expression cassette were employed. The control was pUKC815 which contains no stop codon. Plasmids were obtained from Dr. Mick Tuite (University of Kent at Canterbury) and Dr. Terri Goss Kinzy (University of Medicine and Dentistry of New Jersey).

An inducible $\beta$-galactosidase reporter construct (p416) (Mumberg, Muller, Funk,1994) obtained from ATCC containing LacZ expression cassette fused to an inducible GAL1 promoter with URA3 and $a m p R$ markers was also used to test translation efficiency. In PCR reactions to propagate the nourseothricin (NAT) resistance gene for gene knockout analysis, pAG25 plasmid was used as a template. 
One gene knockout of (YNL040W) was constructed using BY7092 mating type $\alpha$ via homologous recombination using PCR-mediate gene deletion method.

Plasmids from BY4741 mating type a overexpression strains for (YNL040W and YJR014W) were isolated using plasmid extraction kit from Invitrogen and transformed into MAT $\alpha$ for experimentation in the synthetic dosage lethality screen.

\subsection{Transformations}

The yeast MAT a deletion strains of interest were grown in $5 \mathrm{~mL}$ YEPD with 5 $\mu \mathrm{L}$ G418 antibiotic overnight. Plasmids pUKC815 (control), pUKC818 (UAG), pUKC817 (UAA) and pUKC819 (UGA) were transformed into each yeast deletion strain. The transformation was performed using the lithium acetate method as described in (Kawai et al., 2010) but with some modifications. $3 \mathrm{~mL}$ of the overnight culture was transferred to a flask of $50 \mathrm{~mL}$ fresh YEPD and incubated for 2 to $3 \mathrm{hr}$ to obtain $2 \times 10^{7}$ cells corresponding to $\mathrm{OD}_{600} \approx 1.0$ on the Ultraspec 3000 spectrophotometer (Pharmacia Biotech). The centrifuge was set to spin at $3000 \mathrm{rpm}$ for 2 minutes unless stated otherwise. The cells were harvested by centrifugation and washed with $10 \mathrm{ml}$ sterile water and centrifuged. The pellet was then vortexed with $1 \mathrm{~mL}$ of $0.1 \mathrm{M} \mathrm{LiOAC}$ (Bioshop) and centrifuged. $200 \mu \mathrm{L}$ of $0.1 \mathrm{M} \mathrm{LiOAC}$ was added to resuspend the yeast pellet for use in the transformation mix. The transformation mix tube contained 3-5 $\mu \mathrm{L}$ of plasmid, $10 \mu \mathrm{L}$ boiled single stranded DNA, $240 \mu \mathrm{L}$ $50 \%$ polyethylene glycol (PEG) (Bioshop), $36 \mu \mathrm{L} 1 \mathrm{M} \mathrm{LiOAC}$ and $50 \mu \mathrm{L}$ of the resuspended yeast. The tube was incubated at $30^{\circ} \mathrm{C}$ for 60 minutes and vortexed every 20 minutes. $40 \mu \mathrm{L}$ of dimethyl sulfoxide (DMSO) (Bioshop) was added to the 
tube and vortexed then incubated at $42{ }^{\circ} \mathrm{C}$ for 15 minutes and centrifuged at 8000 rpm for 2 minutes. The pellet was resuspended with $110 \mu \mathrm{L}$ Milli-Q water, plated on -URA plates then incubated for 2-3 days.

An inducible $\beta$-galactosidase reporter construct (p416) (Appendix 3) was also transformed with separate overnight cultures of the yeast strains. Transformations of $Y N L 040 W$ and $Y J R 014 W$ overexpression plasmids into MAT $\alpha$ were performed with the same method.

\section{$2.6 \quad \beta$-galactosidase Assay}

The transformed yeast strains with pUKCs were grown in -URA media overnight, and reinoculated and incubated until $\mathrm{OD}_{600} \approx 1.0$. The protocol of the assay was performed as described (Miller, 1972). Each culture was centrifuged at 4000rpm for 4 minutes at $20^{\circ} \mathrm{C}$ and washed with Z-buffer (Appendix 4). This was repeated two more times before $\mathrm{OD}_{600}$ measurement was taken at (1:10) of resuspended cells to Z-buffer for $\beta$-galactosidase reaction calculations. $200 \mu \mathrm{L}$ of cells were then subjected to a mixture of permeabilization solutions including $800 \mu \mathrm{L}$ Z-buffer, $20 \mu \mathrm{L}$ of $0.1 \%$ SDS and $50 \mu \mathrm{L}$ of chloroform. The mixture for each strain was vortexed and incubated for 15 minutes at $30^{\circ} \mathrm{C}$. $200 \mu \mathrm{L}$ of $\mathrm{ONPG}$ was then added, vortexed and incubated to start the $\beta$-galactosidase reaction. When a yellow colour was observed, the reaction was stopped by $\mathrm{Na}_{2} \mathrm{CO}_{3}$, centrifuged, and the supernatant was measured at $420 \mathrm{~nm}$ to obtain the absorbance of O-nitrophenol. Measurement at $\mathrm{OD}_{550}$ was also taken to account for cell debris. The production of O-nitrophenol per unit is proportional to the concentration of $\beta$-galactosidase. Therefore, to calculate the units of $\beta$-galactosidase activity level, the samples were measured at $600 \mathrm{~nm}$ for cell density before permeabilization and readings at OD 420 and OD 550 were taken after 
the reaction of ONPG (Bioshop) had been stopped. The $\beta$-galactosidase activity in MillerâĂŹs unit was calculated following this equation:

MillerâĂŹs unit $=1000 \times((\operatorname{Abs} 420-(1.75 \times$ Abs 550)/(t x V x Abs 600) $)$

The Miller's unit calculates $\beta$-galactosidase activity in nanomoles of ONPG hydrolyzed per microgram of total protein. The absorbance value of O-nitrophenol at $420 \mathrm{~nm}$ is subtracted from the scatter of cell debris measured at $550 \mathrm{~nm} \times 1.75$. 1.75 multiplied by absorbance of cell debris at $550 \mathrm{~nm}$ is an approximated debris scattered at $420 \mathrm{~nm}$. Time (t) is the reaction time in minutes. The volume (V) of cell culture used was $0.200 \mathrm{~mL}$. The $\mathrm{Abs}_{600}$ is the cell density before permeabilization. 1 Miller Unit refers to uninduced E.coli yielding very low $\beta$-gal, thus 1000 is the approximated fully induced culture (Miller, 1972). The calculated $\beta$-galactosidase activity was normalized by the control and a higher MillerâĂŹs number compared to control signifies increased translation infidelity activity (stop codon readthrough) and indicates that these genes are involved in the translation process.

The same protocol was applied when performed with deletion strains transformed with p416 for testing translation efficiency, but with one modification. Cells were grown overnight in minimal media lacking uracil (-URA) with glucose to obtain $\mathrm{OD}_{600}$ $\approx 1.0$ and then induced with -URA media containing galactose for $4 \mathrm{hrs}$. Changes in translation activity presumably indicate translation efficiency, and genes with significantly lower or higher activity indicate they are involved in translation. 


\subsection{Drug Sensitivity Spot Test}

Different translation inhibitory drugs were used to test for sensitivity in the haploid yeast deletion strains. Cycloheximide and paromomycin were the drugs used in this experiment. Cycloheximide (Sigma) concentrations used were $45 \mathrm{ng} / \mathrm{mL}, 50 \mathrm{ng} / \mathrm{mL}$ and $60 \mathrm{ng} / \mathrm{mL}$. Paromomycin (Sigma) concentrations of $13 \mathrm{mg} / \mathrm{mL}$ and $18 \mathrm{mg} / \mathrm{mL}$. Streptomycin (Sigma) $50 \mathrm{mg} / \mathrm{mL}$ and $60 \mathrm{mg} / \mathrm{mL}$ were also used. Yeast cell cultures were grown in YEPD or SC until mid-log phase followed by serial dilutions $\left(10^{-3}\right.$ to $10^{-6}$ folds) spotting onto media. Ten to twenty microliters of each dilution was spotted in decreasing dilutions onto the appropriate drug concentration as mentioned above. Serial dilutions $\left(10^{-3}\right.$ to $10^{-6}$ folds $)$ spot test was done with each strain on YEPD with no drug as a control. Results were visually inspected after 1-2 days at $30{ }^{\circ} \mathrm{C}$ for growth sensitivity compared to the control strain.

\subsection{Quantitative Reverse Transcriptase Polymerase Chain Reaction (qRT-PCR)}

$\beta$-galactosidase activity results from cells containing the $\mathrm{p} 416$ plasmid may be an outcome of the different levels of $\beta$-galactosidase mRNAs. A higher quantity of mRNAs may be the cause of higher activity. To confirm that the results are strictly translational, qRT-PCR was performed to determine the $\beta$-galactosidase mRNA contents.

RNA extractions of the p416 transformed strains were done with RNeasy Mini kit from Qiagen using the mechanical disruption method. The quality and concentration of RNA was accessed using the NanoDrop Spectrophometer ND-1000. The integrity of the RNA extractions was checked by running samples on a denaturing agarose gel 
stained with ethidium bromide (EtBr).

cDNA was synthesized using $2 \mu \mathrm{L}$ of total extracted RNA from each of the strains using iScript cDNA synthesis kit (Bio-Rad Canada) with SYBR green supermix (Bio-Rad Canada) according to manufacturer instructions. Each reaction was incubated at $25^{\circ} \mathrm{C}$ for 5 minutes, then $42{ }^{\circ} \mathrm{C}$ for 30 minutes and finally at $85^{\circ} \mathrm{C}$ for 5 minutes.

The mRNA was quantified with real time PCR with the Rotor Gene RG - 300 . The forward (5'-ACTATCCCGACCGCCTTACT) and reverse (5'- TAGCGGCTGATGTTGAACTG) primers purchased from IDT for the detection of the LacZ mRNA expression level in yeast strains were used. The amplification settings were: initial denaturation at $95^{\circ} \mathrm{C}$ for 10 minutes, $95^{\circ} \mathrm{C}$ for 30 seconds for 40 cycles, then $55^{\circ} \mathrm{C}$ for 20 seconds, and finally $72^{\circ} \mathrm{C}$ for 20 seconds. A negative control containing no template as well as a control with no RT was included. A housekeeping gene (PGK1) from Eurofins was used as an internal standard. The threshold cycle (Ct) values and melting curves were generated with the Rotor Gene 6 software and the quantification of mRNA for each strain was obtained by comparing the $\mathrm{Ct}$ value of the strain with the $\mathrm{Ct}$ value of $P G K 1$.

This was repeated for the deletion strains containing the pUKC plasmids to quantify the $\beta$-galactosidase mRNA contents in those mutant strains.

\subsection{Primer Design}

The primer design for the knockout of $(Y N L 040 \mathrm{~W})$ required the ORF sequence obtained from Saccharomyces Genome Database (SGD). The primers contain 60 
bases complementary to the region upstream and downstream of the gene of interest. Also, 21 bases complementary upstream or downstream of the natMX4 cassette sequence was included. The confirmation primer was designed to have 24 bases and to have a melting temperature of approximately $65^{\circ} \mathrm{C}$. This primer was chosen from regions 700 to 900 bases upstream of the open reading frame (Figure 6). 
Forward Primer 5'-3'

21 bases

natR marker sequence
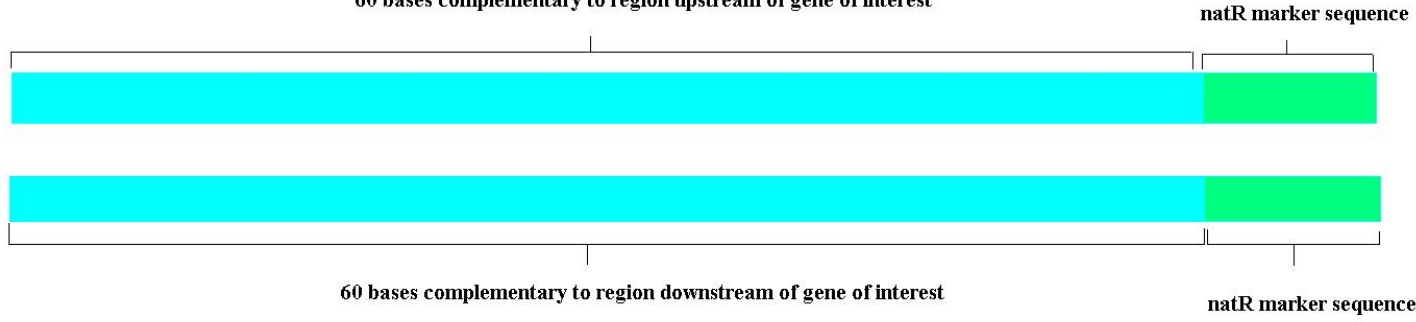

21 bases

Reverse Primer 5'-3'

Figure 6: Primer design for amplification of natR PCR product. The primers contained 60 bases upstream and downstream of the ORF and 21 bases complement to either ends of nat $R$ gene. 


\subsection{PCR-Mediated Gene Deletion and Query Strain Construction}

The target gene (YNL040W) in yeast mating type $\alpha$ from BY7092 was replaced with natMX4 using PCR-mediated gene deletion and transformation (Tong and Boone, 2006). Table 2 contains the primer designs used in the construction of the query strain.

The PCR mix contained $0.5 \mu \mathrm{L}$ of forward and reverse primers, $1 \mu \mathrm{L}$ of pAG25 plasmid used as a template (Figure 7), $14 \mu \mathrm{L}$ sterile water, $2 \mu \mathrm{L} 10 \mathrm{X}-\mathrm{PCR}$ buffer, $0.6 \mu \mathrm{L} \mathrm{MgCl}_{2}, 0.4 \mu \mathrm{L}$ dNTPs and $1 \mu \mathrm{L}$ Taq polymerase. The PCR amplification program was set at $95^{\circ} \mathrm{C}$ for 5 minutes, followed by $95^{\circ} \mathrm{C}$ for 35 cycles of 45 seconds, $48^{\circ} \mathrm{C}$ of 45 seconds and $72^{\circ} \mathrm{C}$ for 180 seconds and paused at $11^{\circ} \mathrm{C}$. The product was transformed into yeast $\alpha$ and transformants (YNL040W $\triangle:$ natR) were selected on YEPD + clonNAT (100 Âtg/mL) (Werner BioAgent, Germany). Homologous recombination between the target sequences (flanking sequences) of the PCR product and the complementary genomic DNA sequence mediated the gene deletion (Figure 8). Colony PCR was used to confirm the correct replacement of the target ORF with nat $M X_{4}$ by using confirmation primers specific to the yeast target loci and natMX4 gene. The sequence was PCR amplified using the same preparation and PCR program setting as previously mentioned and visualized on $0.8 \%$ agarose gel by electrophoresis at $80 \mathrm{~V}$ for 60 minutes. Confirmation primers used are in Table 2. 


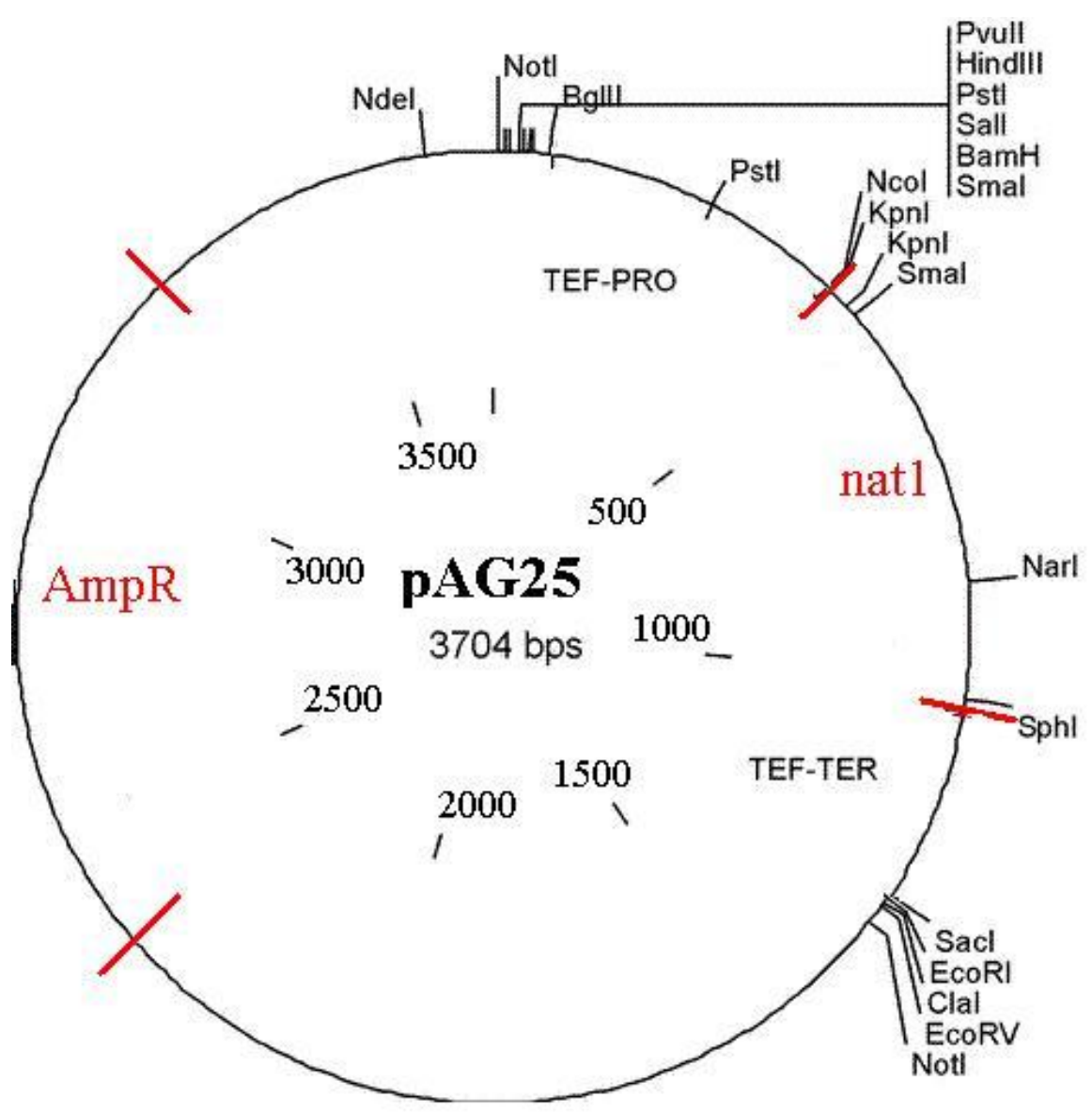

Figure 7: Map of plasmid vector pAG25 containing the drug resistance ORFs, nourseothricin (nat) and ampicillin (AmpR). Figure adapted from Golstein and McCuster, 1999. 


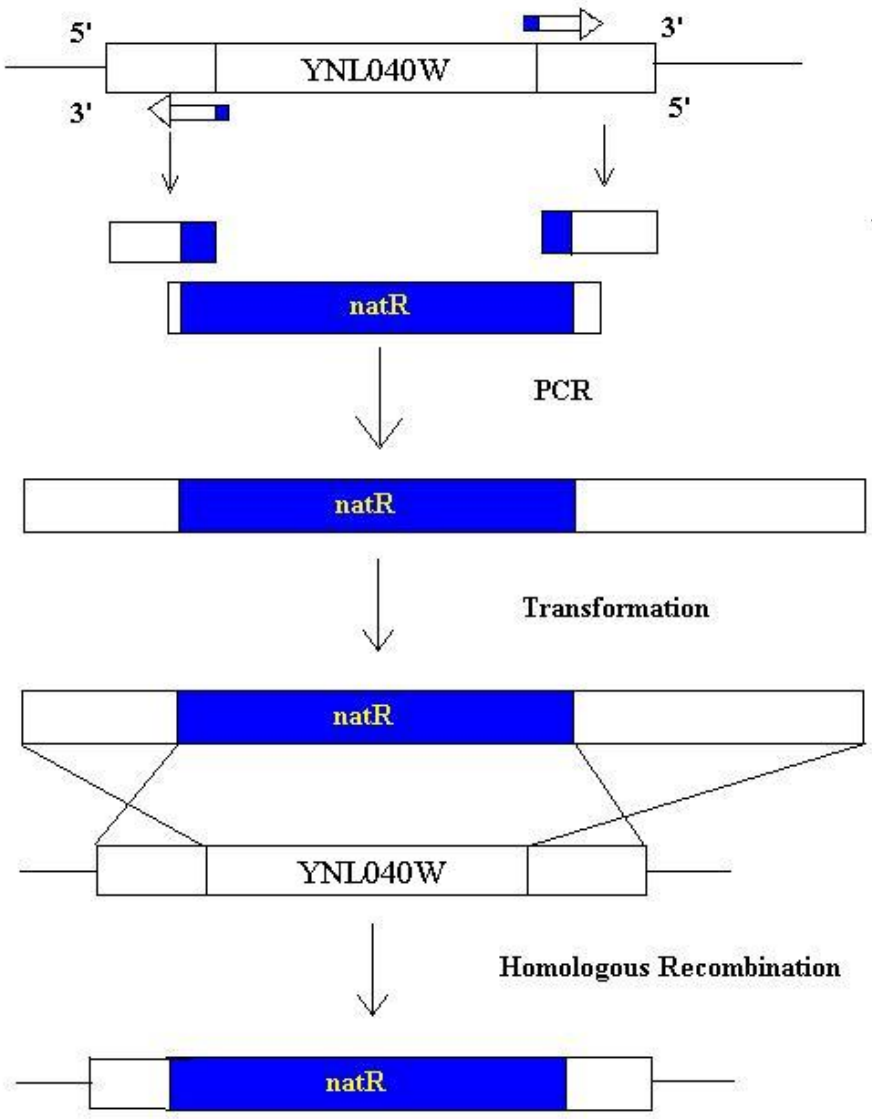

Figure 8: The gene knockout of $Y N L 040 W$ was achieved by PCR-mediated gene deletion. natR was amplified using pAG25 as a template and primers designed as in Figure 6. The PCR product was transformed into yeast " $\alpha$ " and gene knockout of $Y N L 040 \mathrm{~W}$ was succeeded through homologous recombination. The transformants were selected on YEPD + clonNAT. 


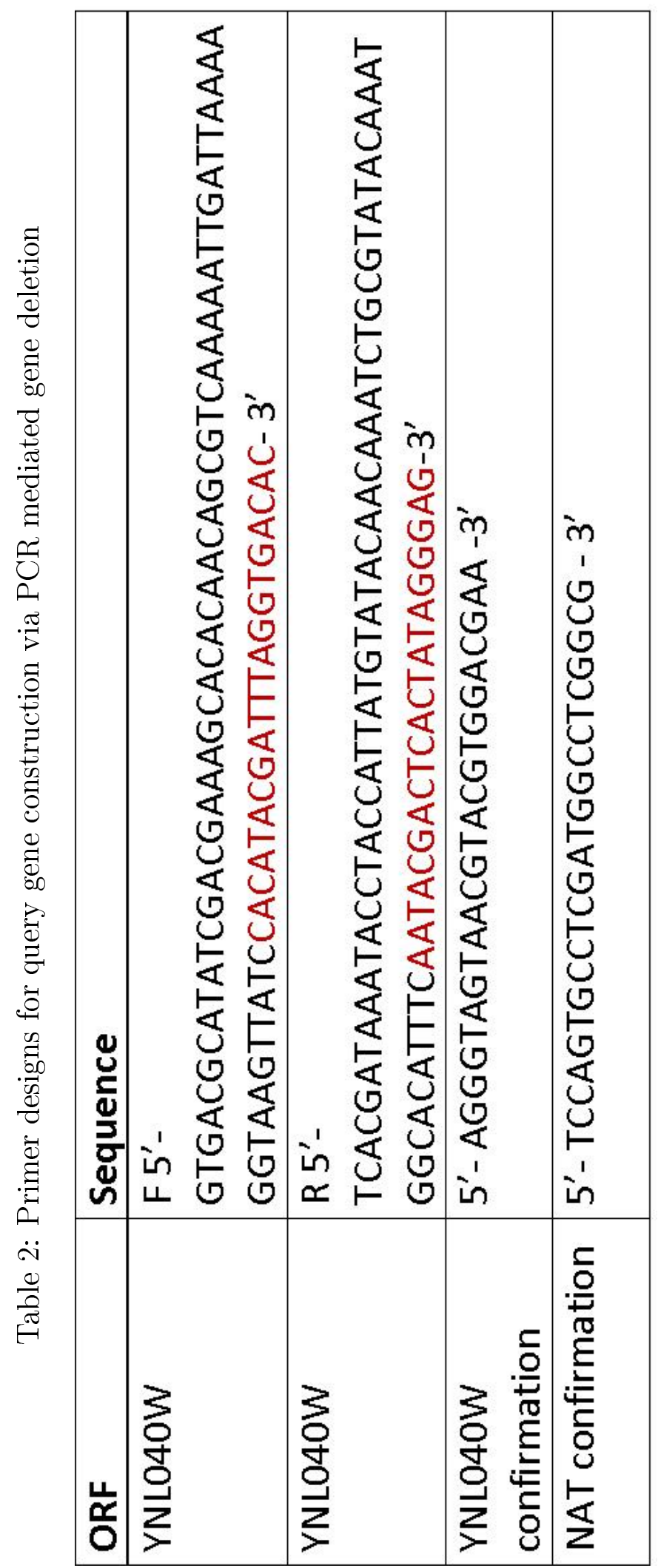




\subsection{Synthetic Genetic Array Analysis}

The constructed query strain $(Y N L 040 W \Delta:: n a t R)$ in MAT $\alpha$ was grown in YEPD + clonNAT overnight, then poured over YEPD plate and transferred onto fresh YEPD plates with the 384 pin replicator. These were left to grow for 1 day to generate newly grown query cells for mating with the opposite mating type MATa yeast deletion strains $(x x x \Delta:: k a n R)$ in the deletion mutant array (DMA). The particular set of array contains genes known or considered to be involved in translation. The synthetic genetic array analysis procedure was performed as described by (Tong and Boone, 2006). After mating of the query strain with the translation deletion mutant array, the heterozygous $M A T \mathrm{a} / \alpha$ diploids were selected onto YEPD + G418/clonNAT plates and the resulting diploids were transferred onto Enriched Sporulation Medium (ESM) to incubate for 9 days at $22^{\circ} \mathrm{C}$ to induce sporulation. The spores were pinned onto SD-His $/$ Arg + canavanine $(50 \mu \mathrm{g} / \mathrm{L})($ Sigma $) /$ thialysine $(50 \mu \mathrm{g} / \mathrm{L})($ Sigma $)$ plates for haploid selection of germinated MATa meiotic progeny and incubated at $30^{\circ} \mathrm{C}$ for 2 days. The MATa progeny was then pinned onto the same medium to germinate and incubated for 1 day in the same condition. The MATa meiotic progeny was then transferred to SD/MSG-His/Arg/Lys + canavanine $(50 \mu \mathrm{g} / \mathrm{L}) /$ thialysine $(50$ $\mu \mathrm{g} / \mathrm{L}) / \mathrm{G} 418(200 \mu \mathrm{g} / \mathrm{L})$ plates for selection of meiotic progeny that carry the gene deletion mutation $(x x \Delta:: n a t R)$. For double mutant selection, the MATa meiotic progeny was transferred one last time to SD/MSG-His/Arg/Lys + canavanine (50 $\mu \mathrm{g} / \mathrm{L}) /$ thialysine $(50 \mu \mathrm{g} / \mathrm{L}) / \mathrm{G} 418(200 \mu \mathrm{g} / \mathrm{L}) /$ clonNAT $(100 \mu \mathrm{g} / \mathrm{L})$ plates. The double mutants (yyy $\Delta:: n a t R$ xxx $\Delta:: k a n R)$ were scored by visual inspection for fitness defect (genetic sick interactions) by comparing the growth to the control set. See Figure 9 for the overview of SGA. Random spore analysis (RSA) was employed to confirm the synthetic sick interactions. 

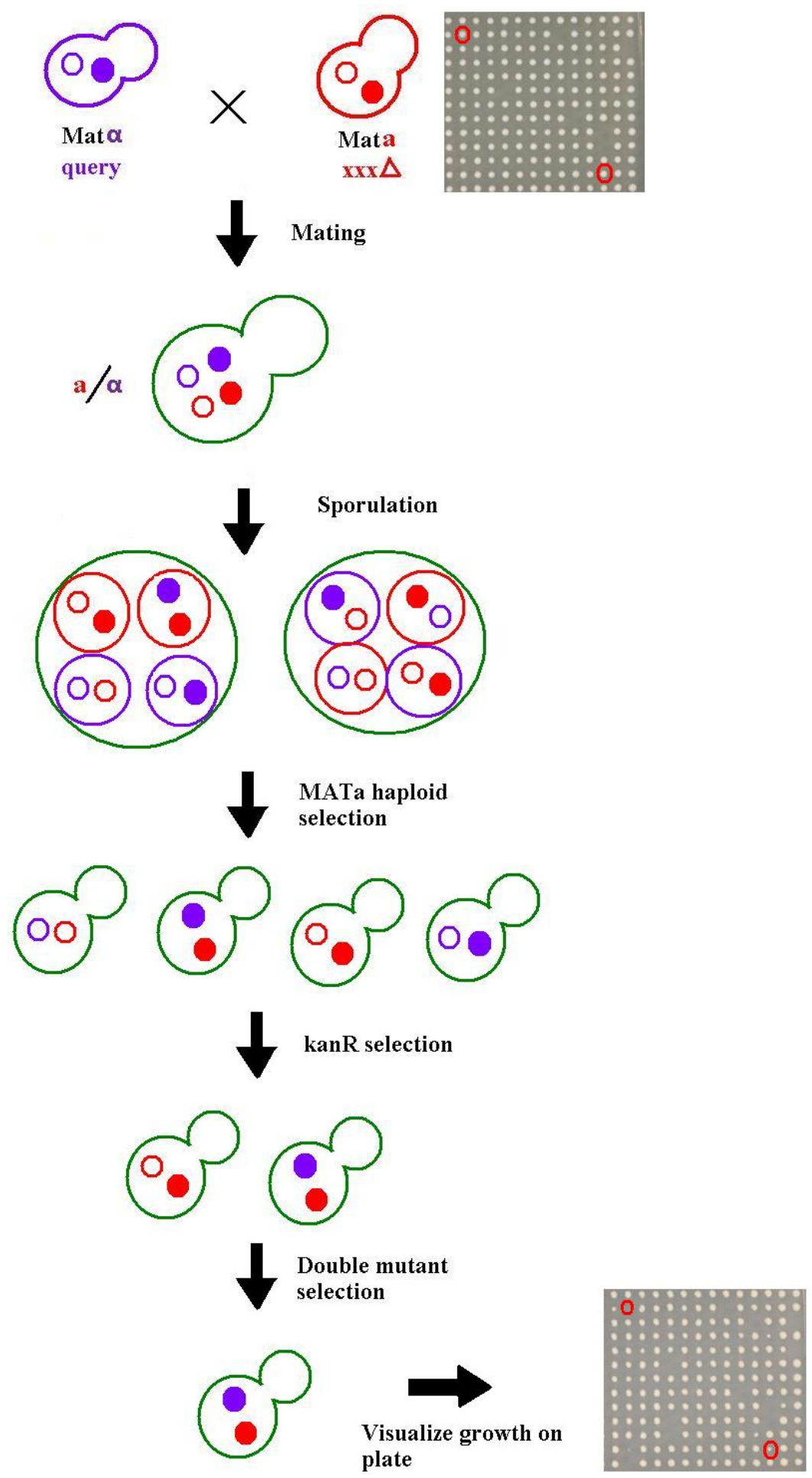

Figure 9: The methodology of synthetic genetic array analysis starting with the mating of the query strain in $M A T \alpha$ to a deletion in $M A T$ a followed by mating. The $M A T \mathrm{a} / \alpha$ diploids are induced for sporulation and the MATa progeny containing nat $R$ are selected followed by a selection for kanR. Finally, progeny containing double mutants are selected and scored for fitness defects. (Boone et al., 2007). Figure adapted from Tong and Boone, 2006. 


\subsection{Random Spore Analysis}

Random spore analysis was performed as described by Tong and Boone, 2006. The spores of each potential synthetic sick double mutants were inoculated in separate $1 \mathrm{~mL}$ sterile water and mixed. $20 \mu \mathrm{L}$ was plated on SD-His/Arg/Lys + canavanine/thialysine plates, $40 \mu \mathrm{L}$ was plated on SD/MSG- His/Arg/Lys + canavanine/thialysine/G418 plates, $40 \mu \mathrm{L}$ was plated on SD/MSG âĂŞ His/Arg/Lys + canavanine/thialysine/clonNAT plates and $80 \mu \mathrm{L}$ was plated on SD/MSG âĂŞ His/Arg/Lys + canavanine/thialysine/G418/clonNAT plates. The plates were incubated for 1-2 days and the colony growth under the different conditions were compared and the double mutants were scored as synthetic sick or no interaction.

\subsection{Conditional Interaction Analysis}

A test for condition interactions was done using a translation inhibitory drug (cycloheximide). The double mutants from SGA were pinned to YEPD + cycloheximide 25 $\mathrm{ng} / \mathrm{mL}$ and $35 \mathrm{ng} / \mathrm{mL}$ plates and incubated for 2 days at $30^{\circ} \mathrm{C}$. The growth of double mutants were visually inspected for sensitivity compared to the double mutants from no drug condition and the translation deletion mutant array plates with and without drug.

\subsection{Synthetic Dosage Lethality Assay}

The overexpression strains contain a plasmid that has an inducible copy of an ORF tagged at the N-terminus with GST and expressed from GAL1/10 promoter that is inducible in galactose and repressed in glucose (Sopko et al., 2006). The query transformants in MAT $\alpha$ strain containing the respective overexpression plasmids were grown overnight in -URA medium. Each query strain was poured over a -URA plate 
and transferred to 3 more -URA plates by a 384 pin replicator and incubated for 1 day. The query strain was mated with the translation deletion mutant array on YEPD plates and incubated for 1 day. The $M A T$ a $/ \alpha$ zygotes were pinned onto $-\mathrm{URA}+\mathrm{G} 418$ $(200 \mu \mathrm{g} / \mathrm{L})$ plates for 2 days to select for $M A T \mathrm{a} / \alpha$ diploids. The resulting diploids were then transferred to Enriched Sporulation Medium (ESM) for 9 days at $22^{\circ} \mathrm{C}$ to induce sporulation. The spores were then transferred onto SD-His/Arg/Ura + canavanine $(50 \mu \mathrm{g} / \mathrm{L})$ plates and incubated for 2 days to select for MATa progeny. The resulting progeny was pinned onto SD-MSG âĂŞHis/Arg/Ura + G418/canavanine plates for 2 days to select for $M A T \mathrm{a} / \mathrm{kanR}$ progeny. Colony growth was scored by visual inspection as synthetic sick interaction or no interaction compared to the single deletion mutants.

\subsection{Phenotypic Suppression Analysis}

Plates from the synthetic dosage lethality screen were used to test for phenotypic suppression under cycloheximide $(25 \mathrm{ng} / \mathrm{mL}$ and $35 \mathrm{ng} / \mathrm{mL})$ drug condition. The sensitivity of the yeast strains with the overexpression plasmids under cycloheximide was assessed by visual inspection. The colony growth was scored as partial compensation or no compensation compared to the control. The potential strains with partial compensation were confirmed using a spot test with cycloheximide $(35 \mathrm{ng} / \mathrm{mL})$ and compared to single deletion strains and strains containing a random non-overexpression plasmid (pUKC819). 


\section{Chapter 3}

\section{Results}

\subsection{Selections of Target Genes for Follow-up Analy- sis}

Previously in our laboratory, a list of approximately 80 translation related genes was assembled using a large-scale $\beta$-galactosidase colony lift assay that utilized plasmids containing premature stop codons in the $L a c Z$ gene (Appendix 5). In this way, gene deletion mutants that altered translation fidelity (decreased accuracy) resulted in an increase in $\beta$-galactosidase production by bypassing premature stop codons. This list contains both known (previously reported) and novel translation related genes. Four genes were selected from this list and were subjected to further analysis for their involvement in translation. Three of these genes, YNL122C, YNL040W and YGR117C are uncharacterized and $Y J R 014 \mathrm{~W}$ codes for a protein of unknown function that has been linked to translation due to its association with ribosomes (Fleischer et al., 2006). YLR192C is a well characterized component of translation initiation factor 3 (eIF3) (Nielsen et al., 2006) and was applied as a positive control. Our selected group of genes contains both known (used as a control) and potentially novel translation associated genes. 


\subsection{Translation Fidelity of Target Genes}

The accuracy of translation must be controlled at all stages of the process to ensure production of functional proteins. Errors in start codon selection during initiation, mis-incorporation of amino acids during elongation or inability of the ribosome to detect a stop codon during termination can alter the integrity of the protein (Alamgir et al., 2008). Our previous large-scale analysis suggested that our target genes affected the fidelity of translation measured by stop codon readthrough. To confirm these observations, we subjected our target genes to a quantitative small scale analysis using the same constructs. For this, strains containing deletions of target genes were transformed with plasmids containing premature stop codon within LacZ expression cassette. $\beta$-galactosidase produced by these strains were measured using a quantitative $\beta$-galactosidase assay and normalized to the control strain. This liquid-based assay utilizes the ability of $\beta$-galactosidase to use O-nitrophenyl-alphaD-galactopyranoside (ONPG) as a substrate to produce galactose and O-nitrophenol (ONP) that yields a yellow colour (Alamgir et al., 2008; Dagbagli and Goksungur, 2008).

As expected, $\beta$-galactosidase activity was significantly higher than the control strain in all deletion strains including the positive control $Y L R 192 C \Delta$, signifying an increase in the stop codon readthrough in mutant strains (Figure 10). These observations confirm the validity of our initial large-scale screen for correctly identifying gene deletions that affect stop codon readthrough. The degree of different stop codon readthrough varied for different mutant strains. For example, YJR014WA had lower readthrough for stop codon UAG (pUKC818) compared to the other stop codons indicating that the translation machinery recognized UAG stop codon more frequently than UAA (pUKC817) and UGA (pUKC819) in the absence of this gene. 
This might be a surprising observation as UAA is generally accepted as a more stringent stop codon (Atkins and Gesteland, 1983). The result for YLR192CA also contradicted this notion for it had a remarkably high readthrough for UAA. Deletions of $Y N L 122 C, Y N L 040 W$ and $Y G R 117 C$ had the highest level of readthrough for premature stop codon UAG (Figure 10). Deletion of YLR192C which is a well characterized component of eIF3 had the highest overall level of readthrough for all the premature stop codons.

The high levels of premature stop codon readthrough could be a result of increased mRNA contents. To test this theory, qRT-PCR was performed on the mRNA contents of the deletion strains with pUKCs plasmids (Figure 11). The mRNA contents of the deletion strains were not significantly different from the control strain, indicating the observed increase in premature stop codon readthrough was at the translation level. 


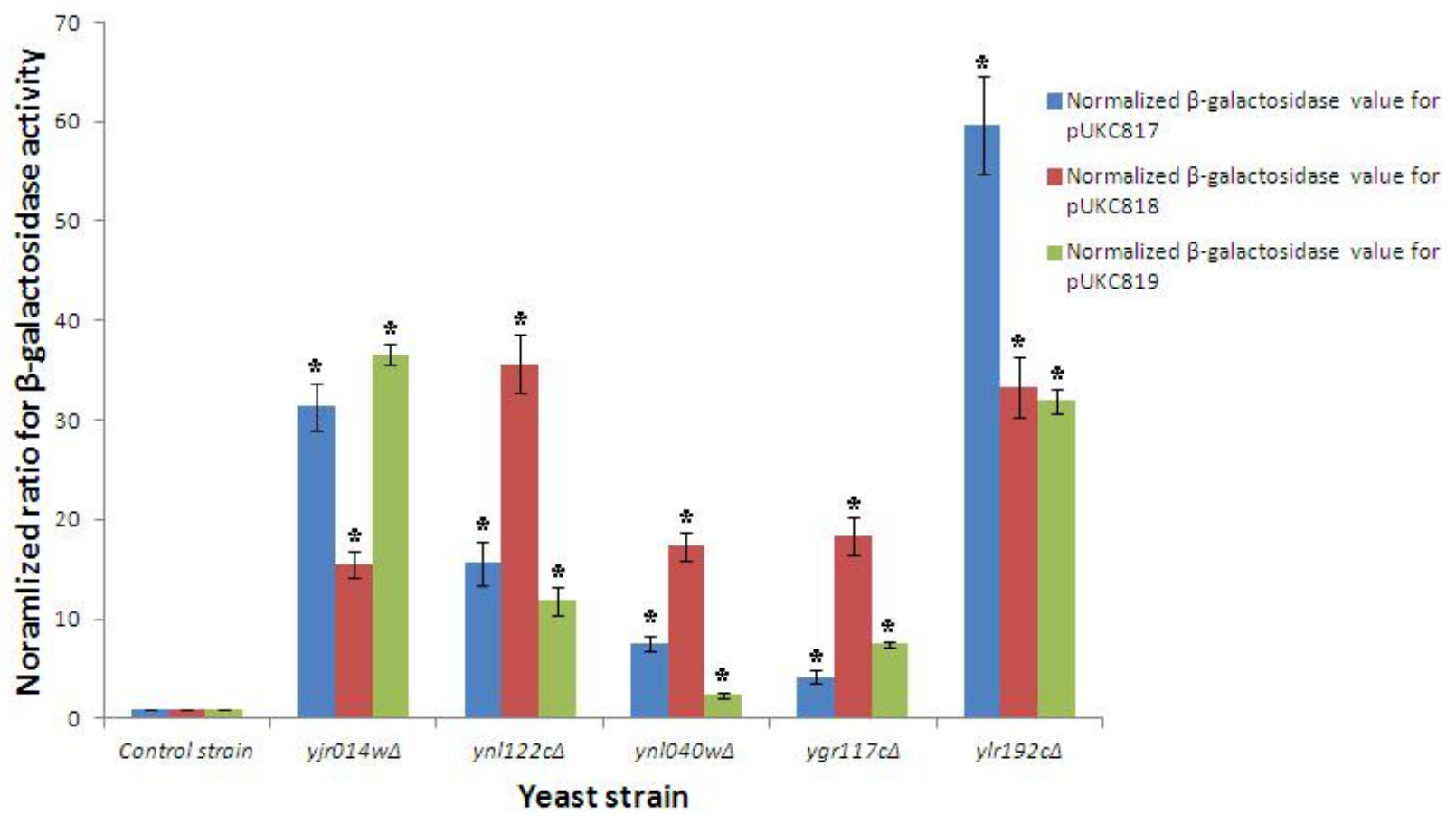

Figure 10: $\beta$-galactosidase activity for carrying pUKC817, pUKC818 and pUKC819 constructs containing premature stop codons UAA, UAG and UGA, respectively, were normalized to that of control plasmid pUKC815. They were then normalized again to the control strain which was set at 1.00. Our positive control was $Y L R 192 C \Delta$. All strains had increased $\beta$-galactosidase activity compared to control strain indicating a potential functional association with translation for the deleted genes. Each experiment was repeated at least three times. Two-tailed t-test. *(P-value $\mathrm{r} 0.05)$ 


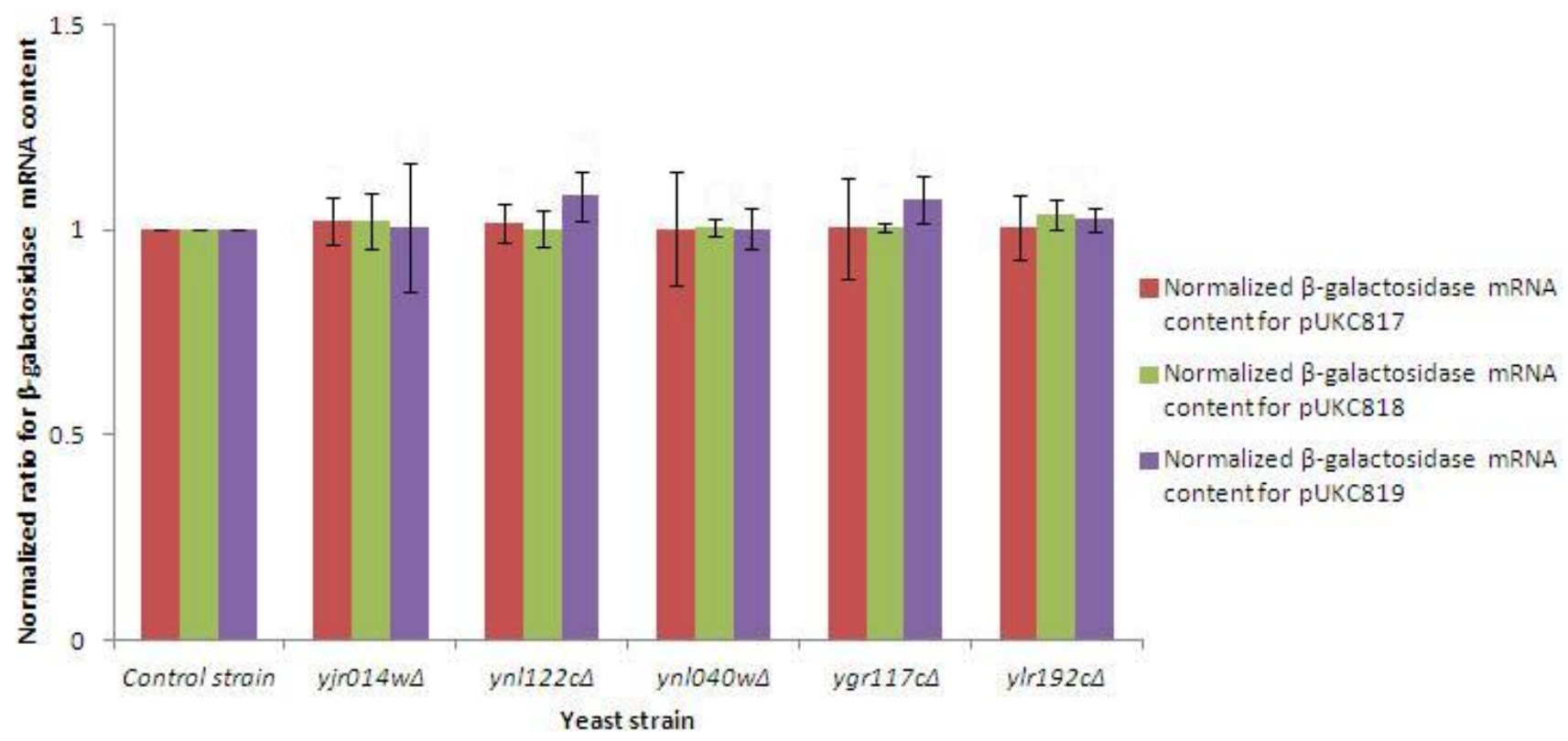

Figure 11: Quantitative Reverse Transcriptase-PCR (qRT-PCR) analysis of $\beta$ galactosidase mRNA in strains containing the pUKC plasmids. Values were obtained by calculating $2^{-\Delta \Delta C t}$ which is an approximation of the quantitative mRNA level. The values were obtained as fold changes normalized to that of $P G K 1$ and then to the control strain. There was no statistically significant difference between the content of the mRNAs for the query strains and control strain. The observed increase and decrease in bypass of premature stop codon was at the translation level. Each strain was repeated three times. Two-tailed t-test, $\mathrm{p}<0.05$. 


\subsection{Translation Efficiency of Selected Genes}

Genes that affect translation fidelity may also influence the efficiency rate of translation. To further confirm the involvement of the target genes in the translation pathway, we examined the effect of their gene deletions on the rate of protein synthesis. This was tested using a modified $\beta$-galactosidase assay with an inducible GAL1 promoter based-plasmid (p416). In this way, the rate of induced protein synthesis can be measured in a quantitative fashion when the target genes are intact or deleted. The strains were grown in -URA (typically containing glucose) overnight, followed by a four hour induction period with -URA + galactose to induce GAL1 promoter and hence protein synthesis. One would expect that compromised translation machinery would ordinarily show a reduced rate of translation. Surprisingly, the deletion of our control gene, YLR192C resulted in an increase rate of translation (Figure 12). A possible explanation for this is that YLR192C may also function as

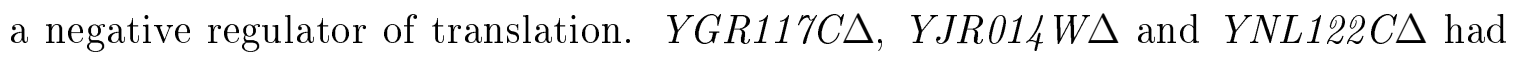
reduced protein synthesis. Deletion of $Y J R 014 W$ or $Y G R 117 C$ each resulted in reduced protein synthesis by approximately eight fold.

Varied protein synthesis could be due to the altered levels of mRNA in the cells and not necessarily be caused by the translation machinery. This was explored further by performing quantitative Reverse Transcriptase Polymerase Chain Reaction (qRT$\mathrm{PCR}$ ) on $\beta$-galactosidase mRNA content of deletion strains containing the GAL1 inducible plasmid. The Ct values obtained from the threshold cycles were used to calculate relative mRNA levels for each gene. Results revealed there were no statistical difference in $\beta$-galactosidase mRNA contents in all p416 transformed deletion strains compared to control (Figure 12). This validated that the increased protein synthesis observed for YLR192CA and YNL040W was due to the protein synthesis stage and 
not from mRNA content level. Although YNL122CA, YJR014WA and YGR117CA each had lower translation efficiency than the control, the mRNA contents for these three strains were similar to the control strain, indicating that the efficiency observed was due to the gene deletions and not a result of the mRNA contents (Figure 13). 


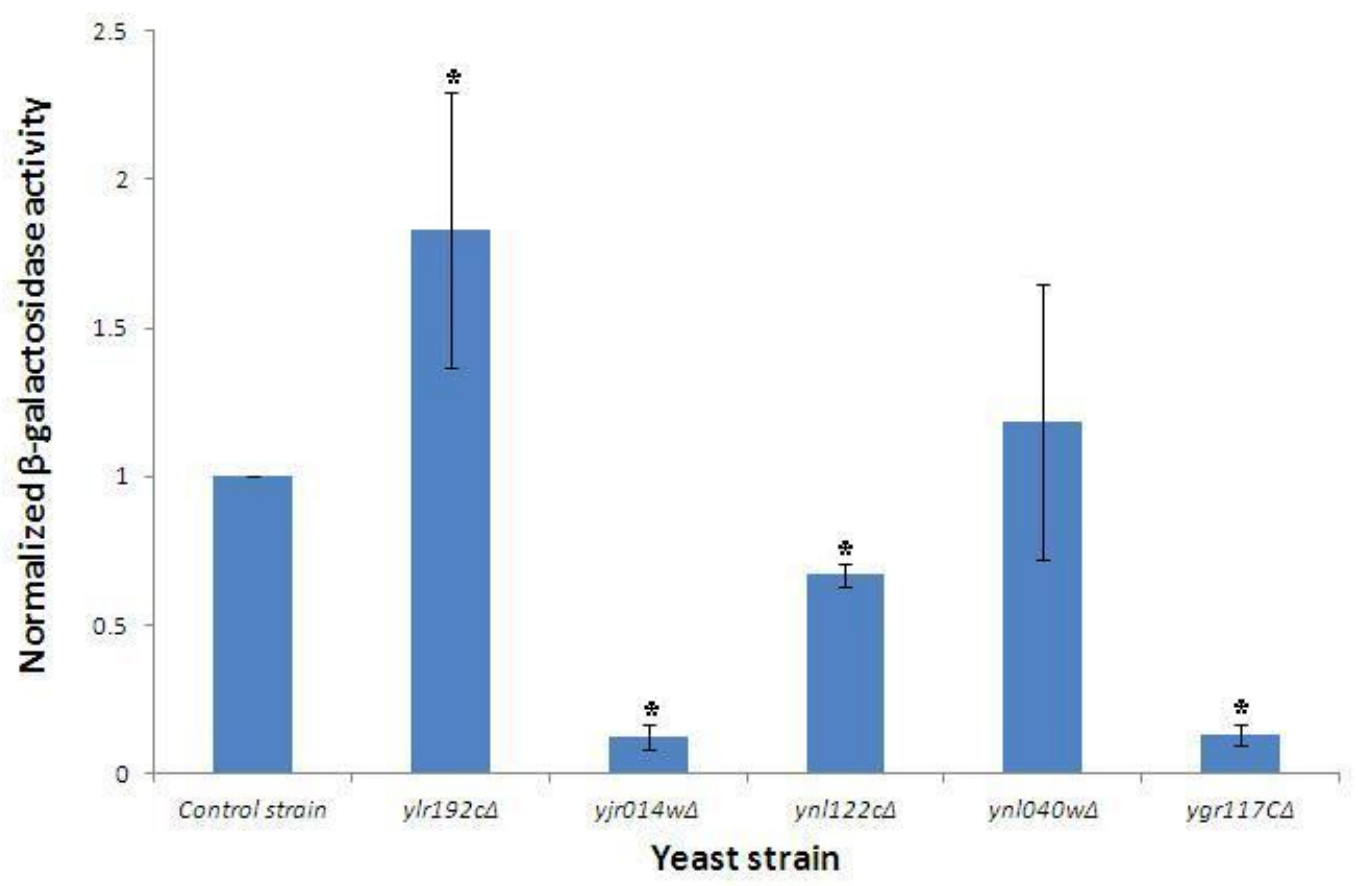

Figure 12: $\beta$-galactosidase assay using an inducible plasmid p416 containing $G A L 1$ promoter in front of a $L a c Z$ reporter gene. Strains were grown overnight in URA with glucose followed by a four hour induction period in -URA + galactose to induce $L a c Z$ expression producing $\beta$-galactosidase. The assay was repeated at least three times for each strain. Relative average activity greater than control strain indicates higher translation efficiency. YLR192C was used as a positive control. YGR117CA and YJR014WD both had translation efficiency significantly different from the control strain with each deletion experiencing an approximate eight fold reduction in protein synthesis. *(P-value $\mathrm{r} 0.05)$. 


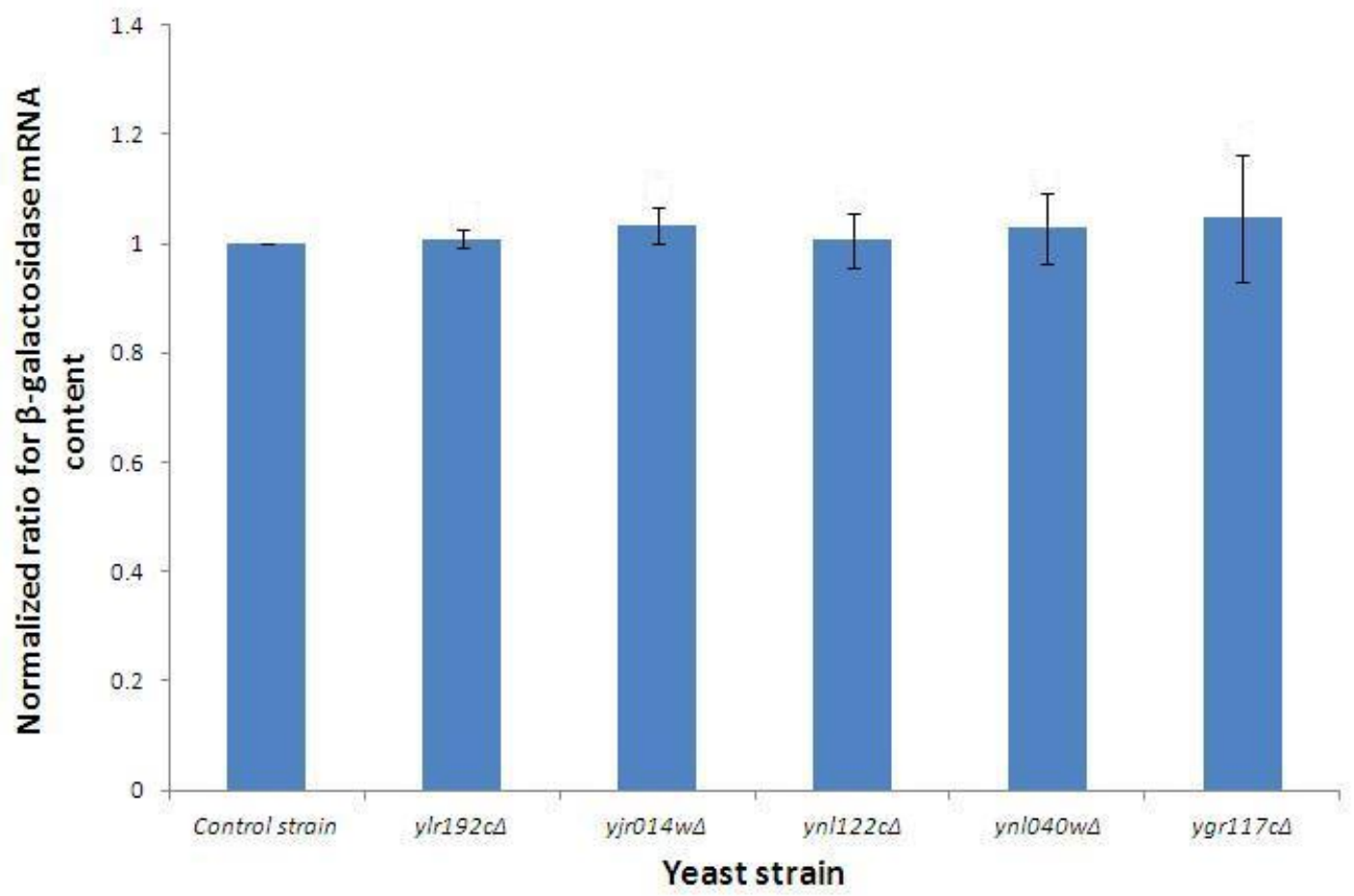

Figure 13: qRT-PCR analysis of $\beta$-galactosidase mRNA in strains containing the inducible plasmid (p416). Values were obtained by calculating $2^{-\Delta \Delta C t}$ which is an approximation of the quantitative mRNA level. The values were obtained as fold changes relative to (PGK1) and related again to the control strain. There was no statistically significant difference between the content of the mRNAs for the query strains and control strain $(Y L R 192 C \Delta)$ to that of control strain. Two-tailed t-test, $\mathrm{p}<0.05$. 


\subsection{Drug Sensitivity Analysis Using Translation In- hibitory Drugs}

Deletions of genes involved in protein synthesis may exhibit altered sensitivity to drugs that target the same pathway. This is on the basis of "double hit" notion where deletion of a target gene can affect a pathway with no phenotypic consequence. However, in the presence of a drug that affects the same pathway, the target gene deletion can now possess a measureable phenotype which is often growth reduction or hypersensitivity (Parsons et al., 2004). Thus, to further investigate the involvement of our target genes in translation, a drug sensitivity test was applied to examine the effect of the deletion of these genes in sensitivity to translation inhibitory drugs, cycloheximide and paromomycin. Cycloheximide is known to interact with the 60S ribosome and prevents the activity of elongation factor 2 (eEF2) during translocation (Schneider-Poetsch et al., 2010). Paromomycin is another anti-translation drug that binds to $18 \mathrm{~S}$ rRNA and causes miscoding. It prevents translocation and ribosome recycling which ultimately compromises translation fidelity (Hirokawa and Kaji, 2007). Streptomycin inhibits protein synthesis by preventing translation initiation (Alamgir et al., 2010). Among the tested strains, two deletion mutants (YNL040W and YJR014WA) had increased sensitivities to cycloheximide (Figure 14). Curiously, only $Y L R 192 C \Delta$, the control strain was sensitive to paromomycin (Figure 15) and none of the deletion strains was sensitive to streptomycin (Appendix 6). The negative results for the remaining drug sensitivity analysis is provided in Appendix 7 and 8 . All the genes being tested are non-essential genes that are not required for growth in typical laboratory conditions. Consequently, one way to interpret these observations is that the targeted genes become important for cell survival under conditions where translation is compromised. 
A)

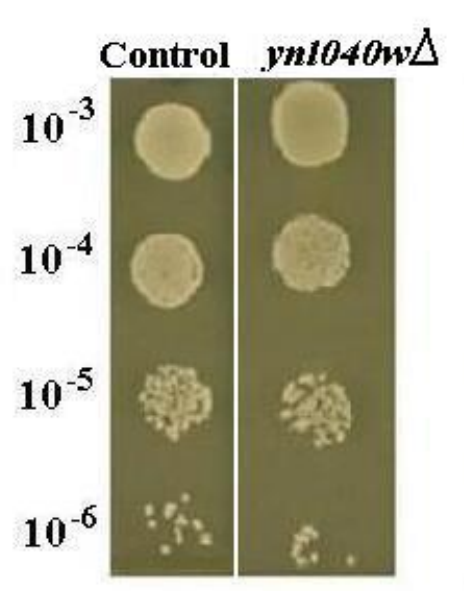

B)

No Drug

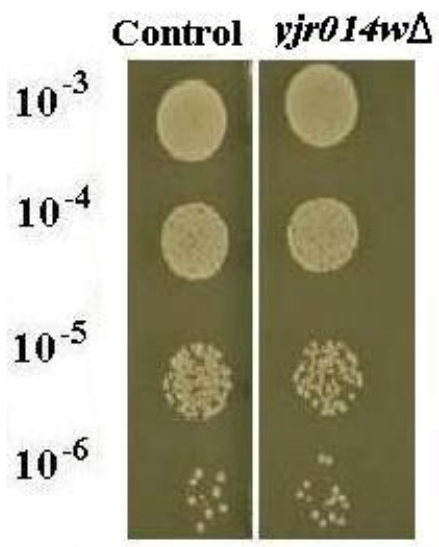

Cycloheximide $45 \mathrm{ng} / \mathrm{mL}$

Cycloheximide $50 \mathrm{ng} / \mathbf{m L}$

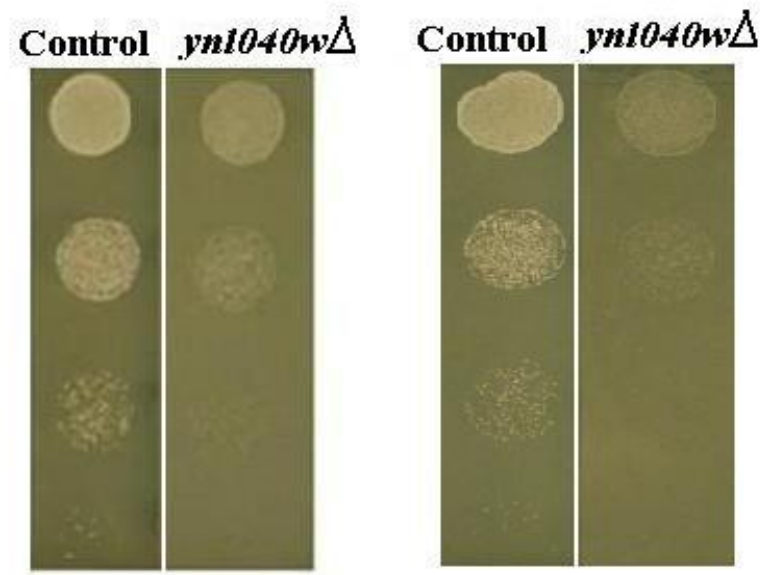

Cycloheximide $50 \mathrm{ng} / \mathbf{m L}$

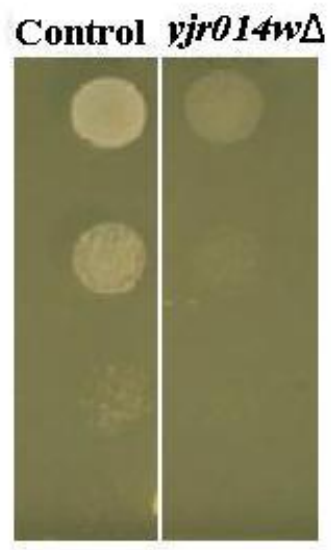

Figure 14: $20 \mu \mathrm{L}$ of each serial dilution of $10^{-3}$ to $10^{-6}$ was spotted in media with or without drug and grown for 2 days at $30^{\circ} \mathrm{C}$. This was repeated with different drug concentrations. (A) Deletion strain for $Y N L 040 W$ was sensitive to cycloheximide at the lowest concentration $45 \mathrm{ng} / \mathrm{mL}$ and (B) YJR014W deletion strain also showed sensitivity to cycloheximide $45 \mathrm{ng} / \mathrm{mL}$. The experiment was repeated at least three times. 


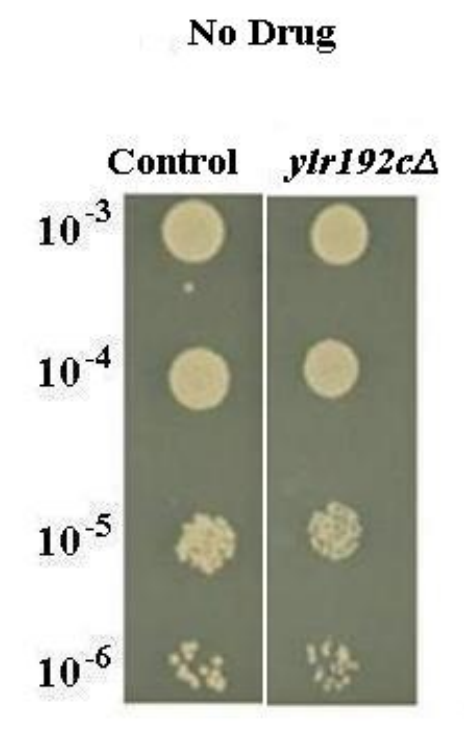

Paromomycin 13 $\mathbf{m g} / \mathbf{m L}$

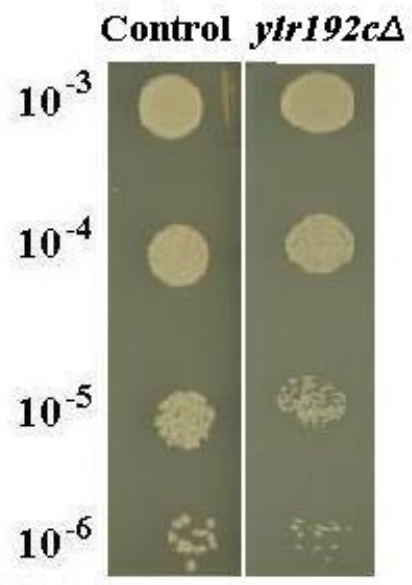

\section{Paromomycm $18 \mathbf{~ m g} / \mathbf{m L}$}

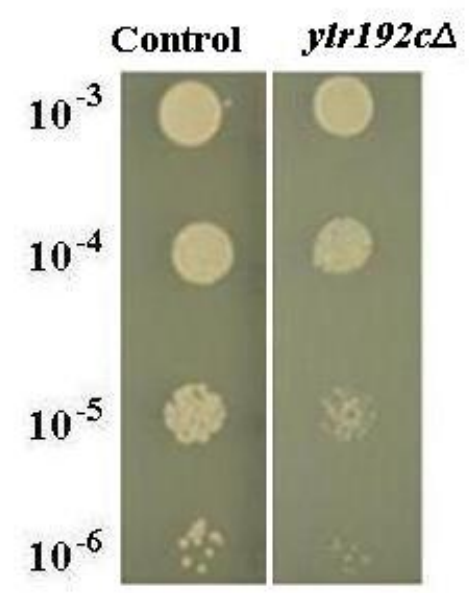

Figure 15: $20 \mu \mathrm{L}$ of each serial dilution of $10^{-3}$ to $10^{-6}$ was spotted in media with or without drug and grown for 2 days at $30^{\circ} \mathrm{C}$. This was repeated with different drug concentrations. Deletion of $Y L R 192 C$ increased sensitivity to the translation inhibitory drug, paromomycin at $13 \mathrm{mg} / \mathrm{mL}$ and $18 \mathrm{mg} / \mathrm{mL}$. The experiment was repeated at least three times. 


\subsection{Synthetic Genetic Interactions of YNL040W with Translation Related Genes}

Genes that are functionally related often genetically interact with each other. Therefore, the activity of a novel gene can be inferred based on the genetic interactions it forms (Samanfar et al., 2014). Genetic interactions between two genes is often defined as follows. If deletion or overexpression of gene A causes phenotype X1, and deletion of gene B causes phenotype X2, then one may anticipate that deletion of both $\mathrm{A}$ and B will cause a phenotype that can somehow be anticipated from phenotypes X1 and $\mathrm{X} 2$. If deletion of $\mathrm{A}$ and $\mathrm{B}$ causes a completely unexpected phenotype, then it is often said that the two genes $\mathrm{A}$ and $\mathrm{B}$ have a genetic interaction. A possible functional relationship between the two genes is that they work in parallel or in overlapping pathways in a way that deletion of both genes could have an overwhelmingly negative effect (negative interaction). Alternatively, deletions of one gene may rescue the phenotype caused by deletions of the other by triggering a new condition within the cell (positive interaction). To further investigate the role of $Y N L 040 \mathrm{~W}$ in translation, we investigated the genetic interactions that this gene made with 384 genes that are known or thought to be involved in translation as well as one random plate containing 384 non translation related genes (negative control) using SGA methodology. To do this, a gene deletion mutant for $Y N L 040 \mathrm{~W}$ in "alpha" mating type was generated. Primers that contained 60 nucleotides complementary to either ends of $Y N L 040 \mathrm{~W}$ and 21 bases complement to both ends of nourseothricin resistance gene, nat $R$ were used to generate a PCR product using the plasmid pAG25 as a template. Next an "alpha" mating type strain was transformed with the PCR product and colonies that showed resistance to nourseothricin were selected. In this manner, the selected colonies, at least in theory, have their $Y N L 040 \mathrm{~W}$ genes replaced with a copy of natR gene. To confirm this replacement, colony PCR was performed using a set of primers 
one inside natR gene and one just outside of $Y N L 040 \mathrm{~W}$ genomic region. Indicated by, Figure 16, our colony PCR analysis confirmed the integration of natR into the correct genomic target site. 


\section{$\begin{array}{lllllll}1 & 2 & 3 & 4 & 5 & 6 & 7\end{array}$}

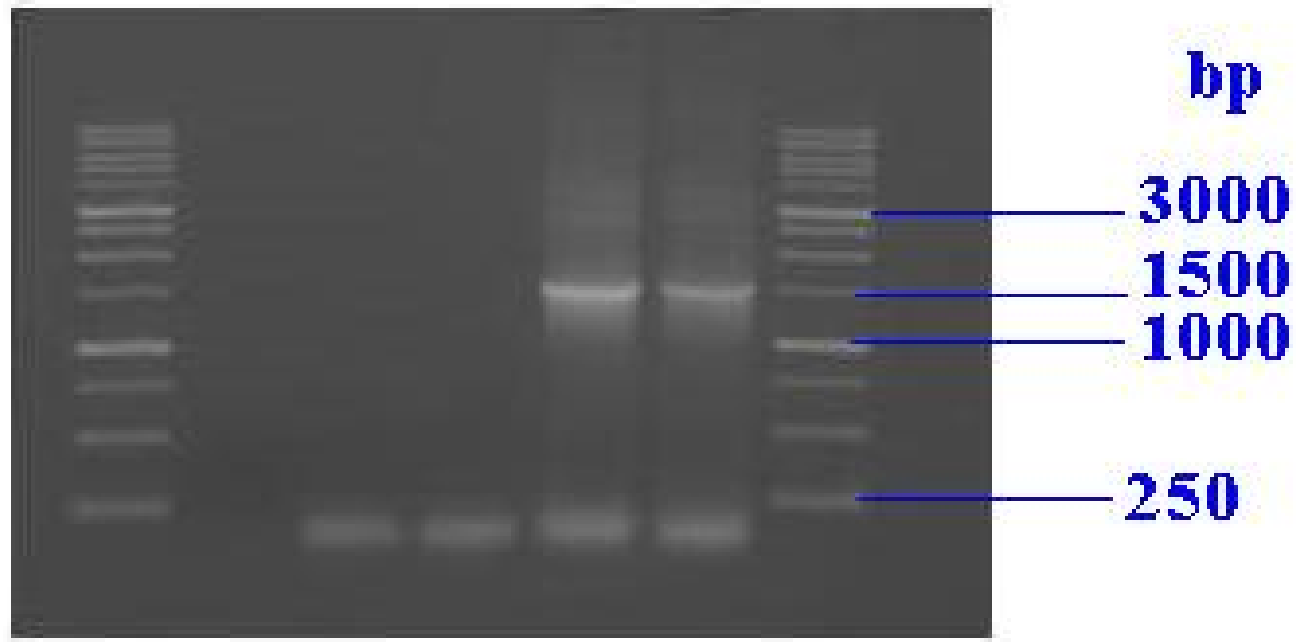

Figure 16: Colony PCR product analysis using gel electrophoresis. The natR gene product was visualized on $0.8 \%$ agarose gel by electrophoresis at $80 \mathrm{~V}$ for 60 minutes. Columns 1 and 7 were loaded with $1 \mathrm{~kb}$ ladder. Column 2 was the negative control containing only water and loading buffer. Column 3 was the PCR control for YJR014W and Column 4 was the PCR control for YNL040W. Column 5 contained colony PCR product for $Y J R 014 W$ and column 6 was the colony PCR product of $Y N L 040 \mathrm{~W}$. The size of the PCR product was estimated at approximately $1500 \mathrm{bp}$ which is in accord with the expected band. 
The alpha knockout strain for $Y N L 040 W(Y N L 040 W \Delta:: n a t R)$ was mated with the translation deletion mutant array ("a" mating type) and the random plate (control). The heterozygous MATa/ $\alpha$ diploids were selected and transferred onto ESM plates to induce sporulation. The spores were then pinned onto selective medium to select for haploid selection of MAT a meiotic progeny. The MAT "a" progeny went through another selection to obtain meiotic progeny that carried the gene deletion mutation $(x x x \Delta:: n a t R)$. After a few rounds of selections, the double mutants carrying gene deletions for $Y N L 040 \mathrm{~W}$ and one of the 384 other genes, (YNL040W $\Delta:: n a t R \operatorname{xxx} \Delta:: \operatorname{kanR}$ ) were selected and scored for fitness defect. The double mutants were scored for fitness on the basis of colony size. Synthetic sick colonies (those that are significantly smaller) were selected by visual inspection. Several colonies were found to have significantly less growth in comparison to their corresponding single mutant strains suggesting a genetic interaction with the query gene. Lethal interactions were not considered as they often carry experimental error while mating and transferring colonies. The interactions observed were confirmed by random spore analysis verifying four genes that $Y N L 040 \mathrm{~W}$ genetically interacted with, YER086W, YGR155W, YEL009C and YDL075W and produced synthetic sick phenotypes (Figure 17 and Appendix 9). We were unable to verify the remaining interactions by random spore analysis. They were omitted from follow up investigations. One gene, YDL075W, that interacted with $Y N L 040 \mathrm{~W}$ codes for a ribosomal protein belonging to $60 \mathrm{~S}$. The other three genetic interactions included genes involved in amino acid biosynthesis, YER086W, YGR155W and YEL009C. YGR $155 \mathrm{~W}$ is involved in cysteine biosynthesis and YER086W is associated with isoleucine production. Interestingly, YEL009C is involved in activating amino acid biosynthesis during amino acid starvation (Appendix 10). In agreement with our observations $Y D L 075 \mathrm{~W}$ has a previously reported genetic interaction with YEL009C, connecting its activity with amino acid biosynthesis (Steffen et al., 2008). These 
results provide additional evidence that $Y N L 040 \mathrm{~W}$ is involved in protein synthesis.

Although YNL040W interacted with four genes, it should be noted that the interactions were observed under standard laboratory conditions and only reflects a portion of the possible interactions this gene may form with translation related genes. It is established that a number of genes may not be required or are inactive in standard laboratory growth conditions, however, during perturbed conditions some of these genes are required for environmental adaptation and their deletions would cause sickness or even lethality when cells are challenged with a stress (Harrison et al., 2006). To test whether there are conditional genetic interactions for $Y N L 040 \mathrm{~W}$ with translation genes, the above double mutants were transferred onto plates containing a subinhibitory concentration of translation inhibitory drug, cycloheximide. As indicated in Figure 18, there were two double mutants that appeared sensitive in the presence of the drug, YGL151WA::YNL040W and YNL175CA::YNL040WA. YGL151W is a component of RNA polymerase II and $Y N L 175 C$ is a nucleolar protein of the preribosomal complexes (Appendix 11). Both these genes are involved in the protein synthesis pathway. 


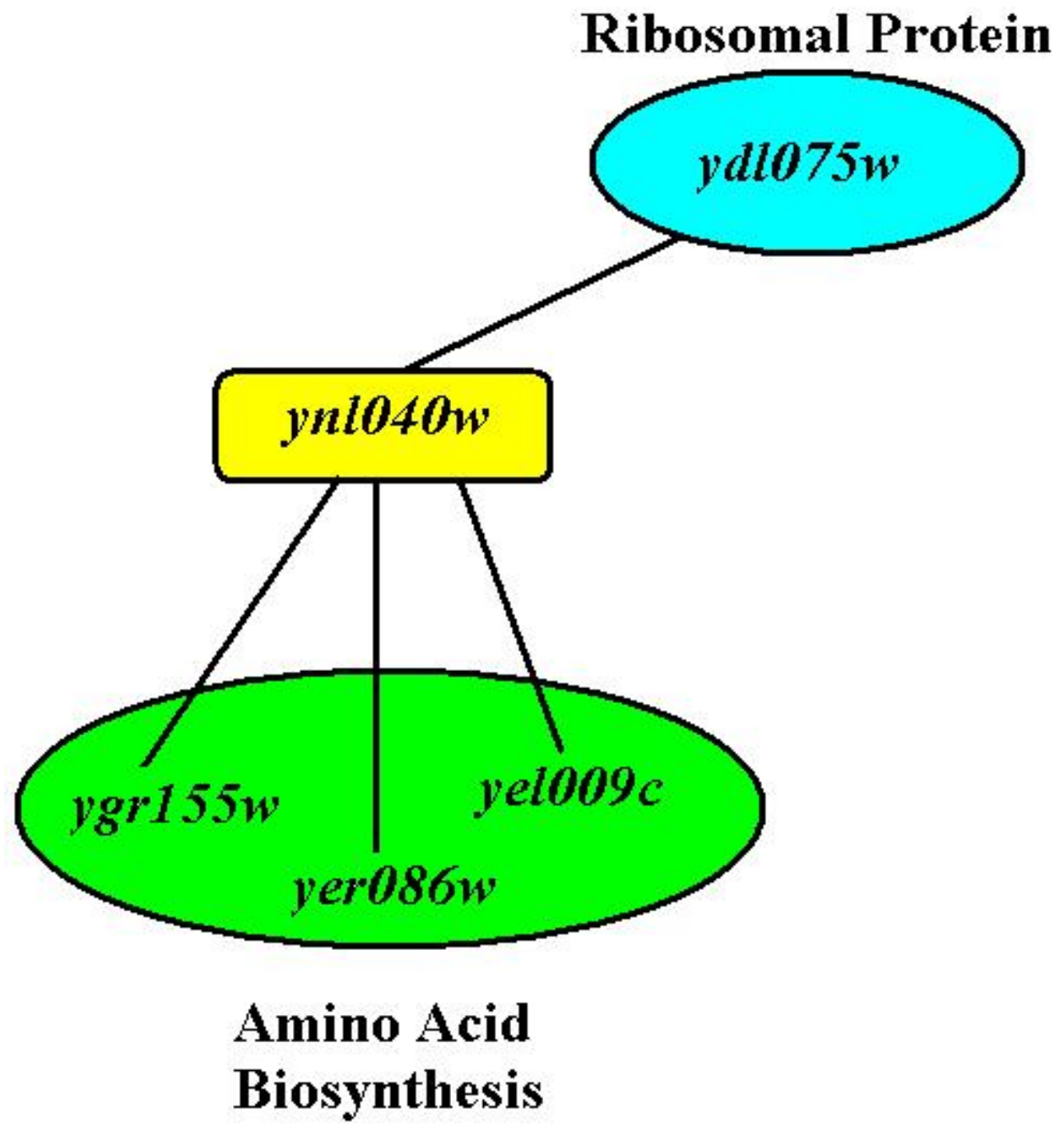

Figure 17: SGA analysis revealed four genetic interactions of $Y N L 040 \mathrm{~W}$ with translation related genes. YNL040W had one interaction with a ribosomal gene and three interactions with amino acid biosynthesis genes. 

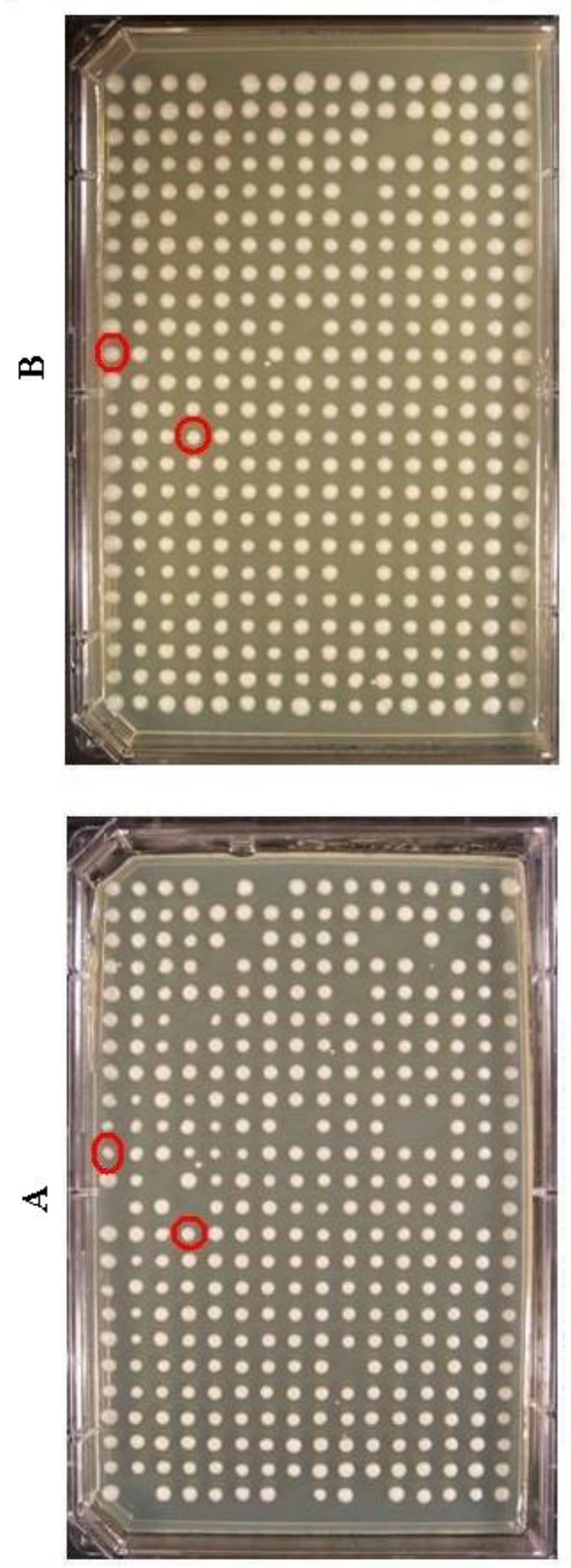
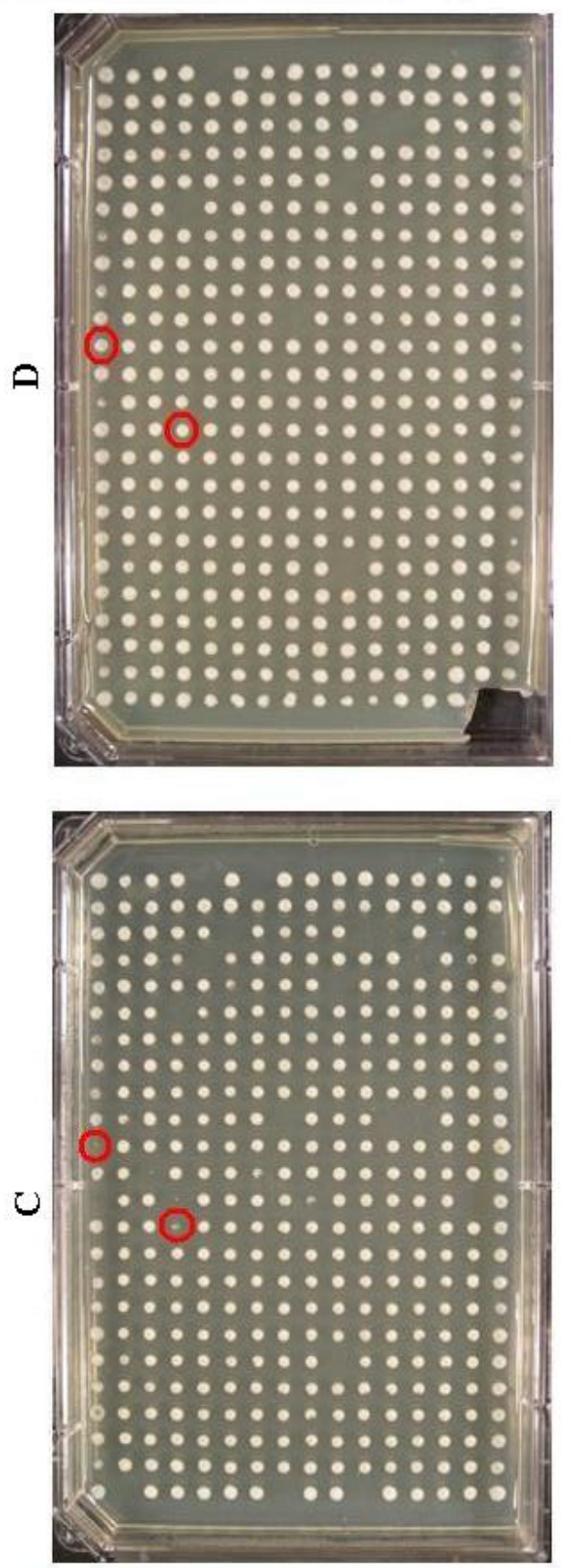

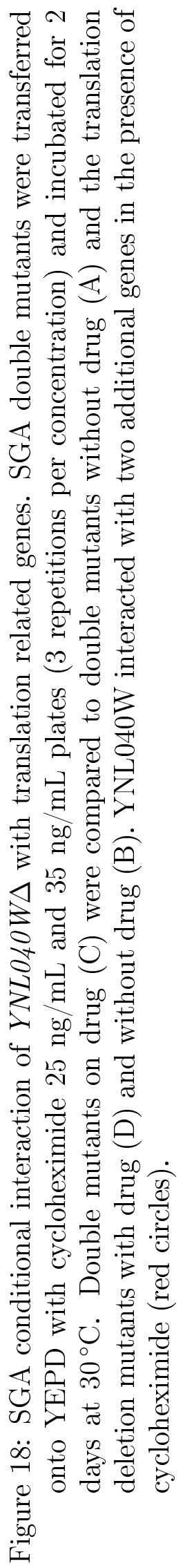




\subsection{Synthetic Dosage Lethality (SDL) Analysis for YNL040W and YJR014W Genes}

SGA tends to identify genetic interactions of genes with similar or compensating functions in parallel pathways. Many genes with no observable interactions are overlooked when they can have apparent genetic effect under altered gene dosage which can indicate genetic interactions with genes involved in the same pathway (Sopko et al., 2006). Synthetic dosage lethality (SDL) is a method used to study gene dosage lethality (or sickness) in cells and is based on the idea that increased level of a protein may have no effect on a wildtype strain, but may cause a phenotype in a mutant strain with reduced activity, and in our case, null activity of the interacting protein (Sopko et al., 2006). These interactions often refer to an involvement of both target genes in the same functional pathway (Alamgir et al., 2008). In this way, we reasoned that YNL040W and YJR014W overexpressions may identify interactions with additional genes. Therefore, these interactions can provide further information about the activity of target genes. Dosage lethality for the target genes was investigated by crossing each transformant of alpha mating type containing the respective overexpression plasmid for the target gene with the translation deletion mutant array and a random plate (used as a control). Through a few rounds of selection, the progeny containing an overexpression plasmid and a gene deletion were selected as above. Visual inspection for growth defect yielded 11 gene deletions that were affected by $Y N L 040 \mathrm{~W}$ overexpression. Six of the genetic interactions are with genes encoding ribosomal proteins, YMR230W, YLR448W, YNR052C, YDL075W, YOR096W and YEL050W. YNL040W had one interaction with an amino acid biosynthesis gene, YAL012W, and one interaction with a translation gene YKL204W. It also had three interactions with genes in other pathways, YNL136W, YPL069C and $Y O L 004 W$ (Appendix 12). 
The overexpression of YJR014W affected 16 gene deletions. Many of the genes that interacted with the overexpression of $Y J R 014 \mathrm{~W}$ were found to code for ribosomal proteins, YNR052C, YGL136W, YFR001W, YEL050C, YLL045C, YOR293C, YOR312C, YHR021C, YGR285C and YGR159C. YJR014W had two interactions with amino acid biosynthesis genes, YGR155W and YER086W, and four interactions with genes in other pathways, YPL069C, YJR118C, YOL004W and YNL136W (Appendix 13).

\subsection{Phentypic Suppression Analysis (PSA) of YNL040W and YJR014W Genes}

Contrary to SDL results, where an overexpression of a gene product becomes lethal to a cell in the absence of a second interacting gene product, phenotypic suppression analysis (PSA) refers to phenotypic suppression by the overexpression of a gene (gene A) in a gene deletion (gene B) that is sensitive to a treatment (Alamgir et al., 2010). In other words, a gene deletion may have no phenotypic consequence on the cell when grown under standard lab conditions. However, the mutant strain might be sensitive to treatment with an inhibitory compound that targets the same pathway that the target gene is involved in. In this case, overexpression of an interacting gene may compensate the sensitivity of the original gene deletion to the inhibitory drug. Such compensation often indicates a functional overlap (Alamgir et al., 2010). PSA analysis was done by transferring mutants from SDL containing the overexpression plasmid of the target gene and a second deletion onto plates with sub-inhibitory concentration of cycloheximide $(35 \mathrm{ng} / \mathrm{mL}$ ) antibiotic for effects of deletion compensation by the overexpression of the target genes. This was compared to the sensitivity of single 
mutants to the drug. From the screen, six deletion strains were rescued by the overexpression of $Y J R 014 \mathrm{~W}$ and five deletion strains were rescued by the overexpression of YNL040W (Figures 19 and 20). 

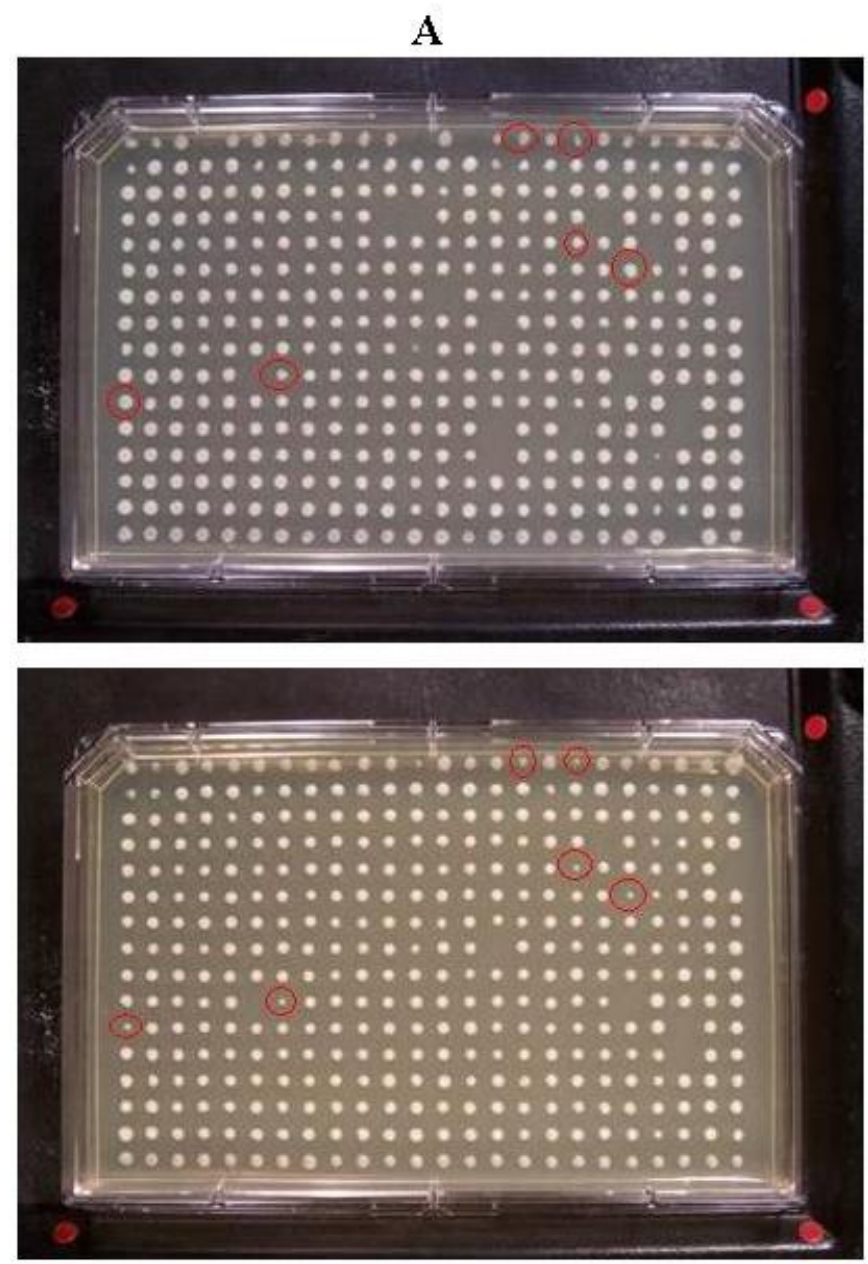

B

Figure 19: The query overexpression strain $Y J R 014 W$ in $M A T \alpha$ was mated with the translation deletion mutant array on YEPD. Diploids $(M A T$ a/ $\alpha)$ were selected on $-\mathrm{URA}+\mathrm{G} 418$. The diploids were then pinned onto ESM to induce sporulation followed by a couple rounds of selections $M A T \mathrm{Ta} /$ kanR progeny. The resulting progeny was then plated onto three plates with medium containing $35 \mathrm{ng} / \mathrm{mL}$ cycloheximide to observe compensations by overexpression of the query gene. (A). Single deletions of the translation mutant array on $35 \mathrm{ng} / \mathrm{mL}$ cycloheximide (B) showed six candidates that appeared to have sick phenotype. When YJR014W was overexpressed in those mutants, the growth defect was recovered (red circles). 
A
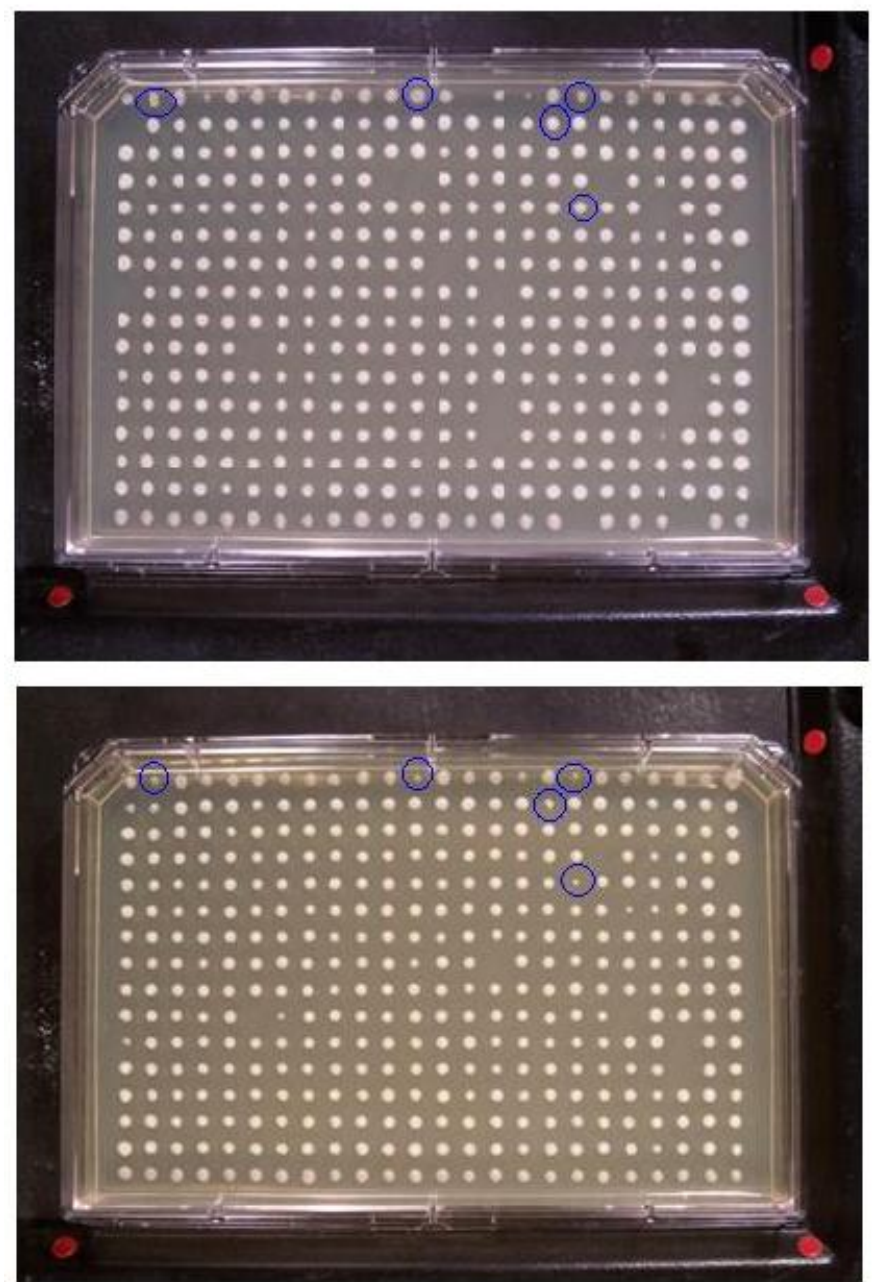

B

Figure 20: The query overexpression strain $Y N L 040 W$ in $M A T \alpha$ was mated with the translation deletion mutant array on YEPD. Diploids $(M A T \mathrm{a} / \alpha)$ were selected on $-\mathrm{URA}+\mathrm{G} 418$. The diploids were then pinned onto ESM to induce sporulation. Through a couple rounds of selections $M A T \mathrm{a} / \mathrm{kanR}$ progeny were selected. The resulting progeny was then plated onto three plates with medium containing $35 \mathrm{ng} / \mathrm{mL}$ cycloheximide to observe for compensations by overexpression of the query gene (A). Single deletions of the translation mutant array on cycloheximide provided five candidates that appeared to have sick phenotype (B). When $Y N L 040 \mathrm{~W}$ was overexpressed in those mutants, the growth defect was recovered (blue circles). 
To confirm the results obtained by the high throughput PSA analysis, a small scale spot test assay was utilized. Spot test analysis, being more focused in nature, has a lower rate of false positives. Using a spot test analysis, a compensation was considered real when drug sensitivity of a single gene deletion strain was similar to that carrying a random plasmid, but was compensated if the plasmid carried a compensating gene. In this manner, the overexpressed compensating gene, reversed the sensitivity of the initial gene deletion to a target drug.

Illustrated in Figure 21, the following strains YGR285CA, YNR052CA, YLR068WA, YOL004WA, YKL204WA and YJR145CA showed sensitivity to cycloheximide. Their sensitivities, however, were compensated in the presence of the plasmid that overexpressed YJR014W gene. YJR145C,YLR068W, YGR285C and YNR052C code for ribosomal proteins and one is a translation gene, YKL204W. YJR145CA with YJR014W overexpression also compensated for one gene involved in chromatin remodeling, YOL004W (Appendix 14).

Similarly, it was observed that $Y N L 040 \mathrm{~W}$ overexpression reversed the growth defect (in the presence of cycloheximide) of single gene deletion strains, YAL013W

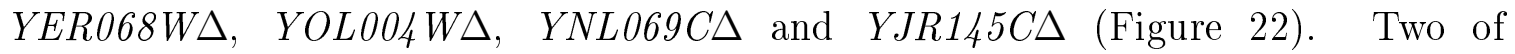
these genes, YJR145C and YNL069C, encode ribosomal proteins. YAL013W and YER068 W are transcription genes and $Y O L 004 \mathrm{~W}$ is involved in an independent pathway (Appendix 15). 


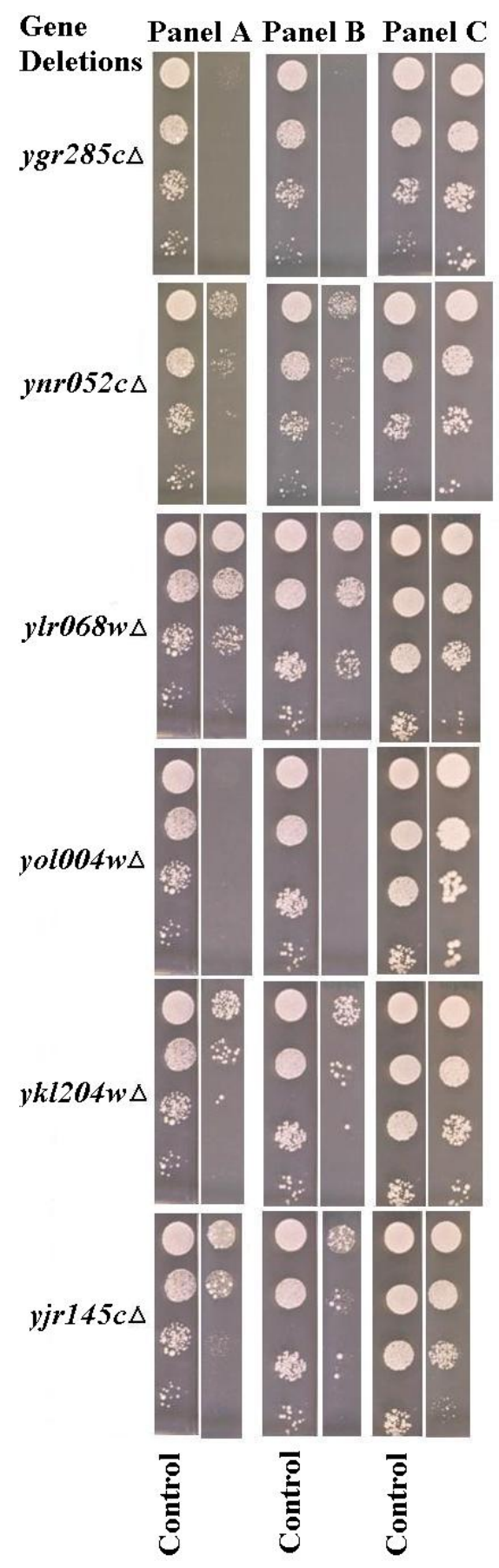

Figure 21: To confirm that the overexpression of YJR014W compensated for gene deletions, suspected deletion mutants with and without YJR014W overexpression were analysed using spot test analysis in the presence of cycloheximide. This was performed two times for the same strain. Panel A. Single deletion strains, Panel B. Strains transformed with random plasmid (pUKC) Panel C. YJR014W overexpression on cycloheximide $35 \mathrm{ng} / \mathrm{mL}$. All represented deletion strains were compensated by the overexpression of YJR014W as indicated by increased growth in the presence of cycloheximide in Panel $\mathrm{C}$. 


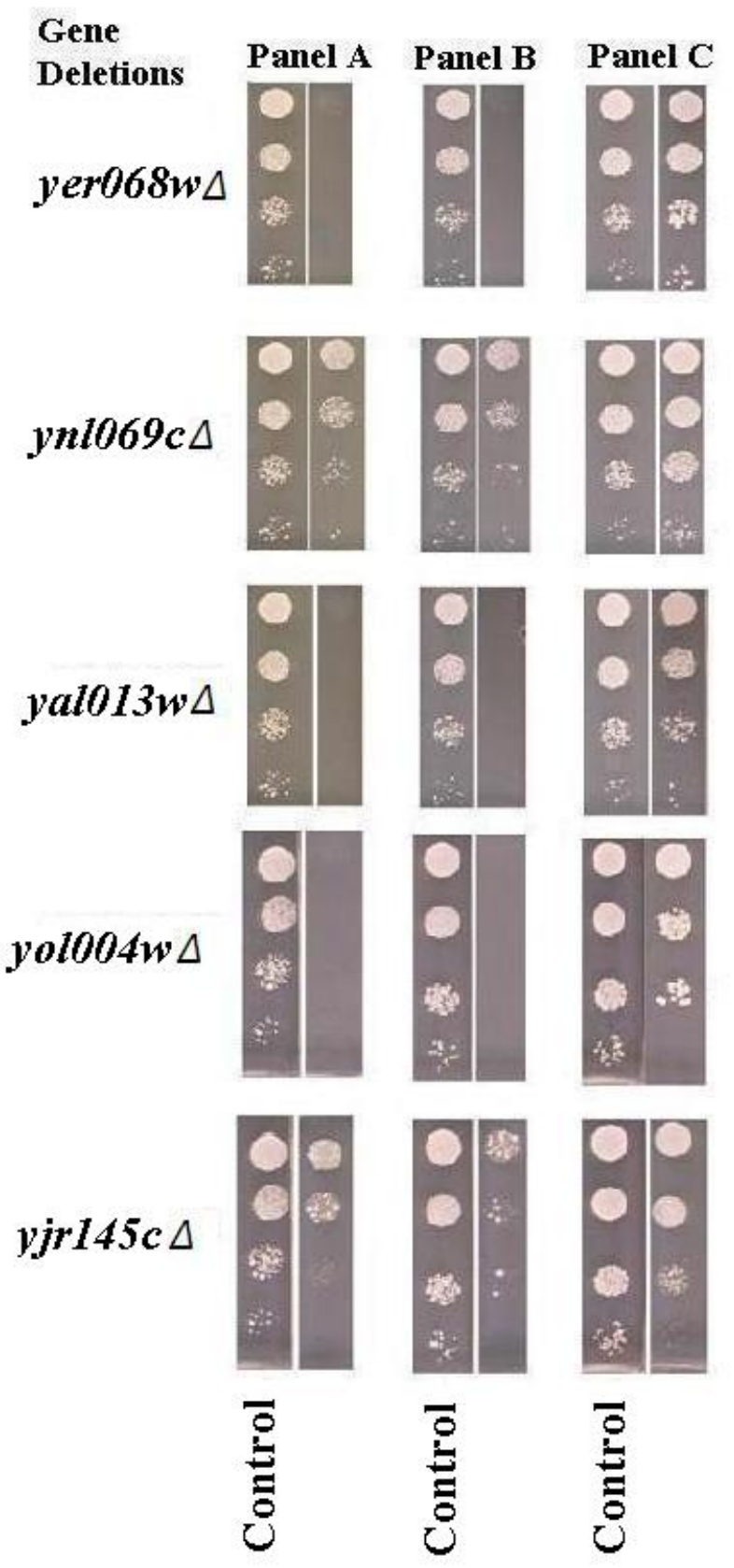

Figure 22: To confirm that the overexpression of YNL040W compensated for gene deletions, suspected deletion mutants with and without YNL040W overexpression were tested in the presence of cycloheximide via the spot test analysis. Confirmation was performed twice for the same strain. Panel A. Single deletion strains, Panel B. Strains transformed with random plasmid (pUKC), Panel C. YNL040W overexpression on cycloheximide $35 \mathrm{ng} / \mathrm{mL}$. All deletion strains were compensated by the overexpression of $Y N L 040 \mathrm{~W}$ as indicated by increased growth in the presence of cycloheximide in Panel $\mathrm{C}$. 


\section{Chapter 4}

\section{Discussions}

A well regulated translation process contributes to a healthy biological system. However, the biological system is very complex and errors are unavoidable. These mistakes may eventually affect the operation of protein synthesis and cause some level of cellular disorder. Since translation is one of the most important steps in gene expression and its regulation, many diseases emanate when units within this process go awry. Translation requires many different elements to be successful, and incredibly, one third of genes are directly or indirectly dedicated to it (Mathews et al., 2000). To date, of the approximately 6000 genes in yeast, there are still over 1000 genes with no known functions, leaving a high probability that many more translation genes remain uncharacterized (Pena-Castillo and Hughes, 2007). In addition, it is very likely that many ill-characterized genes may also have a secondary function in association with protein synthesis. Yeast is a great model for genetic studies for its easily manipulable genome, thus it was used in this study to probe for more genes involved in the translation pathway. Due to sequence conservation between yeast and higher eukaryotes like human, and the fact that protein synthesis is a very conserved process during the course of evolution, our investigation using yeast as a model organism may have direct implication in our current understanding of the process of translation in other eukaryotes. 
To extend our search for novel translation genes in yeast, $\beta$-galactosidase activity was assessed using plasmids containing premature stop codons transformed into the deletion strains for our target genes thought to be involved in translation fidelity. The premature stop codon within the $L a c Z$ gene would prevent the full length polypeptide synthesis of $\beta$-galactosidase in a high fidelity case. Deletion of a gene that affects the recognition of a premature stop codon would allow the bypass of the stop codon and result in $\beta$-galactosidase synthesis. As predicted, these gene deletions had increased $\beta$-galactosidase expression in the presence of premature stop codons and were deduced to be involved in translation. YLR192C is a component of eIF3 and codes for HCR1 protein (High Copy suppressor of RPG1) and is a homologue of the p35 subunit of the eIF3 complex in humans (Valasek et al., 1999). Thus, it was established as a positive control. As expected it was observed that translation fidelity was affected in the absence of this gene.

The gene product of YJR014W had been copurified with the 40S ribosomal protein using ribosome salt wash of different concentrations, followed by mass spectrometry yielded the interacting partners involved in transcription and translation (ASC1, TFA1 and YER007C-A) (Fleischer et al., 2006). This supported our results that $Y J R 014 W$ is a translation gene. From studies in prokaryotes, UAA and UGA are thought to be more stringent stop codons (Atkins and Gesteland, 1983) and were expected to have the lowest readthrough (highest recognition) by the ribosomes. Instead, the deletion of $Y J R 014 \mathrm{~W}$ allowed the recognition of the UAG stop codon more frequently than UAA and UGA. In prokaryotes, there are two release factors that are responsible for detecting stop codons. Release factor one recognizes UAG and UAA and release factor 2 recognizes UAA and UGA (Atkins and Gesteland, 1983). This increases the stringency for the recognition of UAA in prokaryotes. 
However, in eukaryotes, release factor 1 assimilates the functions of both those release factors and can recognize all three stop codons. The stop codon recognition mechanisms by eRF1 has yet to be fully elucidated, thus the results obtained in this experiment may be due to the specific effects of the gene deletions.

$Y N L 122 C \Delta$ had translational readthrough for all three stop codons. Previous research by (Huh et al., 2003), indicated that YNL122C codes for a mitochondrial ribosomal protein found localized in the mitochondria by using green fluorescent protein (GFP) tagged at the carboxyl terminal end of YNL122C protein. In theory, this does not contradict our finding that $Y N L 122 C$ may also have a role in cytoplasmic translation. Besides the inherent experimental errors in localization experiments, many yeast genes have diverse roles in very different cellular processes. Alternatively, it is possible that $Y N L 122 C$ may be involved in ribosome production for both cytoplasmic and mitochondrial ribosomes. In agreement with a link between cytoplasmic and mitochondrial translation machineries, mitochondrial ribosomal proteins have been found to translocate from the mitochondria to function in the cytoplasm (Nimomiya and Ichinose, 2007). All mammalian mitochondrial ribosomal proteins are initially encoded by nuclear genes and synthesized in the cytoplasm before imported into the mitochondria (Zhang and Gerstein, 2003). Furthermore, mitochondrial ribosomal protein L12 in human was found to be involved in mitochondrial transcription and translation to facilitate mitochondrial ribosome biogenesis (Surovtseva et al., 2011). Perhaps, YNL122C as a mitochondrial ribosomal protein has similar roles in expediting ribosome biogenesis outside the mitochondria. If that were the case, the deletion of $Y N L 122 C$ may yield impaired ribosomes and prevent proper interactions with the eRF1 to allow for proper termination of mRNA. eRF1 is known to mimic a tRNA and a mutation of an amino acid residue can lead to suppressor phenotype causing impaired stop codon recognition (Song et al., 2000). 
Furthermore, the stop codons are recognized by only one of the domains (N-terminal domain or Domain 1) of eRF1 and mutations near that domain containing the codon recognition groove will affect stop codon recognition (Song et al., 2000). eRF1 has been assumed that its interactions with U-purine-purine codons stabilize it in a specific conformation, that is very important for accurate termination, allowing it to proceed in selecting and discrimination the stop codon (Chavatte et al., 2003). Therefore, its structure is crucial in stop codon recognition but if the structure of the ribosomes is deformed in such a way that prevents eRF1 from satisfying its conformation in the A site, stop codon recognition and decoding will be compromised.

Similarly, YGR117C deletion also contributed to high translational stop codon readthrough. YGR117C has been found localized in the cyctoplasm by (Huh et al., 2003), when they performed a genome-wide analysis of protein localization in yeast using GFP fusion protein. Although not much information has been discovered regarding this gene, our results indicated it may be involved in the translation pathway.

YNL040W remains uncharacterized, although it has similarity to alanyl-tRNA synthase in Eubacteria. When this gene in yeast was tagged with a GFP marker expressed under the control of the open reading frame (ORF) promoter, no significant GFP fluorescent signal was obtained with fluorescence microscopy to determine where it localizes (Brachat et al., 2000). On the basis of our findings here, YNL040W can be linked to the translation pathway based on the $\beta$-galactosidase assay with premature stop codons.

These deletion strains containing plasmids with premature stop codons in the $L a c Z$ cassette were also subjected to qRT-PCR to confirm that the observed translational bypass of premature stop codons was not due to the mRNA contents. 
The qRT-PCR results confirmed that the increase in translational readthrough of premature stop codons was at the translation level.

All the selected genes appeared to be involved in translation. Next we reasoned that their involvement in translation may also affect the rate of synthesis and their deletions may also have different translation efficiency compared to the control strain. The deletion strains were evaluated using a modified $\beta$-galactosidase assay with an inducible GAL1 promoter to assess their efficiency in translation. YLR192CA had increased translation efficiency and it was suggested that the gene may also be a negative regulator of translation in conjunction to its already well characterized roles. Valasek et al.2001, demonstrated that YLR192C had a dual function and was involved in both translation and ribosomal biosynthesis. Their YLR192CA mutant exhibited sensitivity to paromomycin, a drug that binds to the small ribosomal subunit and affects translation fidelity, which was consistent with our drug sensitivity data.

YNL040W also had increased translation efficiency and may have a similar function to that of YLR192C. The deletions of YNL122C, YJR014W and YGR117C had decreased protein synthesis might be an expected finding if these genes had roles in translation. Alternatively, the observed reduction in $\beta$-galactosidase production could be attributed to low abundance of mRNA, hence less translation. To examine this theory further, qRT-PCR was performed on the $\beta$-galactosidase mRNA contents of the deletion strains containing the inducible $G A L 1$ plasmid to corroborate that these gene deletions were the source of the differences in translation efficiency and not from mRNA contents. There were no significant differences between the mRNA levels of the target strains and the control strain for qRT-PCR results. This affirmed that the observed increase and decrease in $\beta$-galactosidase expression was at the 
translation level.

The $\beta$-galactosidase results provided us further confidence for the involvement of these four genes in the process of protein synthesis. Next, further testing of these gene deletions on drugs inhibiting the same function was completed. Deletion of a target gene may affect protein synthesis but have no measurable phenotype under standard laboratory conditions. However, if we introduce a drug that affects the same pathway (translation), there may be a measurable phenotype shown as growth reduction or hypersensitivity. Only YLR192CA was sensitive to paromomycin. It should be noted that not all deletion of translation genes are expected to be sensitive to general drug. For example, deletions of elongation factor 2 and ribosomal protein, L12, carry no altered sensitivity to protein synthesis drug, sordarin, compared to the control (Botet et al., 2008). YNL040WA and YJR014WD did exhibit sensitivity to cycloheximide drug. Cycloheximide has been shown to inhibit translation elongation and polysome aggregation depending on its concentration (Baliga et al., 1969).

To improve the understanding of the roles that our target genes play in translation, this research attempted to study their genetic interactions with other translation related genes in the deletion mutant array. YNL040W was successfully knocked out in yeast " $\alpha$ " and replaced with the natMX4 gene through PCR mediated gene deletion and transformation. As such, it was the first gene that was subjected to SGA analysis to investigate the genetic interactions it may have with 384 translation related genes. Genetic interactions were detected based on colony size reduction indicating synthetic sick interactions. Lethal interactions may be from pinning errors and contribute to false positives, so they were not examined. However, using repeats can make it more reliable. The deletions that presented synthetic sick interactions with the query mutant gene presented visually smaller colonies than that on the 
control plate. Random spore analysis confirmed four gene deletions (YER086W YGR155WD, YEL009CA and YDL075WA) had synthetic sick phenotype with the deletion of the query gene (Figure 17). Three of the interactions were with genes involved in amino acid biosynthesis and one was with a ribosomal protein gene. YGR155W encodes the first enzyme in cysteine biosynthesis and is involved in vacuolar ATPase regulation to maintain organelles within a cell (Oluwatosin and Kane, 1997). YER086W is a threonine deaminase gene that is involved in catalyzing the first step of isoleucine biosynthesis and regulates the isoleucine-valine pathway (Holmberg and Petersen, 1988). Another amino acid biosynthesis gene was YEL009C which stimulates amino acid transcription in response to amino acid starvation, thus YEL009C is involved in regulating amino acid biosynthesis (Hinnebusch and Natarajan, 2002). The ribosomal protein gene that interacted with YNL040W was YDL075W which encodes Rpl31, a component of the large ribosomal subunit found near the exit site of the ribosome (Peisker et al., 2008). Appendix 7 provides descriptions of these genes that displayed genetic interactions with the query gene. Our interaction data for YNL040W was combined with previously reported data through (http://drygin.ccbr.utoronto.ca) (Samanfar et al., 2014).

Data from Saccharomyces Genome Database (SGD) suggest that on average there are approximately 30-40 genetic interactions for a given gene. On the basis of this number, the number of interactions we observed in the current study was lower than one might expect. It was plausible that there was a high frequency of false negatives (real interactions that were not detected) in our screen. Synthetic genetic array method utilizes the two different mating types of yeast to mate and systematically select for recombinant haploid double-mutant progeny; and this haploid selection is based on mating-type-regulated auxotrophy (MRA) (Singh et al., 2008) resulting from placing an auxotrophy-complementing gene under control of a mating type 
regulated promoter. For example, the MAT $\alpha$ strain with our gene deletion of interest contains the MATa specific promoter STE2 fused to Schizosaccharomyces pombe HIS5 gene which is only expressed in MATa cells. During mating, and after meiosis, MATa haploids containing the MRA cassette can be selected for in medium lacking histidine. If haploids contain no MRA cassette, they will continue to proliferate and mate under negative selections, producing diploids that are heterozygous for one or both deletion alleles. This masks the phenotype of the true haploid double mutant (Singh et al., 2008). However, strains containing STE2 promoter and the HIS5 gene in the MRA cassette have been tested to have low MRA escape compared to other strains containing MRA cassette with MFA1 promoter and the HIS3 gene (Singh et al., 2008). Therefore, there may be some false negative interactions in the case of this particular gene. It could also be that some of the haploid strains did not mate properly during our mating steps, perhaps, due to pinning errors. The lower number of genetic interactions could also be due to the omission of lethal interactions. We assumed that these interactions were caused from pinning errors resulting in improper mating of the yeast cells. However, some of these lethal interactions could potentially be real interactions. Alternatively, it might be possible that $Y N L 040 \mathrm{~W}$ simply does not form many genetic interactions. Since we only investigated around 800 possible interactions in our mini-SGA experiment (in comparison to 5000 in full SGA experiment), an unlikely scenario might be that $Y N L 040 W$ may form a number of additional interactions that were not investigated in the current study. If so, the conclusions drawn from our current genetic interaction investigation might require further analysis. However, we do not expect this to be the case as our control plate carries approximately 400 random gene deletions, none of which interacted with the target gene, making this a highly unlikely scenario.

Genetic interaction is not a static phenomena. Many interactions may only be 
identified under specific conditions. For example, two genes involved in DNA damage may not genetically interact during standard laboratory conditions. However, the same genes may form genetic interaction when DNA is damaged and repair is required (Omidi et al., 2014). Such conditional genetic interactions often refer to the functional similarity between two target genes only in specific conditions. To view conditional genetic interaction for $Y N L 040 \mathrm{~W}$, sub-inhibitory concentrations of cycloheximide were added in the medium. When the double mutants were analyzed for conditional interactions on cycloheximide $(25 \mathrm{ng} / \mathrm{mL}$ and $35 \mathrm{ng} / \mathrm{mL})$, all the double mutant colonies were slightly sensitive. However, two deletion strains had extremely reduced fitness, YGL151WD and YNL175CA, a transcription protein and a protein associated with preribosomal complex, respectively (Appendix 8). YGL151W protein is associated with RNA biosynthesis process and serves as one of the 24 subunits that form the Mediator complex required for Polymerase II response to gene-specific activators for transcription initiation (Guglielmi et al., 2004). The other gene, YNL175C, codes for a nucleolar protein and contains RNA-recognition motifs and is associated with preribosomal complex (Wu et al., 2001). The YNL175C deletion had no phenotypic effect in normal condition and it is a nucleolar protein similar to NOP12, which is a functional ribosomal protein (Wu et al., 2001). These two genes may not be required or are inactive in a normal environment, thus their deletions with the second query gene deletion would have no effect on growth in normal, unperturbed conditions. The only time that these genes interact with YNL040 W is when translation is compromised by cycloheximide providing a direct functional link between these two genes and YNL040W. This observation provides evidence for a possible involvement of $Y N L 040 \mathrm{~W}$ in RNA biosynthesis and hence might affect the synthesis of rRNA molecules. In agreement with an involvement of YNL040W in ribosome biogenesis, several genetic interaction for $Y N L 040 \mathrm{~W}$ with ribosome biogenesis genes have been reported in literature (www.yeastgenome.org). 
The overexpressions of $Y J R 014 W$ and $Y N L 040 W$ were evaluated for their effects in the deletion mutants in the translation array in a synthetic dosage lethality analysis. This was done by over expressing the query gene in MAT $\alpha$ and crossing it with the deletion array. Deletions that cannot tolerate the overexpression of the gene will portray growth defects indicating genetic interactions. The overexpression of $Y J R 014 W$ affected 16 translation related gene. Most of the interactions were with genes coding for ribosomal proteins. There were 10 genes that were ribosome related, and 5 of them were protein components of either the $40 \mathrm{~S}$ or $50 \mathrm{~S}$ ribosomal subunits (Appendix 12). The other 5 interactions were with genes encoding proteins involved in ribosome biogenesis or ribosomal RNAs. YJR014W has been found to interact with $Y E R 007 C$ - $A$ a gene encoding TMA20 protein, which is a component of the 40S subunit (Fleischer et al., 2006). There were also two amino acid biosynthesis genes that were affected by $Y J R 014 W$ overexpression. Their observations provided further evidence for the activity of $Y J R 014 \mathrm{~W}$ in protein biosynthesis.

Out of 384 deletion strains, 11 had growth defects in the presence of YNL040W overexpression (Appendix 13). One of these genetic interactors is the amino acid biosynthesis gene, YAL012W, which codes for cystathionine $\gamma$-lyase required for the biosynthesis of cysteine (Cherest et al., 1993; Ono et al., 1992). The overexpression of YNL040W became lethal to the cells in the absence of cystathionine $\gamma$-lyase further defends $Y N L 040 \mathrm{~W}$ being involved in protein synthesis. Additionally, the majority of interacting deletion genes in this screen were ribosome related including YOR096W and YLR448W, both encode components of the 60S ribosomal subunit (Planta and Mager, 1998). Two other genes, YMR230W and YOR096 W have also been found to encode components of the $40 \mathrm{~S}$ ribosomal subunit (Planta and Mager, 1998). Our gene also interacted with a mitochondrial ribosomal 
protein, YEL050C. It has been mentioned previously that mitochondrial ribosomes could move into the cytoplasm and function there. Yeast mitochondrial translation differs from the cytoplasmic translation in that it has additional stop codons not found in the cytoplasm, however it does utilize two of the stop codons found in the cytoplasm, UAA and UAG (Askarian-Amiri et al., 2000). One explanation for this genetic interaction with $Y E L 050 C$ is that the mitochondrial and cytoplasmic translation machineries may share some similar proteins that can interchange their functions (Towpik, 2005). Most interesting was the interaction with YKL204W, a translation gene that codes for a protein which interacts with eIF4E and was also found to have a second function in genetic stability independent of its function in translation (Chial et al., 2000). Due to its strong similarity to alanyl-tRNA synthetases in Eubacteria and its sequence homology being close to Aquifex aeolicus (Brachat et al., 2000), YNL040W likely codes for a ribosomal protein gene. Another interesting point was that $Y D L 075 \mathrm{~W}$, codes for ribosomal protein L31A, appeared to genetically interact with $Y N L 040 \mathrm{~W}$ in both SGA and SDL screens.

The final screen was performed using phenotypic suppression analysis by transferring mutants from SDL containing the overexpression plasmids of the target genes and a second gene deletion onto plates with cycloheximide. This was done to detect compensations of gene deletions by the overexpressions of the genes of interest, YNL040W and YJR014W. YJR014W had many interacting genes that were ribosomal (Appendix 14). There was also one translation factor gene YKL204W in which the phenotypic effect of its deletion was rescued by $Y J R 014 W$ overexpression. YGR285CA had a decreased growth phenotype in the presence of cycloheximide; YJR014W overexpression compensated for this phenotype. The other gene deletions that exhibited the same effect were YOL004WD and YNR052CA (Figure 23). YGR285C codes for a nucleic acid binding protein and functions with single 
stranded binding proteins, Ssz1p and SSb1/2, as a chaperone on the ribosome (Yan et al., 1998). Whereas YNR052C codes for a nuclease that mediates mRNA deadenylation for mRNA degradation (Daugeron et al., 2001). YOL004W is a part of a histone complex and has many different functions in the cell which accounts for the overlap of this gene in many of the screens. When these genes were deleted in the presence of cycloheximide, they experienced growth defect. However, the overexpression of $Y J R 014 W$ suppressed the hypersensitivities of these deletion strains to the drug. Taken together, these results reinforced the involvement of YJR014W in protein synthesis. More specifically, it may have a role in ribosome biogenesis from its interactions with ribosome biogenesis genes and ribosomal RNAs. 


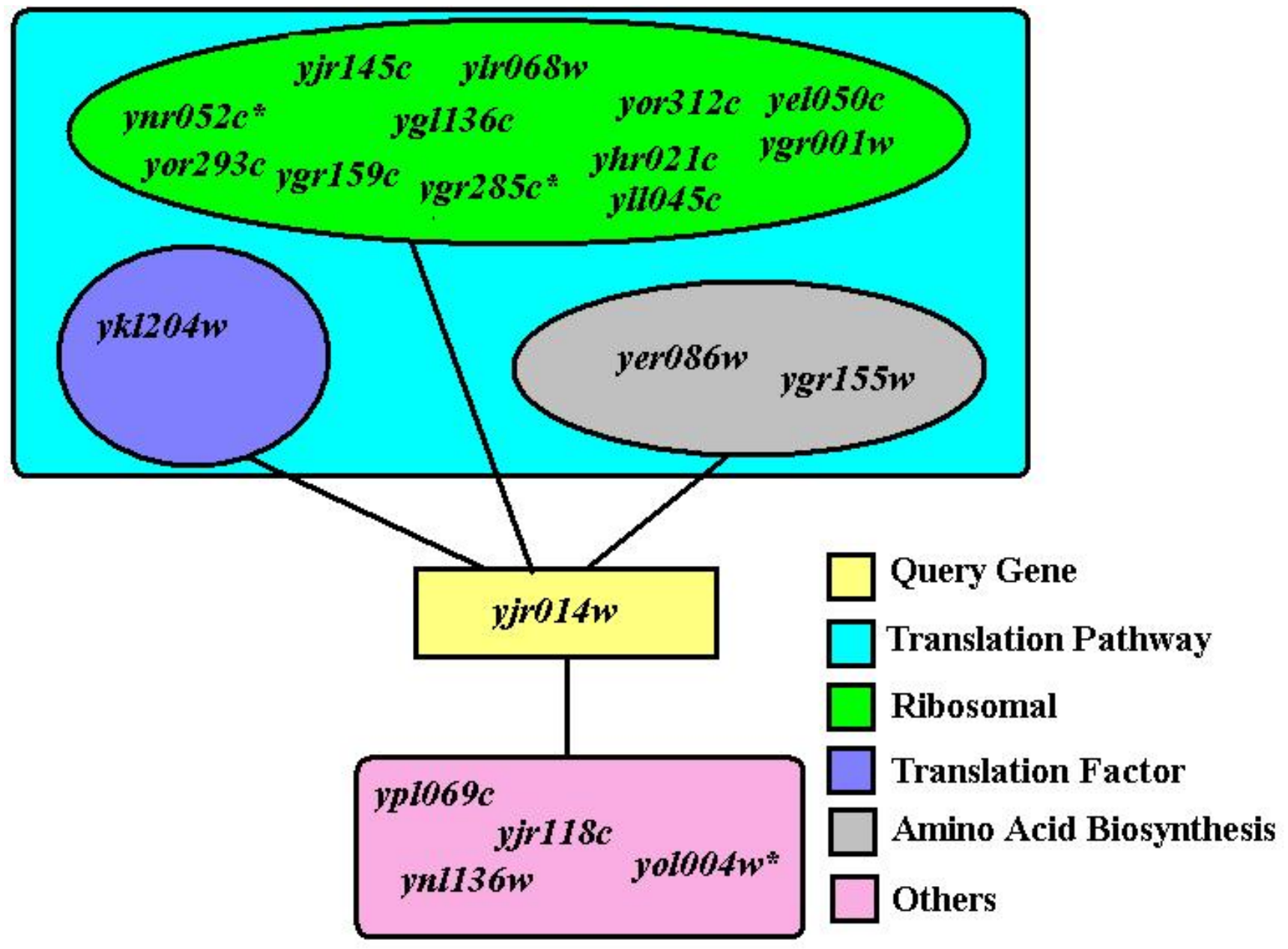

Figure 23: Interactions from both SDL and PSA were clustered to study the function of YJR014W overexpression. From both experiments, many of the interacting genes were found to be ribosomal proteins. * indicates overlapping genes found from the two different screens. 
$Y N L 040 \mathrm{~W}$ overexpression compensated for the deletions of a couple of ribosomal genes. These genes were $Y N L 069 C$ and $Y J R 145 C$, both of which are components of the ribosomal subunit (Appendix 15). Taken together with SGA results, these interactions continue to support the involvement of $Y N L 040 \mathrm{~W}$ in protein synthesis (Figure 24). 


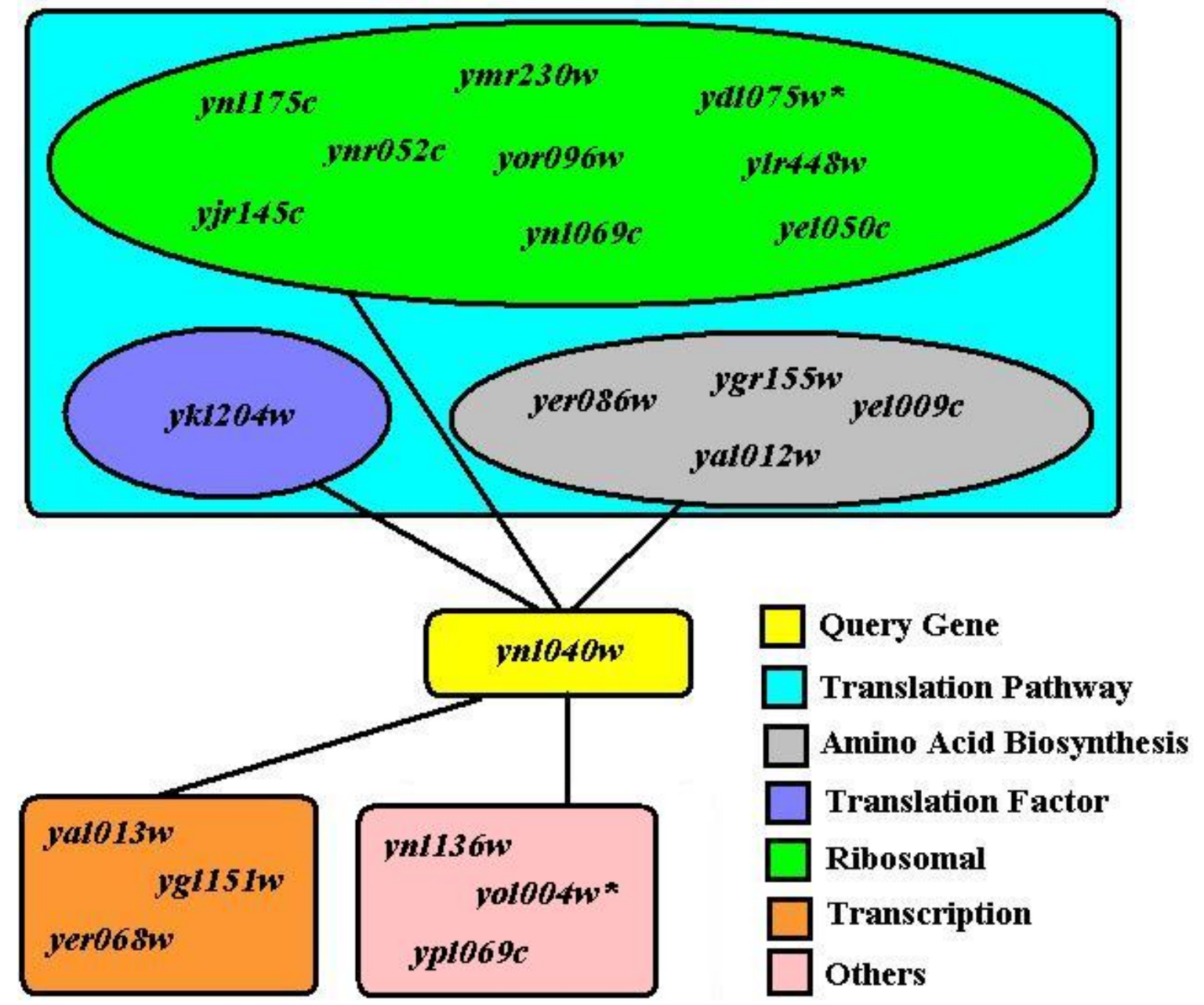

Figure 24: Interactions from SGA, SDL and PSA were clustered to study the function of $Y N L 040 \mathrm{~W}$. Many genes were ribosomal and amino acid biosynthesis related genes. * indicates overlapping genes found from the different screens. 


\section{Chapter 5}

\section{Conclusions}

Translation is a fundamental step of the gene expression pathway and is an essential process for life of a cell. It represents a multifaceted process with complex pathways and is affected by a large number of genes. Although translation has been the subject of vigorous investigations for the past decades, details of the associated genes, their functions as well as their cross-communications with other cellular processes require

further investigation. In this study, we hypothesized that there exist a number of genes that are involved in translation and are yet to be discovered. Many of these genes might be those that have previously been linked to other processes and the rest are uncharacterized gene. In the model eukaryotic organism, the baker yeast S. cerevisiae, of the 6000 genes, approximately 1000 are thought to be orphans (uncharacterized). Some of these genes may represent novel factors that affect the integrity of translation.

Large scale $\beta$-galactosidase colony lift assay analysis yielded many potential genes with novel association with the process of protein synthesis. This screen was on the basis of transforming the collection of yeast gene knockout strains with $\beta$-galactosidase expression plasmids that contain premature stop codons. In the current study, we investigated the involvement of four of these genes in the process 
of translation. We confirmed that deletion of these four genes increased the rate of stop codon readthrough and hence reduced fidelity of translation. We also reported that deletion of these four genes affected the rate of protein synthesis. Further confirmation for their involvement in translation came from genetic interaction analysis that connected the activity of these target genes to those of characterized translation genes. Identification of novel genes that affect protein synthesis confirm our expectations that there exist a number of uncharacterized genes that can influence the process of translation. In addition, it also verifies that our initial large scale screen was successful in detecting novel gene functions in translation. This study sets path for further investigations to identify other translation related genes. The process of translation is known to be important for the onset of important human conditions such as certain types of cancer. It is also the target of a number of commercially important antimicrobial drugs. Consequently, understanding the details of translation not only enhances our current understanding of this important cellular process, but it can also provides us with important targets for drug development.

Due to lack of time it was not possible to finish all three types of genetic interaction analysis for all four target genes. As a continuation of this research, the genetic interaction studies of the candidate genes should be completed. SGA analysis should be done for the remaining genes of interest YJR014W, YNL122C and YGR117C to enhance characterization of their functions based on additional genetic interactions with translation related genes. Identification of the four genes with novel activity in translation demonstrates the ability of our original screen in identifying novel translation genes. In this screen, we identified approximately 80 candidates, some of which have not been previously linked to translation. In light of our current findings in this thesis, it is very likely that many of these genes are in fact novel translation genes. Further investigations are needed to examine this possibility. 


\section{References}

Akhmaloka, Susilowati, P.E., Subandi, and Madayanti, F. Mutation at tyrosine in amlry (gilry like) motif of yeast erf1 on nonsense codons suppression and binding affinity to erf3. Int. J. Biol. Sci. 2008, 4.

Alamgir, M.D., Eroukova, V., Jessulat, M., Xu, J., and Golshani, A. Chemical-genetic profile analysis in yeast suggests that a previously uncharacterized open reading frame, ybr261c, affects protein synthesis. Bmc Genomics 2008, 9:583.

Alamgir, M.D., Erukova, V., Jessulat, M., Azizi, A., and Golshani, A. Chemicalgenetic profile analysis of five inhibitory compounds in yeast. BMC Chemical Biology 2010, 10:6.

Andrade, M.A. and Valencia, A. Automatic extraction of keywords from scientific text: application to the knowledge domain of protein families. Bioinformatics 1998, 14:600-607.

Askarian-Amiri, M., Pel, HJ., Guevremont, D., McCaughan, KK., Poole, ES., Sumpter, VG., and Tate, WP. Functional characterization of yeast mitochondrial release factor 1. J Biol Chem 2000, 275.

Atkins, F., John and Gesteland, R.F. Resolution of the discrepancy between a gene translation-termination codon and the deduced sequence for release of the encoded polypeptide. Eur. J. Biochem 1983, 137. 
Baliga, B.S., Pronczuk, A.W., and Munro, H.N. Mechanism of cycloheximide inhibition of protein synthesis in a cell-free system prepared from rat liver. Journal of Biological Chemistry 1969, 244:4480-.

Belova, L., Tenson, T., Xiong, L., McNicholas, P.M., and Mankin, A.S. A novel site of antibiotic action in the ribosome: Interaction of evernimicin with the large ribosomal subunit. PNAS 2001, 98.

Bidou, L., Rousset, J.-P., and Namy, O. Translational errors: from yeast to new therapeutic targets. Fems Yeast Research 2010, 10:1070-1082.

Bjornsti, M.A. Cancer therapeutics in yeast. Cancer Cell 2002, 2:267-273.

Boone, C., Bussey, H., and Andrews, B.J. Exploring genetic interactions and networks with yeast. Nature Reviews 2007, 8:437-449.

Botet, J., Rodriquez-Mateos, M., Juan, JPG. Ballesta, Revuelta, JL., and Ramacha, M. A chemical genomic screen in Saccharomyces cerevisiae reveals a role for diphthamidation of translation elongation 2 in inhibition of protein synthesis by sorarin. Antimicrobial Agens and Chemotherapy 2008, 52.

Brachat, A., Liebundguth, N., Rebischung, C., Lemire, S., Scharer, F., Hoepfner, D., Demchyshyn, V., Howald, I., and Dusterhoft, A. et al. Analysis of deletion phenotypes and gfp fusions of 21 novel Saccharomyces cerevisiae open reading frames. Yeast 2000, 16:241-253.

Brodersen, D.E., Clemons Jr, W.M., Carter, A.P., Morgan-Warren, R.J., Wimberly, B.T., and Ramakrishnan, V. The structural basis for the action of the antibiotics tetracycline, pactamycin, and hygromycin b on the 30 s ribosomal subunit. Cell $2000,103$. 
Butland, G., Babu, M., Diaz-Mejia, J.J., Bohdana, F., Phanse, S., Gold, B., Yang, W., Li, J., Gagarinova, A.G., and Pogoutse, O. et al. esga: E. colisynthetic genetic array analysis. Nature Methods 2008, 5:789-795.

Chavatte, L., Kervestin, S., Favre, A., and Jean-Jean, O. Stop codon selection in eukaryotic translation termination: comparison of the discriminating potential between human and ciliate erf1s. PLoS ONE 2003, 2.

Chen, D., Pan, K.Z., Palter, J.E., and Kapahi, P. Longevity determined by developmental arrest genes in Caenorhabditis elegans. Aging Cell 2007, 6:525-533.

Cheng, Z., Saito, K., Pisarev, A.V., Wada, M., Pisareva, V.P., Pestova, T.V., Gajda, M., Round, A., Kong, C., Lim, M., Nakamura, Y., Svergun, D.I., Ito, K., and Song, H. Structural insights into erf3 and stop codon recognition by erf1. Genes and Development 2009, 23.

Chepelev, N., Chepelev, L., Alamgir, M.D., and Golshani, A. Large-scale proteinprotein interaction detection approaches: Past, present and future. Biotechnology Biotechnological Equipment 2008, 22:513-529.

Cherest, H., Thomas, D., and Surdin-Kerjan, Y. Cysteine biosynthesis in Saccharomyces cerevisiae occurs through the transsulfuration pathway which has been built up by enzyme recruitment. J. Bacteriol. 1993, 175:5366-5374.

Chial, H.J., Stemm-Wolf, J., McBratney, S., and Winey, M. Yeast eap1p, an eif4eassociated protein, has a separate function involving genetic stability. Current Biology 2000, 10:1519-1522.

Chuang, H.-Y., Hofree, M., and Ideker, T. A decade of systems biology. Annual Review of Cell and Developmental Biology, Vol 26 2010, 26:721-744. 
Cole, S.E., LaRiviere, F.J., Merrikh, C.N., and Moore, M.J. A convergence of rrna and mrna quality control pathways revealed by mechanistic analysis of nonfunctional rrna decay. Mol. Cell 2009, 34:440-450.

Costanzo, M., Baryshnikova, A., Bellay, J., Kim, Y., Spear, E.D., Sevier, C.S., Ding, H., Koh, J.L.Y., Toufighi, K., Mostafavi, S., Prinz, J., St Onge, R.P., and Boone, C. et al. The genetic landscape of a cell. Science 2010, 327:425-431.

Dagbagli, S. and Goksungur, Y. Optimization of beta-galactosidase production using kluyveromyces lactis nrrl y-8279 by response surface methodology. Electronic Journal of Biotechnology 2008, 11:12.

Daugeron, M.C., Mauxion, F., and Seraphin, B. The yeast POP2 gene encodes a nuclease involved in mrna deadenylation. Nucleic Acids Research 2001, 29:24482455.

Diaz-Guerra, E., Vernal, R., Cantero, W., Mullner, E.W., and Garcia-Sanz, J.A. Translation controlled mrnas: New drug targets in infectious diseases? Infectious Disorders- Drug Targets 2008, 8.

Dinman, J.D. The eukaryotic ribosome: Current status and challenges. The Journal of Biological Chemistry 2009, 284:11761-11765.

Dixon, S.J., Constanzo, M., Baryshnikova, A., Andrews, B., and Boone, C. Systematic mapping of genetic interaction networks. Annu. Rev. Genet. 2009, 43:601-625.

Draptchinskaia, N., Gustavsson, P., Andersson, B., Pettersson, M., Willig, T.N., Dianzani, I., Ball, S., Tchernia, G., Klar, J., Matsson, H., Tentler, D., Mohandas, N., Carlsson, B., and Dahl, N. The gene encoding ribosomal protein s19 is mutated in diamond-blackfan anaemia. Nature genetics 1999, 21:169-175. 
Fleischer, T.C., Weaver, C.M., McAfee, K.J., Jennings, J.L., and Link, A.J. Systematic identification and functional screens of uncharacterized proteins associated with eukaryotic ribosomal complexes. Genes development 2006, 20:1294-1307.

Frank, J. and Spahn, C.M.T. The ribosome and the mechanism of protein synthesis. Rep. Prog. Phys. 2006, 69:1383-1417.

Frolova, L.Y., Tsivkovskii, R.Y., Sivolobova, G.F., Oparina, N.Y., Serpinsky, O.I., Blinov, V.M., Tatkov, S.I., and Kisselev, L.L. Mutations in the highly conserved ggq motif of class 1 polypeptide release factors abolish ability of human erf1 to trigger peptidyl-trna hydrolysis. $R N A$. 1999, 5 .

Fromont-Racine, M., Senger, B., Saveanu, C., and Fasiolo, F. Ribosome assembly in eukaryotes. Gene 2003, 313:17-42.

Fu, P. Gene expression study of Saccharomyces cerevisiae under changing growth conditions. J. Chem. Technol. Biotechnol. 2009, 84.

Fujii, K., Kitabatake, M., Sakata, T., Miyata, A., and Ohno, M. A role for ubiquitin in the clearance of nonfunctional rrnas. Genes Dev. 2009, 23:963-974.

Gallie, D.R. The cap and poly(a) tail function synergistically to regulate mrna translational efficiency. Genes development 1991, 5:2108-2116.

Gao, H., T.B., Toro, M., Paschini, B., Braunstein-Ballew, R.B., Cervantes, and V, Lundblad. Telomerase recruitement in Saccharomyces cerevisiae is not dependent on tel1-mediated phosphorylation of cdc13. Genetics 2010, 4:1147-1159.

Guglielmi, B., van Berkum, N.L., Klapholz, B., Bijma, T., Boube, M., Boschiero, C., Bourbon, H-M., Holstege, F.C.P., and Werner, M. A high resolution protein interaction map of the yeast mediator complex. Nucleic Acids Research 2004, 32. 
Hanson, C.L., Fucini, P., Ilag, L.L., Nierhaus, K.H., and Robinson, C.V. Dissociation of intact Escherichia coliribosomes in a mass spectrometer. The Journal of Biological Chemistry 2003, 278:1259-1267.

Harrison, R., Papp, B., Pal, C., Oliver, S.G., and Delneri, D. Plasticity of genetic interactions in metabolic networks in yeast. PNAS 2006, 104.

Hartwell, L.H. Role of yeast in cancer research. Cancer 1992, 69:2615-2621.

Hartwell, L.H. Yeast and cancer. Bioscience Reports 2004, 24:523-544.

HernÃąndez, G., Altmann, M., and Lasko, P. Origins and evolution of the mechanisms regulating translation initiation in eukaryotes. Trends in biochemical sciences 2009, $35: 63-73$.

Hinnebusch, A.G. and Natarajan, K. Gcn4p, a master regulator of gene expression, is controlled at multiple levels by diverse signals of starvation and stress. Eukaryotic Cell 2002, 1:22-32.

Hirokawa, G. and Kaji, A H.and Kaji. Inhibition of antiassociation activity of translation initiation factor 3 by paromomycin. Antimicrobial Agents and Chemotherapy 2007, 51:175-180.

Holmberg, S. and Petersen, G.L. Regulation of isoleucine-valine biosynthesis in Saccharomyces cerevisiae. Curr. Genet. 1988, 13:207-217.

Horn, T., Sandmann, T., Fischer, B., Axelsson, E., Huber, W., and Boutros, M 2011,

Huh, W.K., Falvo, J.V., Gerke, L.C., Carroll, A.S., Howson, R.W., Weissman, J.S., and O'Shea, E.K. Global analysis of protein localization in budding yeast. Nature 2003, 425:686-691. 
Ideker, T., Galitski, T., and Hood, L. A new approach to decoding life: Systems biology. Annu. Rev. Genomics Hum. Genet. 2001, 2:343-372.

Jackson, R.J., Hellen, C.U.T., and Pestova, T.V. The mechanism of eukaryotic translation initiation and principles of its regulation. Nature Reviews Molecular Cell Biology 2010, 11:113-127.

Kapp, L.D. and Lorsch, J.R. The molecular mechanisms of eukaryotic translation. Annu.Rev.Biochem. 2004, 73:657-704.

Kawai, S., Hashimoto, W., and Murata, K. Transformation of saccharomyces cerevisiae and other fungi. Bioengineered Bugs 2010, 1:395-403.

Kelly, R. and Ideker, T. Systematic interpretation of genetic interactions using protein networks. Nature 2005, 23:561-566.

Kitano, H. Systems biology: a brief overview. Science 2002, 295:1662-1664.

Kobayashi, T., Heck, DJ., and Nomura, M. et al. Expansion and contraction of ribosomal dna repeats in Saccharomyces cerevisiae: requirement of replication fork blocking (fob1) protein and the role of rna polymerase i. Genes Dev 1998, 12.

Kothe, U. Recent progress on understanding ribosomal protein synthesis. 2010, 5:353382.

Kowalczuk, M., Mackiewicz, P., Gierlik, A., and Rudek, M.R. Total number of coding open reading frames in the yeast genome. Yeast 1999, 15:1031-1034.

Kressler, D., Hurt, E., and Baßler, J. Driving ribosome assembly. Biochimica et Biophysica Acta 2010, 1803:673-693.

Kroll, E.S., Hyland, K.M., Hieter, P., and Li, J.J. Establishing genetic interactions by a synthetic dosage lethality phenotype. Genetics 1996, 143. 
Lammich, S., Schobel, S., Zimmer, A.-K., Lichtenthaler, S.F., and Haass, C. Expression of the alzheimer protease bace1 is suppressed via its 5'-untranslated region. EMBO reports 2004, 5:620-625.

Linder, P. Molecular-biology of translation in yeast. Antonie Van Leeuwenhoek International Journal of General and Molecular Microbiology 1992, 62:47-62.

Lundblad, V. Saccharomyces cerevisiae. 1997, Ch.13.

Mani, R., St. Onge, R.P., Hartman IV, J.L., Giaever, G., and Roth, F.P. Defining genetic interaction. PNAS 2007, 105:3461-3466.

Mathews, M.B., Sonenberg, N., and Hershey, J.W.B. Translational control of gene expression. 2000, 1-31.

Measday, V., Baetz, K., Guzzo, J., Yuen, K., Kwok, T., Sheikh, B., Ding, H.M., Ueta, R., Hoac, T., Cheng, B., Pot, I., Tong, A., Yamaguchi-Iwai, Y., Boone, C., Hieter, P., and Andrews, B. Systematic yeast synthetic lethal and synthetic dosage lethal screens identify genes required for chromosome segregation. Proceedings of the National Academy of Sciences of the United States of America 2005, 102:1395613961.

Measday, V. and Hieter, P. Synthetic dosage lethality. Guide to Yeast Genetics and Molecular and Cell Biology, Pt B 2002, 350:316-326.

Miko, I. Epistasis: Gene interaction and phenotype effects. Nature Education 2008, $1: 1$.

Mikulits, W., Pradet-Balade, B., Habermann, B., Beug, H., Garcia-Sanz, J.A., and Mullner, E.W. Isolation of translationally controlled mrnas by differential screening. FASEB 2000, 14. 
Miller, J.H. Experiments in molecular genetics. 1972, .

Nielsen, K.H., Valasek, L., Sykes, C., Jivotovskaya, A., and Hinnebusch, A.G. Interaction of the rnp1 motif in prt1 with her1 promotes 40s binding of eukaryotic initiation factor 3 in yeast. Molecular and Cellular Biology 2006, 26:2984-2998.

Nimomiya, Y. and Ichinose, S. Subcellular distribution of mitochondrial ribosomal rna in the mouse oocyte and zygote. PLoS ONE 2007, 2.

O’Conner, T., Doherty-Sadleir, K.R., Maus, E., Velliquette, R.A., Zhao, J., Cole, S.L., Eimer, W.A., Hitt, B., Bembinster, L.A., Lammich, S., Lichtenthaler, S.F., Hebert, S.S., Strooper, B.D., Haass, C., Bennett, D.A., and Vassar, R. Phosphorylation of the translation initiation factor eif $2 \alpha$ increases bace 1 levels and promotes amyloidogenesis. Neuron 2008, 6 .

Oluwatosin, Y.E. and Kane, P.M.. Mutations in the $C Y S 4$ gene provide evidence for regulation of the yeast vacuolar $H^{\text {ATPase }}$ by oxidation and reducation in Vivo. The Journal of Biological Chemistry 1997, 272:28149-28157.

Omidi, K., Hooshyar, M., Jessulat, M., Samanfar, B., Sanders, M., Burnside, D., Pitre, S., Schoenrock, A., Xu, J., Babu, M., and Golshani, A. Phosphatase complex pph3/psy2 is involved in regulation of efficient non-homologous end-joining pathway in the yeast Saccharomyces cerevisiae. PLoS One 2014, 9(1).

Ono, B-I., Tanaka, K., Naito, K., Heike, C., Shinoda, S., Yamamoto, S., Ohmori, S., Oshima, T., and Toh-E, A. Cloning and characterization of the CYS3 (CYI1) gene of Saccharomyces cerevisiae. J. Bacteriol. 1992, 174:3339-3347.

Ooi, S.L., Shoemaker, D.D., and Boeke, J.D. Dna helicase gene interaction network defined using synthetic lethality analyzed by microarray. Nature Genetics 2003, $35: 277-286$. 
Pan, K.Z., Palter, J.E., Rogers, A.N., Olsen, A., Chen, D., Lithgow, G.J., and Kapahi, P. Inhibition of mrna translation extends lifespan in Caenorhabditis elegans. Aging Cell 2007, 6:111-119.

Parsons, AB., Brost, RL., Ding, H., Li, Z., Zhang, C., Sheikh, B., Brown, GW., Kane, PM., Hughes, TR., and Boone, C. Integration of chemica-genetic and genetic interaction data links bioactive compounds to cellular target pathways. Nat. Biotechnol 2004, 22(1).

Peisker, K., Braun, D., Wolfle, T., Hentschel, J., Funfschilling, U., Fischer, G., Sickmann, A., and Rospert, S. Ribosome-associated complex binds to ribosomes in close proximity of rpl31 at the exit of the polypeptide tunnel in yeast. Molecular Biology of the Cell 2008, 19:5279-5288.

Pena-Castillo, L. and Hughes, T.R. Why are there still over 1000 uncharacterized yeast genes? Genetics 2007, 176:7-14.

Planta, R.J. and Mager, W.H. The list of cytoplasmic ribosomal proteins of Saccharomyces cerevisiae. Yeast 1998, 14:471-477.

Preiss, T. and Hentze, M.W. Starting the protein synthesis machine: eukaryotic translation initiation. BioEssays 2003, 25:1201-1211.

Qin, S.L., Xie, A.G., Bonato, M.C.M., and Mclaughlin, C.S. Sequence-analysis of the translational elongation-factor 3 from saccharomyces-cerevisiae. Journal of Biological Chemistry 1990, 265:1903-1912.

Ramakrishnan, V. Ribosome structure and the mechanism of translation. Cell 2002, 108:557-572.

Rudra, D. and Warner, J.R. What better measure than ribosome synthesis? Genes and Development 2004, 18. 
Ruggero, D., Grisendi, S., Piazza, F., Rego, E., Mari, F., Rao, P.H., Cordon-Cardo, C., and Pandolfi, P.P. Dyskeratosis congenita and cancer in mice deficient in ribosomal rna modification. Science 2003, 299:259-262.

Ruggero, D. and Pandolfi, P.P. Does the ribosome translate cancer? Nature Reviews Cancer 2003, 3:179-192.

Samanfar, B., Tan, L., Shostak, K., Chalabian, F., Wu, Z., Alamgir, MD., Sunba, N., Burnside, D., Omidi, K., Hooshyar, M., Marquez, IG., Jessulat, M., Smith, M., Babu, M., Aziz, A., and Golshani, A. A global investigation of gene deletion strains that affect premature stop codon bypass in yeast, Saccharomyces cerevisiae. Mol BioSyst 2014, 10(4).

Scheper, G.C., van der Knaap, M.S., and Proud, C.G. Translation matters: protein synthesis defects in inherited disease. Nature Review Genetics 2007, 8.

Schneider-Poetsch, T., Ju, J., DE., Eyler, Dang, Y., Bhat, S., Merrick, WC., Green, R., Shen, B., and Liu, JO. Inhibition of eukaryotic translation elongation by cycloheximide and lactimidomycin. Nat Chem Biol 2010, 6.

Singh, I., Pass, R., Togay, S.O., Rodgers, J.W., and Hartman IV, J.L. Stringent mating-type-regulated auxotrophy increases the accuracy of systematic genetic interaction screens with Saccharomyces cerevisiae mutant arrays. Genetics Society of America 2008, 181:289-300.

Sonenberg, N. and Hinnebusch, A.G. Regulation of translation initiation in eukaryotes: Mechanisms and biological targets. Cell 2009, 136:731-745.

Song, H., Mugnier, P., Das, A.K., Webb, H.M., Evans, D.R., Tuite, M.F., Hemmings, B.A., and Barford, D. The crystal structure of human eukaryotic release factor 
erfl-mechanism of stop codon recognition and peptidyl-trna hydrolysis. Cell 2000, 100.

Sopko, R., Huang, D., Preston, N., Chua, G., Papp, B., Kafadar, K., Snyder, M., Oliver, S.G., Cyert, M., Hughes, T.R., Boone, C., and Andrews, B. Mapping pathways and phenotypes by systematic gene overexpression. Molecular Cell 2006, 21:319-330.

Stahlberg, A., Elbing, K., Andrade-Garda, J.M., Sjogreen, B., Forootan, A., and Kubista, M. Multiway real-time pcr gene expression profiling in yeast Saccharomyces cerevisiae reveals altered transcriptional response of $A D H$-genes to glucose stimuli. BMC Genomics 2008, 9:170.

Steffen, KK., MacKay, VL., Kerr, EO., Tsuchiya, M., Hu, D., Fox, LA., Dang, N., Johnston, ED., Oakes, JA., Tchao, BN., Pak, DN., Fields, S., Kennedy, BK., and Kaeberlein, M. Yeast life span extension by depletion of 60 s ribosomal subunits is medicated by gcn4. Cell 2008, 133(2).

Surovtseva, Y.V., Shutt, T.E., Cotney, J., Cimen, H., Chen, S.Y., Koc, E.C., and Shadel, G.S. Mitochondrial ribosomal protein 112 selectively associated with human mitochondrial rna polymerase to activate transcription. PNAS 2011, 108.

Tong, A.H. and Boone, C. Synthetic genetic array analysis in Saccharomyces cerevisiae. Methods Mol. Biol. 2006, 313:171-192.

Tong, A.H.Y., Evangelista, M., Parsons, A.B., Xu, H., Bader, G.D., Page, N., Robinson, M., Raghibizadeh, S., Hogue, C.W.V., Bussey, H., Andrews, B., Tyers, M., and Boone, C. Systematic genetic analysis with ordered arrays of yeast deletion mutants. Science. 2001, 294:2364-2368.

Tong, G., A.H.and Lesage, Bader, G.D., Ding, H., Xu, H., Xin, X., Young, J., Berriz, 
G.F., Brost, R., Chang, M., Chen, Y., and Cheng, X. et al. Global mapping of the yeast genetic interaction network. Science 2006, 303:808-813.

Towpik, J. Regulation of mitochondrial translation in yeast. Cellular Molecular Biology Letters 2005, 10.

Triana-Alonso, F.J., Chakraburtty, K., and Nierhaus, K.H. The elongation-factor3 unique in higher fungi and essential for protein-biosynthesis is an e-site factor. Journal of Biological Chemistry 1995, 270:20473-20478.

Valasek, L., Hasek, J., Trachsel, H., Imre, E.M., and Ruis, H. The saccharomyces cerevisiae hcr1 gene encoding a homologue of the p35 subunit of human translation initiation factor 3 (eif3) is a high copy suppressor of a temperature-sensitive mutation in the rpg1p subunit of yeast eif3. Journal of Biological Chemistry 1999, $274: 27567-27572$.

Venema, J. and Tollervey, D. Ribosome synthesis in Saccharomyces cerevisiae. Annu. Rev. Genet. 1999, 33:261-311.

Wach, A., Brachat, A., Pohlmann, R., and Philippsen, P. New heterologous modules for classical or pcr-based gene disruptions in Saccharomyces cerevisiae. Yeast 1994, 10:1793-1803.

Wu, K., Wu, P., and Aris, J.P. Nucleolar protein nop12p participates in synthesis of 25s rrna in Saccharomyces cerevisiae. Nucleic Acids Research 2001, 29:2938-2949.

Yan, W., Schilke, B., Pfund, C., Walter, W., Kim, S., and Craig, E.A. Zuotin, a ribosome-associated dnaj molecular chaperone. The EMBO 1998, 17:4809-4817.

Zaher, H.S. and Green, R. Fidelity at the molecular level: Lessons from protein synthesis. Cell 2009, 136:746-762. 
Zhang, Z. and Gerstein, M. Identification and characterization of over 100 mitochondrial ribosomal protein pseudogenes in the human genome. Genomics 2003, 81.

Zhao, J., Fu, Y., Yasvoina, M., Shao, P., Hitt, B., O’Conner, T., Logan, S., Maus, E., Citron, M., Berry, R., Binder, L., and Vassar, R. $\beta$-site amyloid precursor protein cleaving enzyme 1 levels become elevated in neurons around amyloid plaques: Implications for alzheimer's disease pathogenesis. The Journal of Neuroscience 2007, $27: 3639-3649$. 


\section{Appendix}

Appendix 1: $1 \mathrm{~L}$ YEPD medium was prepared with yeast extract, peptone and agar in one flask filled up to $800 \mathrm{~mL}$ distilled water and $20 \mathrm{~g}$ glucose in $200 \mathrm{~mL}$ distilled water in a separate flask. The two were combined after sterilization. For -URA dropout (DO) media, yeast nitrogen base (YNB) without amino acids with ammonium sulphate was used along with DO mixture. YNB, and -URA DO mixture were combined in one flask with $250 \mathrm{~mL}$ distilled water. In a separate flask, $20 \mathrm{~g}$ agar was filled with $500 \mathrm{~mL}$ distilled water. $20 \mathrm{~g}$ of glucose in another flask was filled with $250 \mathrm{~mL}$ distilled water. All ingredients were autoclaved and combined for $1 \mathrm{~L}$-URA medium. For liquid media, agar was removed. Drugs was added after sterilization and only YNB without amino acids, without ammonium sulphate was used with G418.

\begin{tabular}{llll}
\hline YEPD ingredients & Quantity $(\mathrm{g})$ & -URA ingredients & Quantity $(\mathrm{g})$ \\
\hline \hline Yeast Extract & 10 & YNB & 6.7 \\
Peptone & 20 & -URA & 2 \\
Agar & 20 & Agar & 20 \\
Glucose & 20 & Glucose & 20 \\
\hline
\end{tabular}


Appendix 2: Amino acids supplement power mixture for synthetic complete media contained all amino acids and required supplements. Drop out (DO) power mixture contained the combination of the following ingredients minus the appropriate supplement.

\begin{tabular}{ll}
\hline Amino Acids and supplements & Quantity $(\mathrm{g})$ \\
\hline \hline adenine & 3 \\
uracil & 2 \\
inositol & 2 \\
para-aminobenzoic acid & 0.2 \\
alanine & 2 \\
arginine & 2 \\
asparagine & 2 \\
aspartic acid & 2 \\
cysteine & 2 \\
glutamic acid & 2 \\
glutamine & 2 \\
glycine & 2 \\
histidine & 2 \\
isoleucine & 2 \\
leucine & 2 \\
lysine & 2 \\
methionine & 2 \\
phenylalanine & 2 \\
proline & 2 \\
serine & 2 \\
threonine & 2 \\
tryptophan & 2 \\
tyrosine & 2 \\
valine & 2 \\
\hline
\end{tabular}




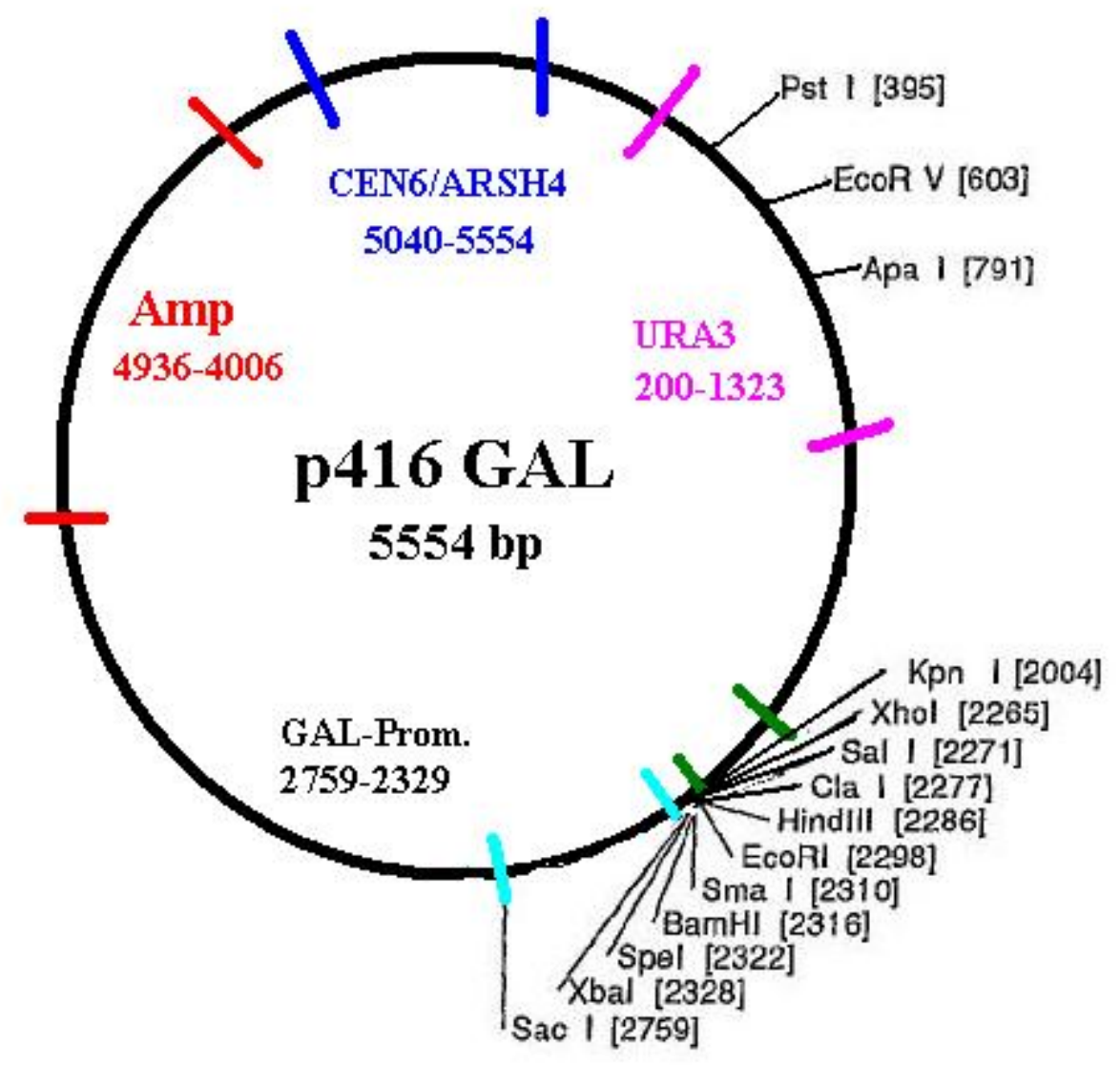

Appendix 3: Map of p416 (ATCC), the plasmid used to test translation efficiency in the $\beta$-gal assay. The plasmid contains GAL1 promoter in the $L a c Z$ gene which is inducible under galactose. 


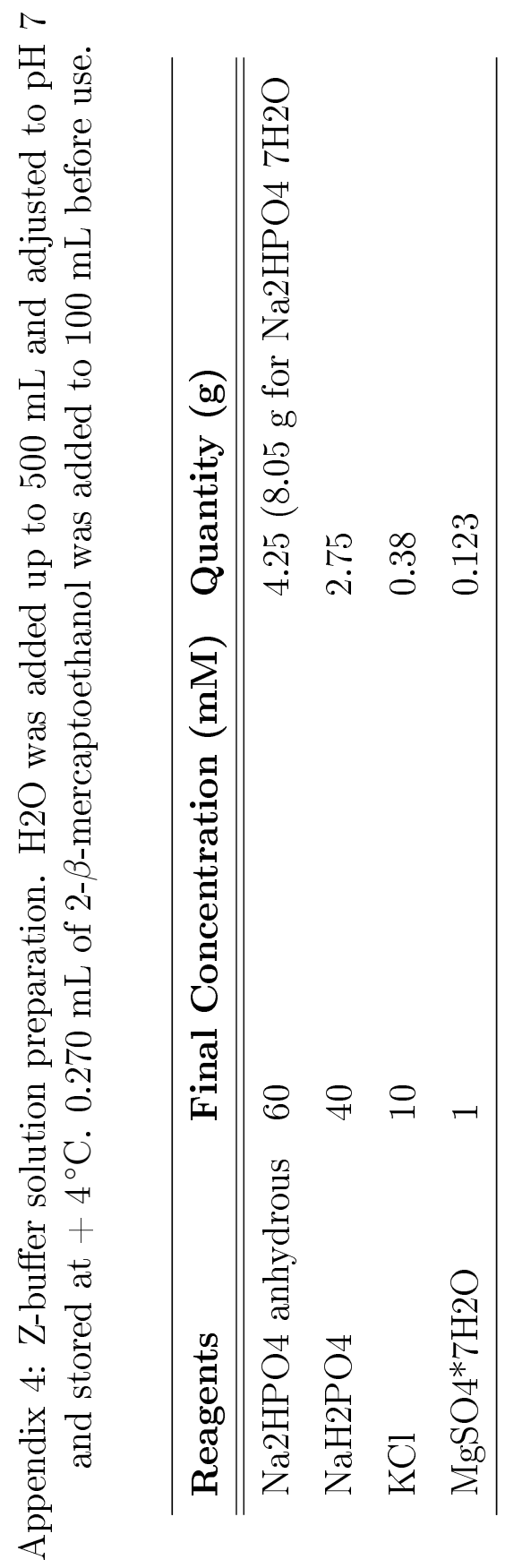




\begin{tabular}{|c|c|c|c|c|c|c|c|c|c|c|c|c|c|}
\hline 突离 & : : & $\begin{array}{l}\text { त. } \\
0 \\
0 \\
\end{array}$ & ఫึ & $\begin{array}{l}0 \\
0 \\
\end{array}$ & 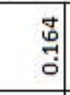 & ڤั. & 苟 & 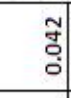 & $\stackrel{0}{0}$ & $\begin{array}{l}\text { a } \\
0 \\
0 \\
0 \\
\end{array}$ & & & \\
\hline 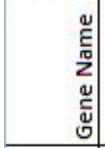 & 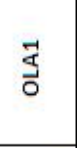 & $\sum_{\frac{1}{2}}^{N}$ & 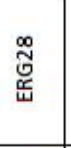 & 欨 & సี & $\underset{\mathbf{I}}{\tilde{E}}$ & 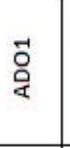 & $\sum_{\frac{x}{I}}^{\vec{T}}$ & 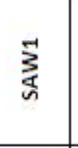 & 5 & & & \\
\hline 密焉 & $\begin{array}{l}\text { : } \\
\text { : } \\
0\end{array}$ & : & $\begin{array}{l}0 \\
0 \\
0 \\
0 \\
\end{array}$ & $\begin{array}{l}\text { : } \\
\vdots \\
\end{array}$ & : & 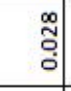 & $\begin{array}{l}9 \\
\vdots \\
0 \\
\end{array}$ & 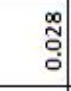 & $\begin{array}{l}\text { o: } \\
\vdots \\
\vdots \\
\end{array}$ & $\begin{array}{l}\text { g. } \\
\vdots \\
\vdots \\
\end{array}$ & 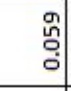 & $\begin{array}{l}0 \\
\vdots \\
\vdots\end{array}$ & $\begin{array}{l}0 \\
\vdots \\
0\end{array}$ \\
\hline 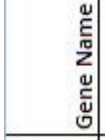 & ت્ & $\underset{\varpi}{\vec{x}}$ & $\vec{E}$ & $\sum_{\frac{\Sigma}{x}}^{N}$ & $\sum_{\substack{x \\
\alpha}}^{N}$ & $\overrightarrow{0}$ & 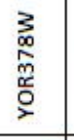 & $\sum_{\xi}^{-1}$ & 点 & 吉 & $\frac{\vec{E}}{2}$ & 笅 & 竎 \\
\hline 密密 & $\begin{array}{l}\overrightarrow{0} \\
\dot{0} \\
\end{array}$ & 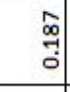 & 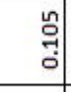 & $\begin{array}{l}\text { g: } \\
\stackrel{0}{0} \\
\end{array}$ & ज़ & $\begin{array}{l}\text { בิ } \\
\vdots \\
\vdots\end{array}$ & $\begin{array}{l}\text { : } \\
\text { : } \\
\end{array}$ & \begin{tabular}{c} 
\pm \\
\multirow{7}{0}{} \\
\end{tabular} & : & $\begin{array}{l}\text { gे } \\
\stackrel{5}{0} \\
\end{array}$ & : & 离 & ㅎ․ㅇ. \\
\hline 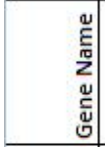 & 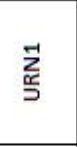 & 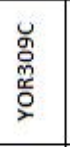 & 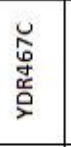 & 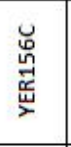 & 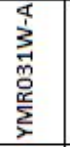 & 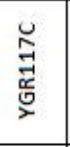 & 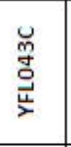 & 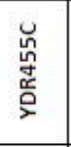 & $\underset{⿱ 亠}{\grave{D}}$ & $\stackrel{n}{\underline{n}}$ & $\overrightarrow{\underline{\mathbf{I}}}$ & $\sum_{\tilde{u}}^{\bar{n}}$ & 중 \\
\hline 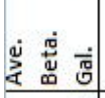 & 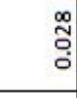 & 声 & $\begin{array}{l}\text { na } \\
\text { o. } \\
\end{array}$ & $\begin{array}{l}m \\
\vdots \\
\vdots \\
\end{array}$ & $\begin{array}{l}\infty \\
\vdots \\
0\end{array}$ & 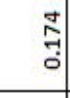 & $\begin{array}{l}0 \\
0 \\
0 \\
0 \\
0 \\
\end{array}$ & $\begin{array}{l}\text { ?. } \\
\text { : } \\
\end{array}$ & : & $\begin{array}{l}0 \\
0 \\
0 \\
0 \\
\end{array}$ & : & : & : \\
\hline 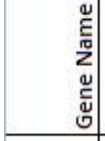 & $\frac{\vec{E}}{\tilde{V}}$ & 莣 & $\frac{\mathbb{a}}{\frac{0}{3}}$ & $\frac{\vec{\alpha}}{\Gamma}$ & $\sum_{n}^{-1}$ & $\sum_{\frac{\pi}{\alpha}}^{N}$ & $\begin{array}{l}\overrightarrow{5} \\
\frac{5}{2}\end{array}$ & $\frac{m}{\Sigma}$ & $\stackrel{\infty}{\stackrel{0}{0}}$ & $\sum_{0}^{\tilde{N}}$ & 愈 & ป్ & $\begin{array}{l}\text { N } \\
\hat{O} \\
0 \\
0\end{array}$ \\
\hline ذَّ & : & : & $\begin{array}{l}\text { g } \\
\stackrel{0}{0} \\
\end{array}$ & กี่ & $\begin{array}{l}0 \\
\vdots \\
\end{array}$ & 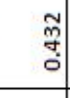 & 赑 & \begin{tabular}{l}
$\stackrel{\infty}{\infty}$ \\
\multirow{\sim}{*}{} \\
\end{tabular} & : & $\begin{array}{l}0 \\
\vdots \\
\vdots\end{array}$ & 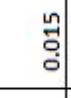 & ल्ले & ले: \\
\hline 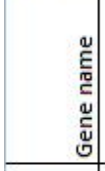 & $\underset{\frac{a}{\alpha}}{\stackrel{a}{a}}$ & 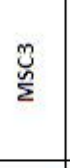 & $\stackrel{\infty}{\circ}$ & 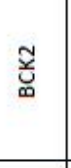 & 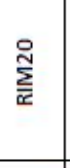 & $\sum_{x}^{\vec{n}}$ & 㝚 & $\begin{array}{l}\overrightarrow{\tilde{E}} \\
\stackrel{\underline{I}}{I}\end{array}$ & 売 & 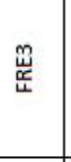 & $\sum_{0}^{n}$ & $\sum_{\Sigma}^{̃}$ & $\begin{array}{l}\vec{n} \\
\frac{10}{\nu}\end{array}$ \\
\hline 离 & $\stackrel{\substack{0 \\
0}}{0}$ & $\begin{array}{l}\text { o. } \\
0 \\
\vdots \\
\end{array}$ & กิ & $\begin{array}{l}0 \\
0 \\
0 \\
0 \\
0\end{array}$ & $\begin{array}{l}0 \\
0 \\
0 \\
0 \\
0\end{array}$ & 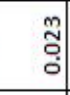 & ปุ. & 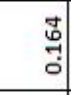 & : & : & $\begin{array}{l}\text { un } \\
0 \\
0 \\
0 \\
0\end{array}$ & 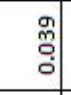 & : \\
\hline 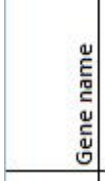 & $\sum_{k}^{m}$ & $\sum_{0}^{\frac{\text { fq }}{2}}$ & 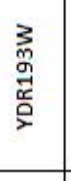 & 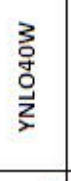 & $\begin{array}{l}\bar{F} \\
\text { 吾 }\end{array}$ & 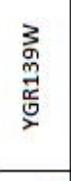 & 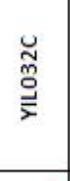 & $\sum_{\tilde{W}}^{\bar{z}}$ & $\frac{\tilde{a}}{\underline{x}}$ & 홍 & 폼 & $\sum_{\tilde{u}}^{7}$ & 퐆 \\
\hline 这密 & ?: & ปี & ते & ปั่ & $\begin{array}{l}\infty \\
0 \\
0 \\
0 \\
0\end{array}$ & $\begin{array}{l}\infty \\
: \\
:\end{array}$ & जे: & $\begin{array}{l}0 \\
\vdots \\
\vdots \\
:\end{array}$ & 会 & $\begin{array}{l}\text { g. } \\
\text { gे } \\
0\end{array}$ & $\begin{array}{l}0 \\
\vdots \\
\vdots \\
\vdots\end{array}$ & : & 잉 \\
\hline 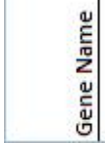 & 章 & 产 & 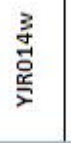 & 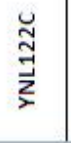 & a & $\stackrel{\Xi}{a}_{a}^{a}$ & 言 & $\frac{\tilde{T}}{\Sigma}$ & $\overline{\bar{H}}$ & 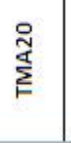 & 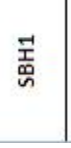 & ह & 氙 \\
\hline
\end{tabular}


A

\section{No drug}

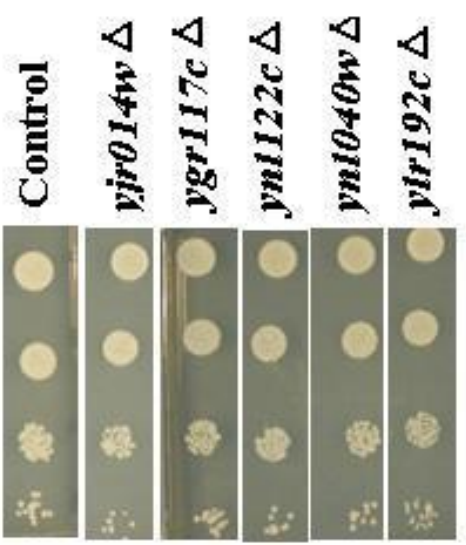

\section{B stretomycin $50 \mathrm{mg} / \mathrm{mL}$}

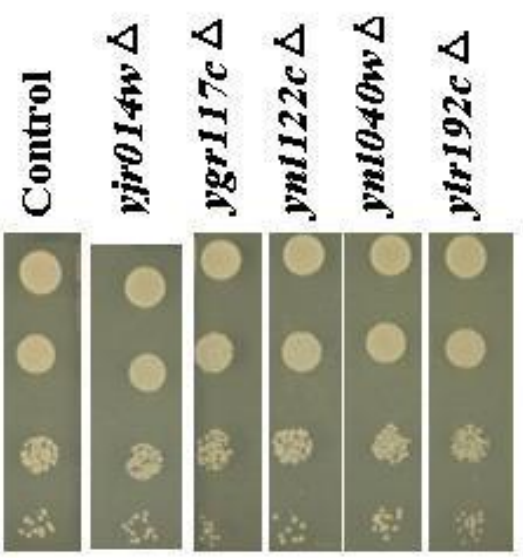

Appendix 6: $20 \mu \mathrm{L}$ of each serial dilution of $10^{-3}$ to $10^{-6}$ was spotted in media with or without drug and grown for 2 days at $30^{\circ} \mathrm{C}$. This was repeated with streptomycin $50 \mathrm{mg} / \mathrm{mL}$ and $60 \mathrm{mg} / \mathrm{mL}$ drug concentrations, . (A) Deletion strains on synthetic complete media (B) Deletion strains plated onto media containing streptomycin $50 \mathrm{mg} / \mathrm{mL}$. The experiment was repeated at least three times. 

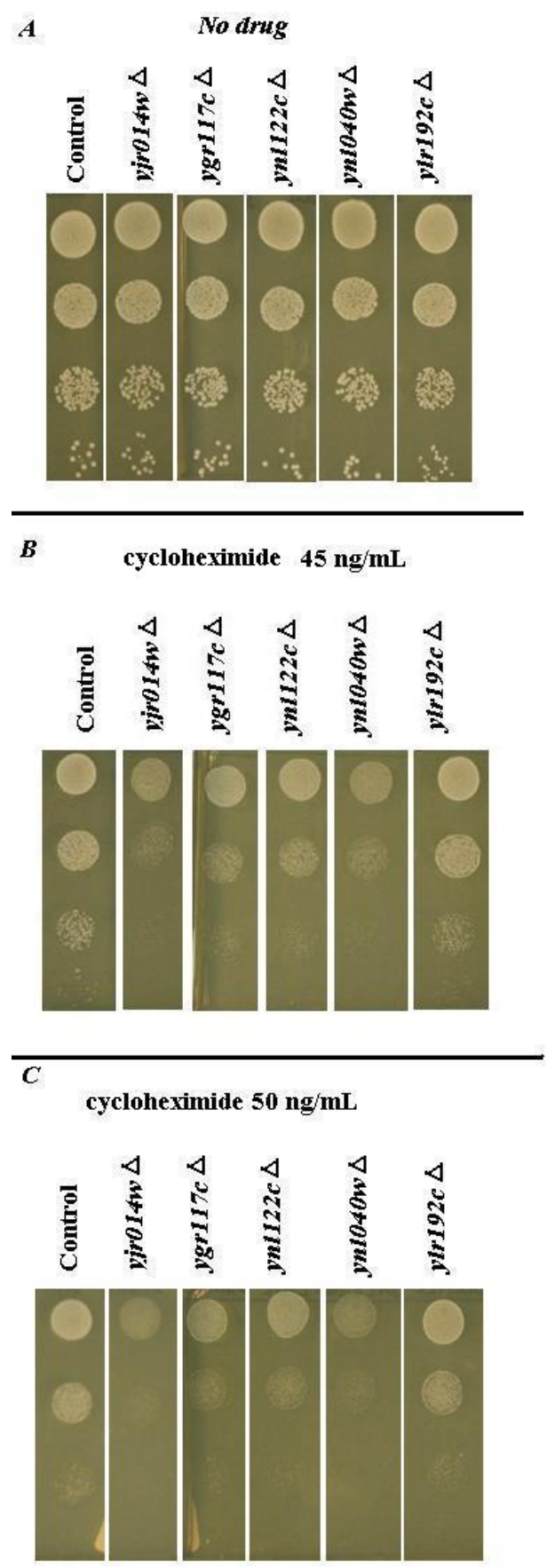

Appendix 7: $20 \mu \mathrm{L}$ of each serial dilution of $10^{-3}$ to $10^{-6}$ was spotted in media with or without drug and grown for 2 days at $30^{\circ} \mathrm{C}$. This was repeated with different drug concentrations. (A) Deletion strains on YPD (B) Deletion strains plated onto media containing cycloheximide $45 \mathrm{ng} / \mathrm{mL}$. (C) Deletion strains plated onto media containing cycloheximide $50 \mathrm{ng} / \mathrm{mL}$. The experiment was repeated at least three times. 
A

\section{No drug}

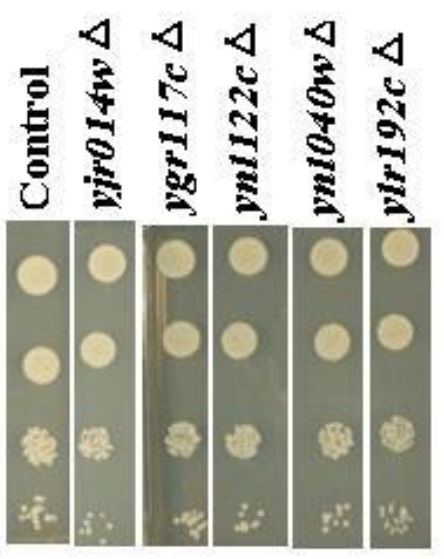

B

paromomycin $18 \mathrm{mg} / \mathbf{m L}$
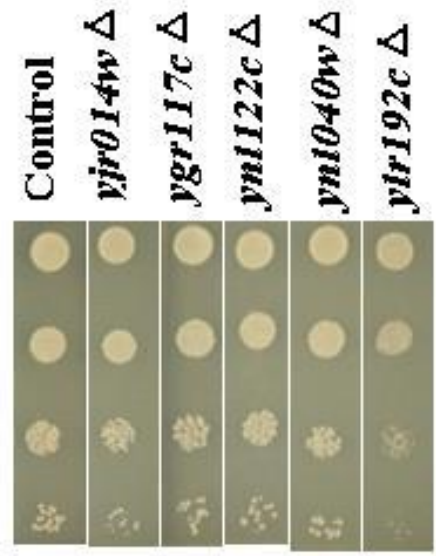

Appendix 8: $20 \mu \mathrm{L}$ of each serial dilution of $10^{-3}$ to $10^{-6}$ was spotted in media with or without drug and grown for 2 days at $30^{\circ} \mathrm{C}$. This was repeated with paromomycin $13 \mathrm{mg} / \mathrm{mL}$ and $18 \mathrm{mg} / \mathrm{mL}$ concentrations. (A) Deletion strains on synthetic complete media (B) Deletion strains plated onto media containing paromomycin $18 \mathrm{mg} / \mathrm{mL}$. The experiment was repeated at least three times. 
Panel A
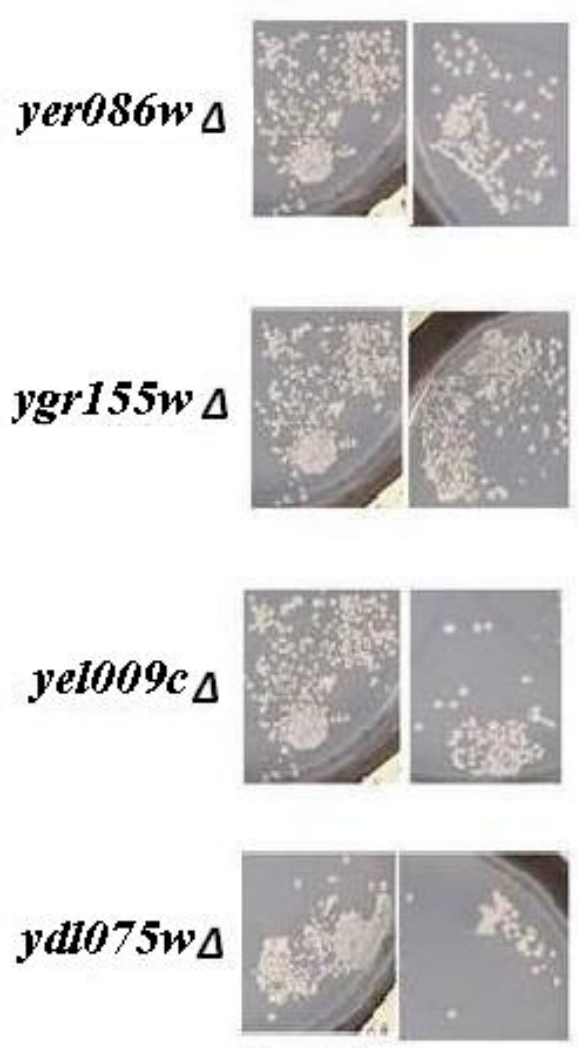

Control
Panel B
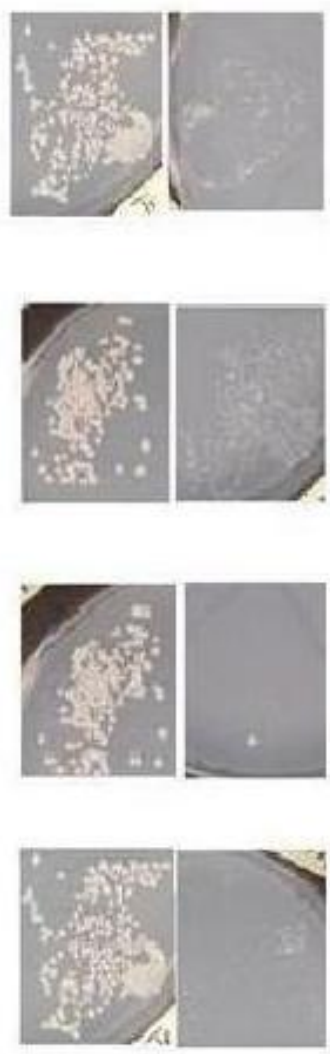

Control

Appendix 9: Random spore analysis confirmed YER086W YEL009CA and YDL075W genetically interacted with YNL040WA. Panel A. A pinprick amount of spores from each selected double mutants from SGA were inoculated in $1 \mathrm{~mL}$ sterile water and $40 \mu \mathrm{L}$ was spread onto plates containing canavanine $(50 \mathrm{mg} / \mathrm{L})$ and thialysine $(50 \mathrm{mg} / \mathrm{L})$. Panel B. $80 \mathrm{uL}$ of each inoculated double mutant spores were spread onto plates containing canavanine $(50 \mathrm{mg} / \mathrm{L})$, thialysine $(50 \mathrm{mg} / \mathrm{L})$, clonNAT $(100 \mathrm{mg} / \mathrm{L})$ and $\mathrm{G} 418(200 \mathrm{mg} / \mathrm{L})$. Plates were incubated at $30{ }^{\circ} \mathrm{C}$ for two days. 


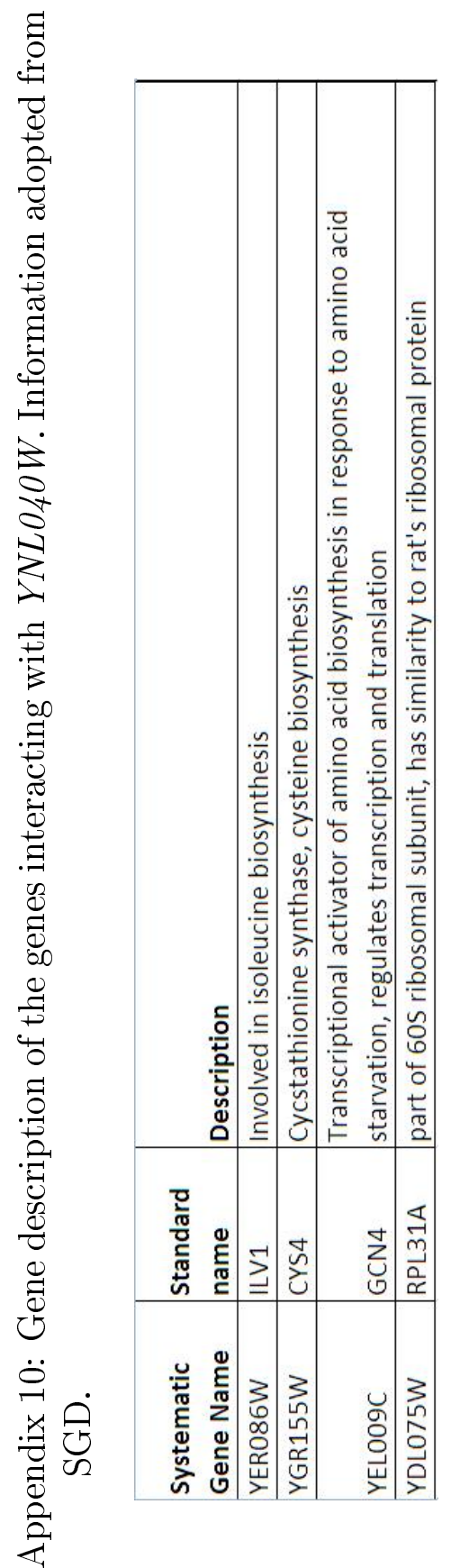




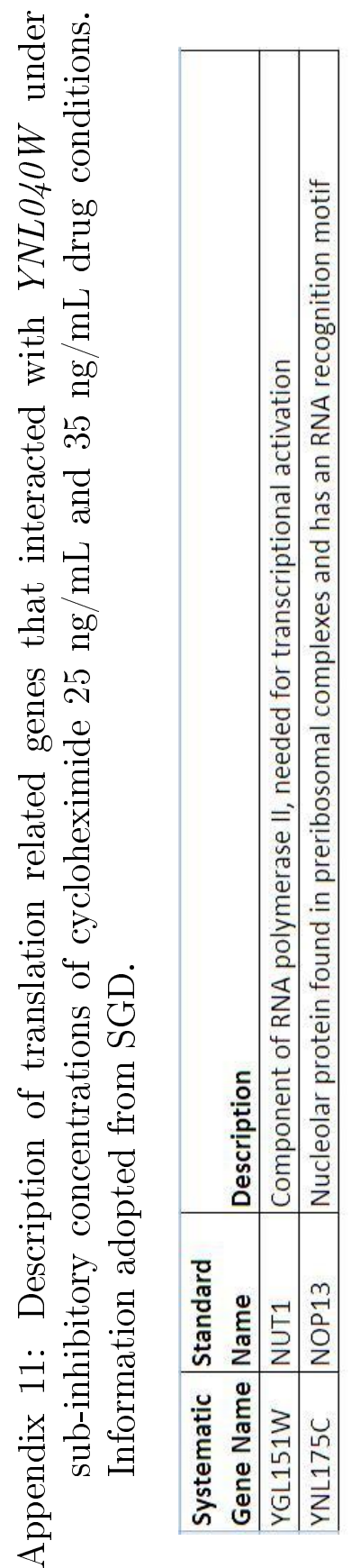




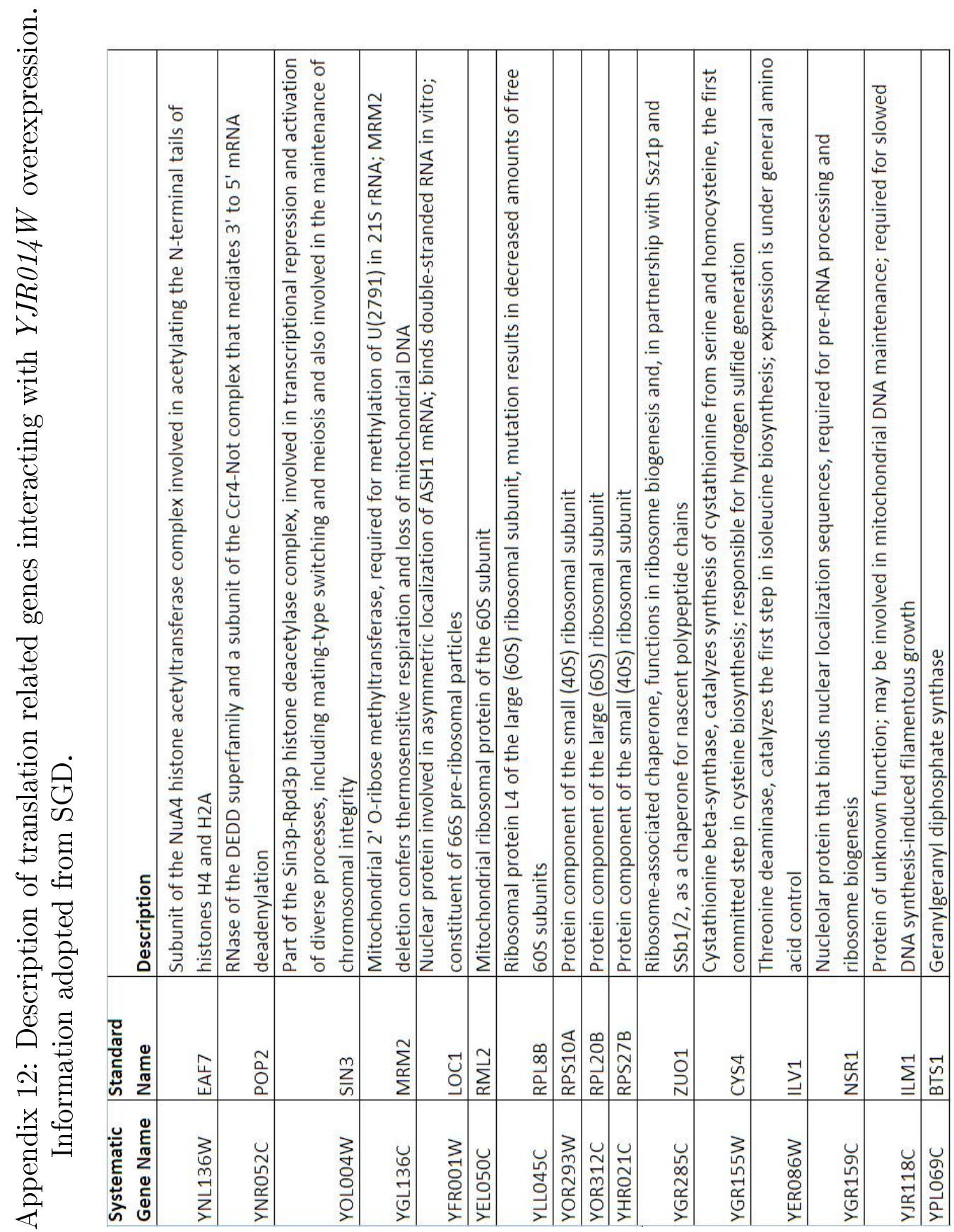




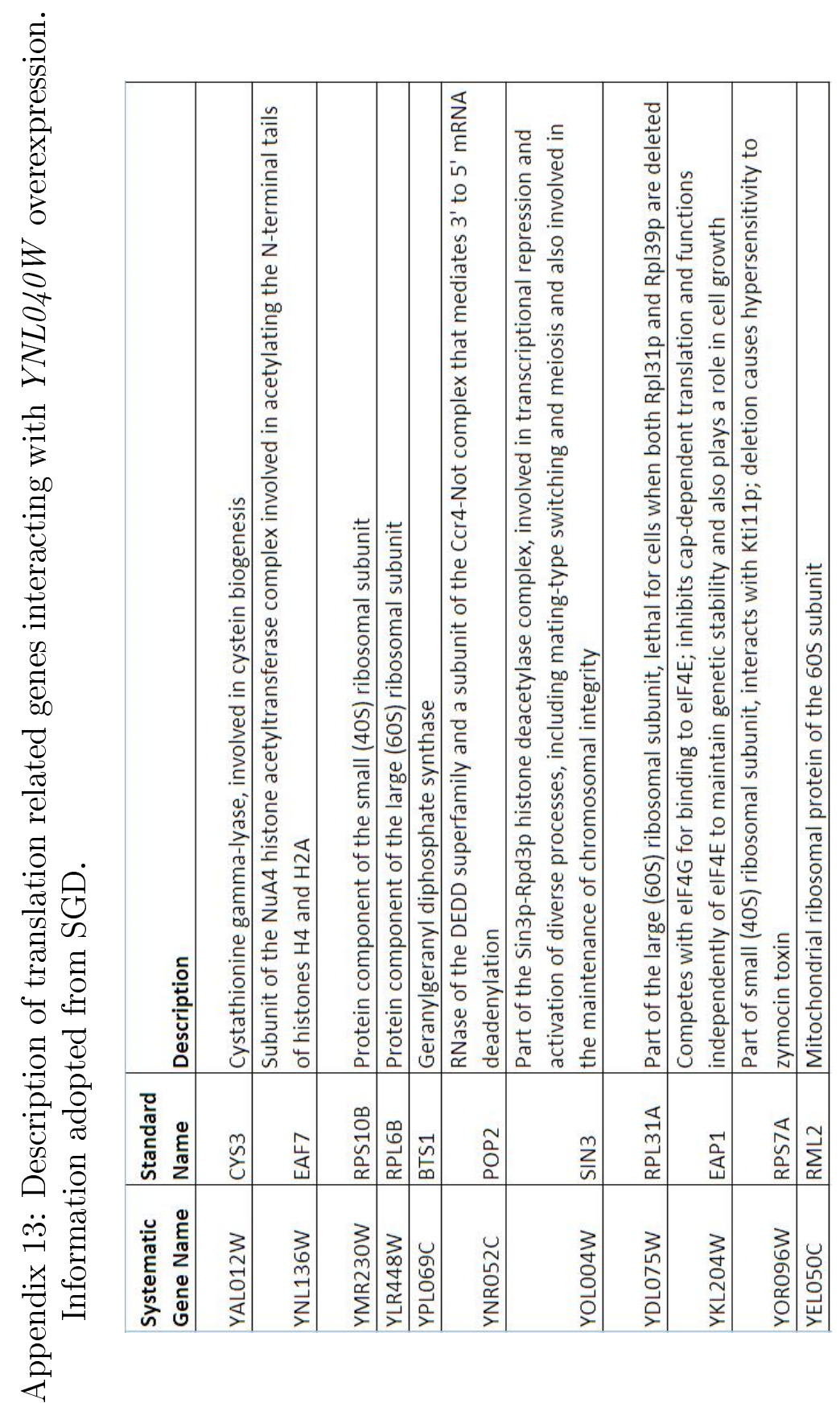




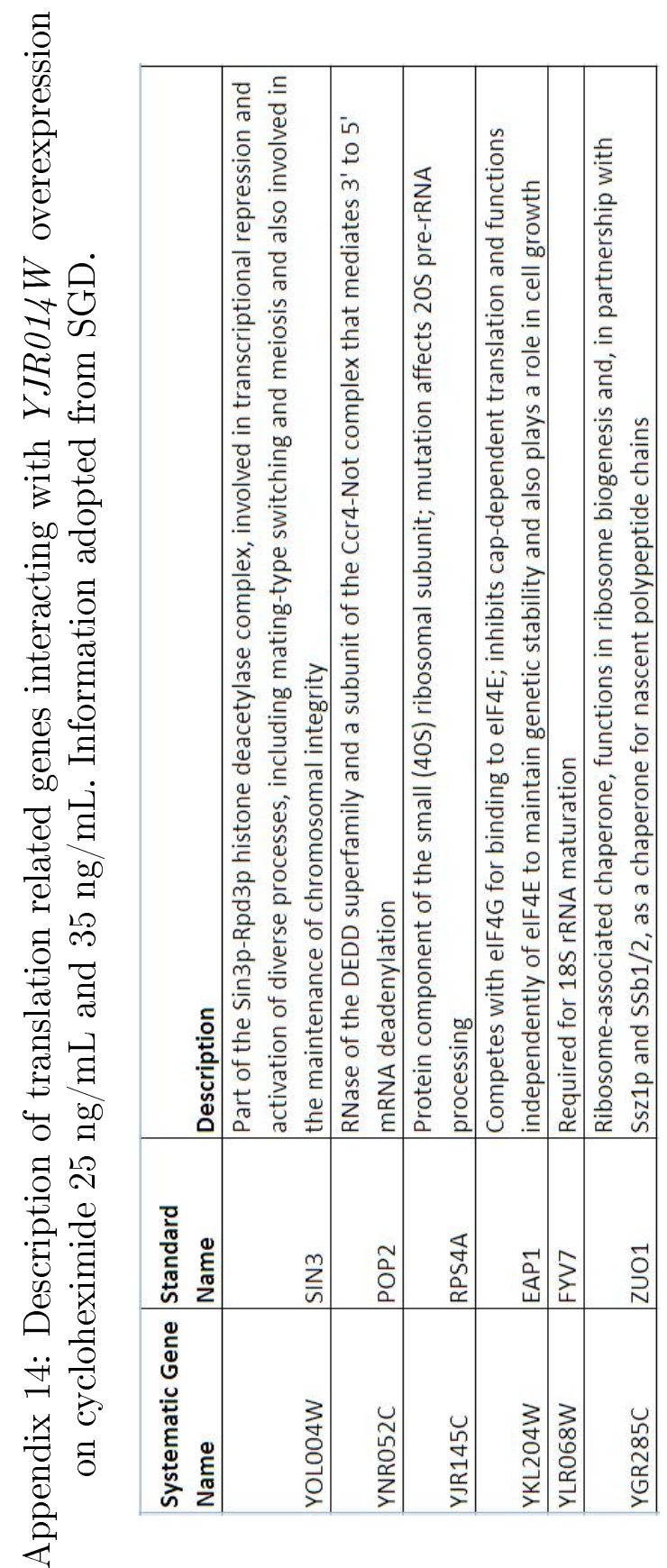




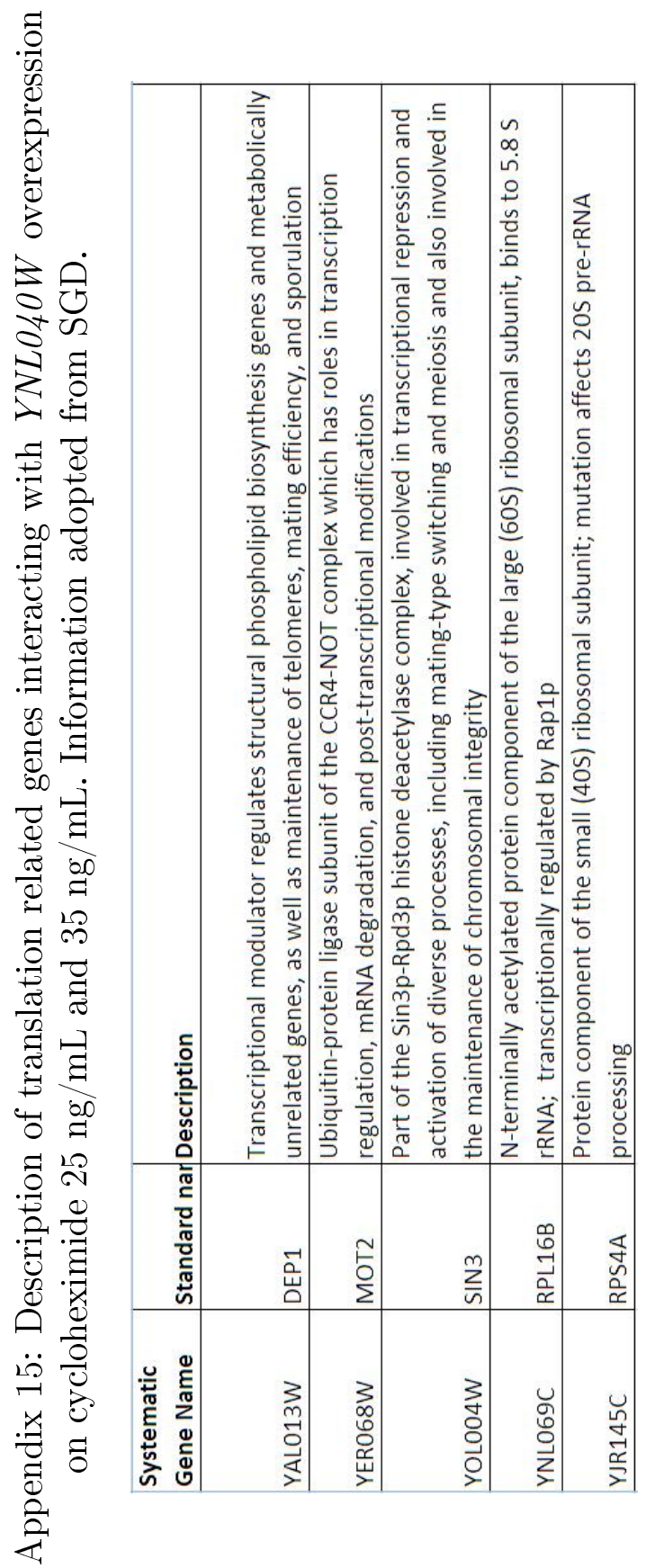

